
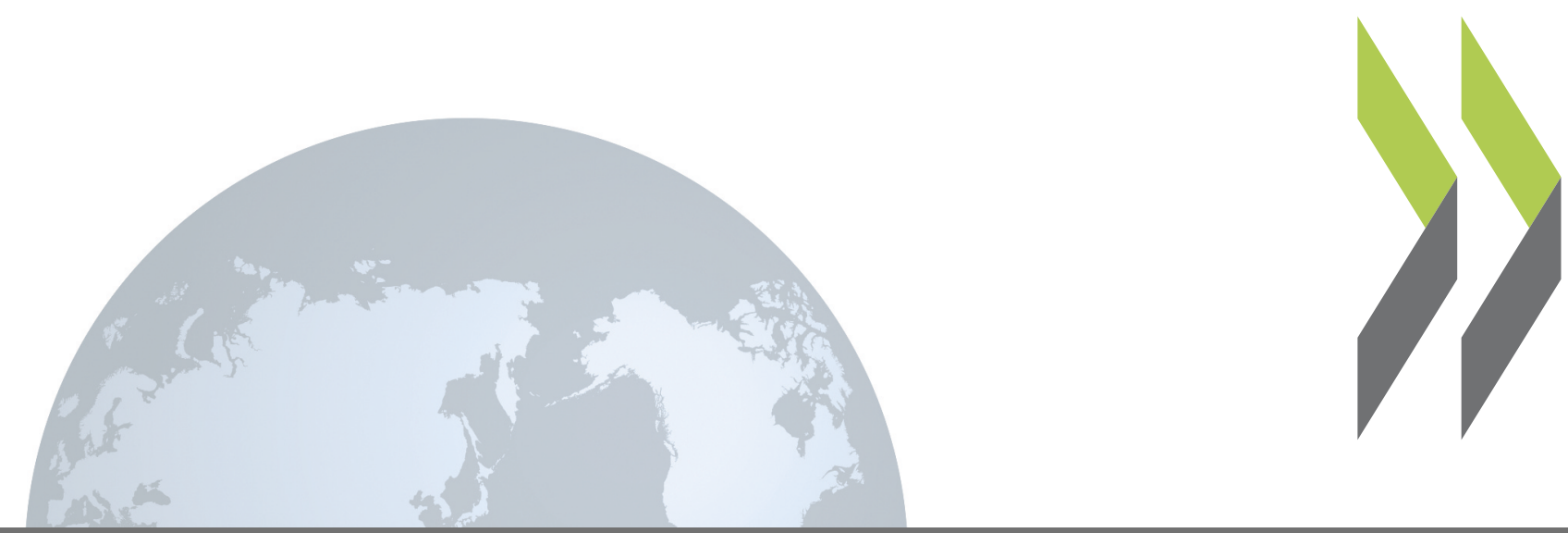

OECD Series on Adverse Outcome Pathways No. 6

Adverse Outcome Pathway on binding of agonists to ionotropic glutamate receptors in adult brain leading to excitotoxicity that Magdalini Sachana, mediates neuronal cell Sharon Munn, death, contributing to learning and memory impairment 


\section{Foreword}

This Adverse Outcome Pathway (AOP) on Binding of agonists to ionotropic glutamate receptors in adult brain leading to excitotoxicity that mediates neuronal cell death, contributing to learning and memory impairment, has been developed under the auspices of the OECD AOP Development Programme, overseen by the Extended Advisory Group on Molecular Screening and Toxicogenomics (EAGMST), which is an advisory group under the Working Group of the National Coordinators for the Test Guidelines Programme (WNT). The AOP has been reviewed internally by the EAGMST, externally by experts nominated by the WNT, and has been endorsed by the WNT and the Task Force on hazard Assessment (TFHA) in April 2016.

Through endorsement of this AOP, the WNT and the TFHA express confidence in the scientific review process that the AOP has undergone and accept the recommendation of the EAGMST that the AOP be disseminated publicly. Endorsement does not necessarily indicate that the AOP is now considered a tool for direct regulatory application.

The Joint Meeting of the Chemicals Committee and the Working Party on Chemicals, Pesticides and Biotechnology agreed to declassification of this AOP on 17 June 2016.

This document is being published under the responsibility of the Joint Meeting of the Chemicals Committee and the Working Party on Chemicals, Pesticides and Biotechnology. 


\section{Table of Contents}

Authors. 3

Abstract .3

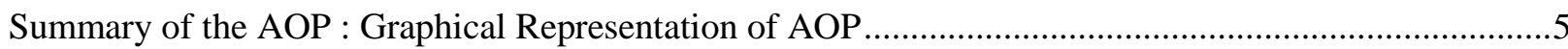

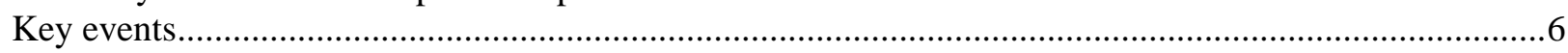

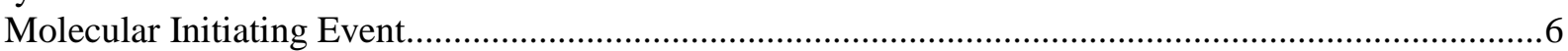

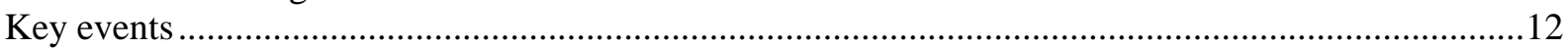

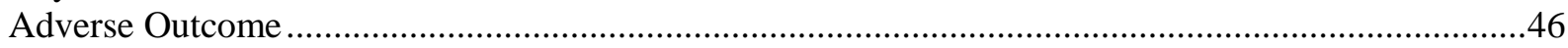

Key Event Relationships: Scientific evidence supporting the linkages in the AOP ...............................51

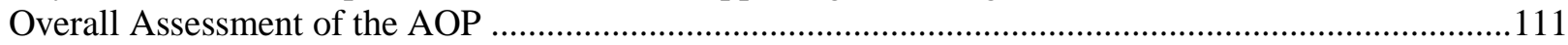

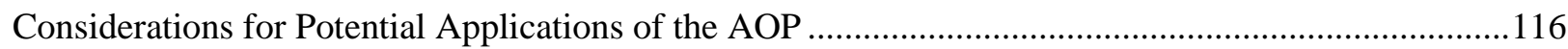

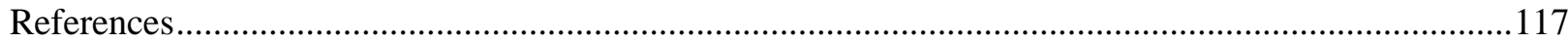




\title{
ADVERSE OUTCOME PATHWAY ON BINDING OF AGONISTS TO IONOTROPIC GLUTAMATE RECEPTORS IN ADULT BRAIN LEADING TO EXCITOTOXICITY THAT MEDIATES NEURONAL CELL DEATH, CONTRIBUTING TO LEARNING AND MEMORY IMPAIRMENT.
}

Short name: ionotropic glutamatergic receptors and cognition

\begin{abstract}
Authors
Magdalini Sachana, Sharon Munn, Anna Bal-Price

European Commission Joint Research Centre, Institute for Health and Consumer Protection; Corresponding author: anna.price@ec.europa.eu
\end{abstract}

\begin{abstract}
Under physiological conditions activation of glutamate ionotropic receptors such as N-methyl-Daspartate (NMDARs), alpha-amino-3-hydroxy-5-methyl-4-isoxazolepropionate (AMPARs) and kainate (KARs) is responsible for basal excitatory synaptic transmission and main forms of synaptic plasticity such as long-term potentiation (LTP) and long-term depression (LTD) that are fundamental for learning and memory processes (Schrattenholz and Soskic, 2006). However, sustained (direct or indirect) over-activation of these receptors can induce excitotoxic neuronal cell death. Indeed, mainly increased $\mathrm{Ca}^{2+}$ influx through NMDARs promotes many pathways of toxicity due to generation of free radical species, reduced ATP production, endoplasmic reticulum (ER) stress and protein aggregation. Neuronal injury induced by over-activation of these receptors and the excessive $\mathrm{Ca}^{2+}$ influx is considered an early key event of excitotoxicity. Additionally, the excessive activation of NMDARs has been found to play a significant role in a variety of neurological disorders ranging from acute hypoxic-ischemic brain injury to chronic neurodegenerative diseases (Mehta et al., 2013). The proposed AOP is relevant to adult neurotoxicity testing. A molecular initiating event (MIE) has been defined as a direct binding of agonists to NMDARs or indirect, through prior activation of AMPARs and/or KARs resulting in sustained NMDARs over-activation causing excitotoxic neuronal cell death, mainly in hippocampus and cortex, two brain structures fundamental for learning and memory processes. The AOP is based on the empirical support describing (1) domoic acid (DomA) induced excitotoxicity triggered by indirect (through KARs/AMPARs) NMDARs over-activation leading to impaired learning and memory and (2) glufosinate (GLF) induced excitotoxicity that through direct binding to NMDARs causes convulsions and memory loss. GLF is the methylphosphine analog of L-glutamate, used as a component of bactericidal and fungicidal herbicidal. DomA, a natural toxin that accumulates in mussels and shellfish is also an analogue of L-glutamate and among the most prominent features described after human exposure to DomA is memory impairment (Lefebvre and Robertson, 2010). DomA and GLF are described as the examples of the stressors due to large amounts of published data (especially in the case of DomA), however this AOP is relevant to any agonist that directly or indirectly cause NMDARs over-activation. Some of the known agonists selective for the NMDARs are derived from the naturally occurring amino acids such as ibotenic acid, homocysteine and l-aspartate and polyamines like spermidine.
\end{abstract}




\section{References}

Lefebvre, K.A. and A. Robertson (2010), Domoic acid and human exposure risks: A review, Toxicon, Vol. 56, pp. 218-230.

Mehta, A. et al., (2013), Excitotoxicity: bridge to various triggers in neurodegenerative disorders. European Journal of Pharmacolology, Vol. 698, pp. 6-18.

Schrattenholz, A. and V. Soskic V. (2006), NMDA receptors are not alone: dynamic regulation of NMDA receptor structure and function by neuregulins and transient cholesterol-rich membrane domains leads to disease-specific nuances of glutamate-signalling, Current Topics in Medicinal Chemistry 1, Vol. 6, No. 7, pp. 663-686. 
Summary of the AOP: Graphical Representation of AOP

\begin{tabular}{|c|c|c|}
\hline $\begin{array}{c}\text { Molecular } \\
\text { Initiating Event } \\
\text { (MIE) }\end{array}$ & Cellular effects & Organ effects \\
\hline
\end{tabular}

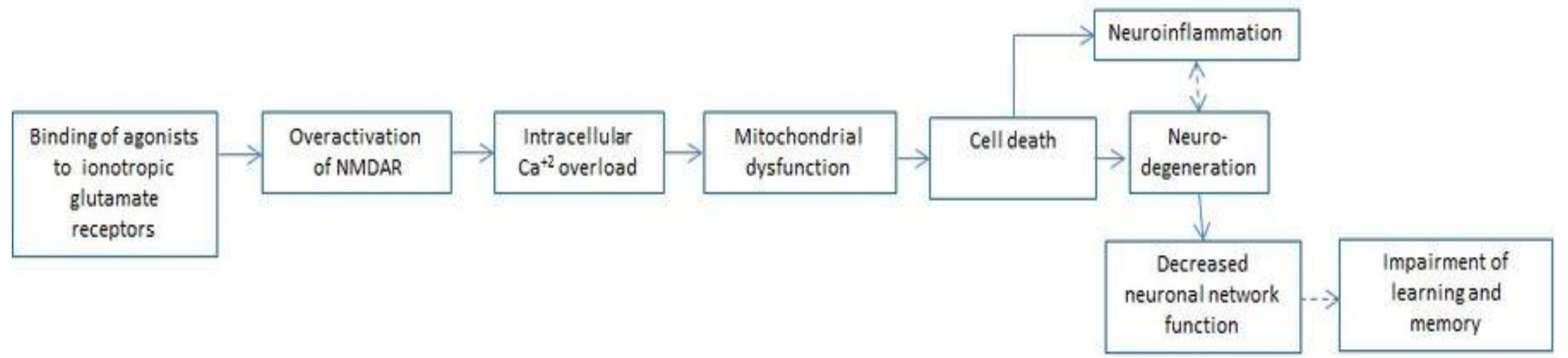




\section{Key events}

\section{Molecular Initiating Event}

\begin{tabular}{|c|}
\hline Molecular Initiating Event \\
\hline Inotropic glutamate receptors, Binding of agonist \\
\hline
\end{tabular}

Ionotropic glutamate receptors, Binding of agonist

AOPs including this Key Event

\begin{tabular}{|l|l|l|}
\hline AOP Name & $\begin{array}{l}\text { Event } \\
\text { Type }\end{array}$ & Essentiality \\
\hline $\begin{array}{l}\text { Binding of agonists to ionotropic glutamate receptors in adult brain causes } \\
\text { excitotoxicity that mediates neuronal cell death, contributing to learning and } \\
\text { memory impairment. }\end{array}$ & MIE & Strong \\
\hline
\end{tabular}

\section{Chemical Initiators}

The following are chemical initiators that operate directly through this Event:

1. Domoic acid

How this Key Event works

\begin{tabular}{|l|}
\hline Level of biological organisation \\
\hline Molecular \\
\hline
\end{tabular}

The MIE of this AOP can be triggered by direct binding of an agonist to NMDARs or indirectly through initial activation of KA/AMPARs. Indeed, binding of agonist to KA/AMPARs results in ion influx $\left(\mathrm{Na}^{+}\right.$and a small efflux of $\left.\mathrm{K}^{+}\right)$and glutamate release from excitatory synaptic vesicles causing depolarisation of the postsynaptic neuron (Dingledine et al., 1999). Upon this depolarisation the $\mathrm{Mg}^{2+}$ block is removed from the pore of NMDARs, allowing sodium, potassium, and importantly, calcium ions to enter into a cell. At positive potentials NMDARs then show maximal permeability (i.e., large outward currents can be observed under these circumstances). Due to the time needed for the $\mathrm{Mg}^{2+}$ removal, NMDARs activate more slowly, having a peak conductance long after the KA/AMPAR peak conductance takes place. It is important to note that NMDARs conduct currents only when $\mathrm{Mg}^{2+}$ block is relieved, glutamate is bound, and the postsynaptic neuron is depolarized. For this reason the NMDA receptors act as "coincidence detectors" and play a fundamental role in the establishment of Hebbian synaptic plasticity which is considered the physiological correlate of associative learning (Daoudal and Debanne, 2003; Glanzman, 2005). Post-synaptic membrane depolarisation happens almost always through activation of KA/AMPARs (Luscher and Malenka, 2012). Therefore, a MIE of this AOP is defined as binding of an agonist to these three types of ionotropic receptors (KA/AMPA and 
NMDA) that can result in a prolonged overactivation of NMDARs through (a) direct binding of an agonist or (b) indirect, mediated through initial KA/AMPARs activation. The excitotoxic neuronal cell death, triggered by sustained NMDARs overactivation in the hippocampus and/or cortex leads to the impaired learning and memory, defined as the adverse outcome (AO) of this AOP.

Biological state: L-glutamate (Glu) is a neurotransmitter with important role in the regulation of brain development and maturation processes. Two major classes of Glu receptors, ionotropic and metabotropic, have been identified. Due to its physiological and pharmacological properties, Glu activates three classes of ionotropic receptors named: $\alpha$-amino-3-hydroxy-5-methyl-4isoazolepropionic acid (AMPA receptors), 2-carboxy-3-carboxymethyl-4-isopropenylpyrrolidine (kainate receptors) and N-methyl-D-aspartate (NMDA receptors, NMDARs), which transduce the postsynaptic signal. Ionotropic glutamate receptors are integral membrane proteins formed by four large subunits that compose a central ion channel pore. In case of NMDA receptors, two NR1 subunits are combined with either two NR2 (NR2A, NR2B, NR2C, NR2D) subunits and less commonly are assembled together with a combination of NR2 and NR3 (A, B) subunits (reviewed in Traynelis et al., 2010). To be activated NMDA receptors require simultaneous binding of both glutamate to NR2 subunits and of glycine to either NR1 or NR3 subunits that provide the specific binding sites named extracellular ligand-binding domains (LBDs). Apart from LBDs, NMDA receptor subunits contain three more domains that are considered semiautonomous: 1) the extracellular amino-terminal domain that plays important role in assembly and trafficking of these receptors; 2) the transmembrane domain that is linked with LBD and contributes to the formation of the core of the ion channel and 3) the intracellular carboxyl-terminal domain that influences membrane targeting, stabilisation, degradation and post-translation modifications.

Biological compartments: The genes of the NMDAR subunits are expressed in various tissues and are not only restricted to the nervous system. The level of expression of these receptors in neuronal and non-neuronal cells depends on: transcription, chromatin remodelling, mRNA levels, translation, stabilisation of the protein, receptor assembly and trafficking, energy metabolism and numerous environmental stimuli (reviewed in Traynelis et al., 2010). In hippocampus region of the brain, NR2A and NR2B are the most abundant NR2 family subunits. NR2A-containing NMDARs are mostly expressed synaptically, while NR2B-containing NMDARs are found both synaptically and extrasynaptically (Tovar and Westbrook, 1999).

General role in biology: NMDA receptors, when compared to the other Glu receptors, are characterised by higher affinity for Glu, slower activation and desensitisation kinetics, higher permeability for calcium $\left(\mathrm{Ca}^{2+}\right)$ and susceptibility to potential-dependent blockage by magnesium ions $\left(\mathrm{Mg}^{2+}\right)$. NMDA receptors are involved in fast excitatory synaptic transmission and neuronal plasticity in the central nervous system (CNS). Functions of NMDA receptors:

1. They are involved in cell signalling events converting environmental stimuli to genetic changes by regulating gene transcription and epigenetic modifications in neuronal cells (Cohen and Greenberg, 2008).

2. In NMDA receptors, the ion channel is blocked by extracellular $\mathrm{Mg}^{2+}$ and $\mathrm{Zn}^{2+}$ ions, allowing the flow of $\mathrm{Na}^{+}$and $\mathrm{Ca}^{2+}$ ions into the cell and $\mathrm{K}^{+}$out of the cell which is voltage-dependent. $\mathrm{Ca}^{2+}$ flux through the NMDA receptor is considered to play a critical role in pre- and post-synaptic plasticity, a cellular mechanism important for learning and memory (Barria and Malinow, 2002). 
3. The NMDA receptors have been shown to play an essential role in the strengthening of synapses and neuronal differentiation, through long-term potentiation (LTP), and the weakening of synapses, through long-term depression (LTD). All these processes are implicated in the memory and learning function (Barria and Malinow, 2002).

\section{How it is Measured or Detected}

1. Ex vivo: The most common assay used is the NMDA receptor (MK801 site) radioligand competition binding assay (Reynolds and Palmer, 1991; Subramaniam and McGonigle, 1991; http://pdsp.med.unc.edu/UNC-CH\%20Protocol\%20Book.pdf;

http://www.currentprotocols.com/WileyCDA/CPUnit/refId-ph0120.html). This assay is based on the use of the most potent and specific antagonist of this receptor, MK801 that is used to detect and differentiate agonists and antagonists (competitive and non-competitive) that bind to this specific site of the receptor. Also radioligand competition binding assay can be performed using D, L-(E)-2-amino-4-[3H]-propyl-5-phosphono-3-pentenoic acid ([3H]-CGP 39653), a high affinity selective antagonist at the glutamate site of NMDA receptor, which is a quantitative autoradiography technique (Mugnaini et al., 1996). D-AP5, a selective N-methyl-D-aspartate (NMDA) receptor antagonist that competitively inhibits the glutamate binding site of NMDA receptors, can be studied by evoked electrical activity measurements. AP5 has been widely used to study the activity of NMDA receptors particularly with regard to researching synaptic plasticity, learning, and memory (Evans et al., 1982; Morris, 1989). The saturation binding of radioligands are used to measure the affinity $(\mathrm{Kd})$ and density $(\mathrm{Bmax})$ of kainate and AMPA receptors in striatum, cortex and hippocampus (Kürschner et al., 1998).

2. In silico: The prediction of NMDA receptor targeting is achievable by combining database mining, molecular docking, structure-based pharmacophore searching, and chemical similarity searching methods together (Neville and Lytton, 1999; Mazumder and Borah, 2014).

Evidence Supporting Taxonomic Applicability

\begin{tabular}{|l|l|l|l|}
\hline \multicolumn{1}{c|}{ Name } & \multicolumn{1}{c|}{ Scientific Name } & Evidence & Links \\
\hline Drosophila melanogaster & Drosophila melanogaster & Strong & NCBI \\
\hline Rattus norvegicus & Rattus norvegicus & Strong & NCBI \\
\hline Primates sp. BOLD:AAA0001 & Primates sp. BOLD:AAA0001 & Strong & NCBI \\
\hline human & Homo sapiens & Strong & NCBI \\
\hline mice & Mus sp. & Strong & NCBI \\
\hline
\end{tabular}

The major determinants for ligand e.g. for both co-agonist glycine binding and L-glutamate binding are well conserved between species from lower organism to mammals (reviewed in Xia and Chiang, 2009). PCR analysis, cloning and subsequent sequencing of the seal lion NMDA receptors showed $80 \%$ homology to those from rats, but more than $95 \%$ homologus to those from dogs (Gill et al., 2010). 


\section{Evidence for Chemical Initiation of this Molecular Initiating Event}

L-Glutamate and glycine (or D-serine) are endogenous agonists that bind to the LBD of specific NMDA receptor subunits. Here listed some known agonists for NMDA receptor, some of them are specific to the NR1 subunit and some others to the NR2 subunit (reviewed in Traynelis et al., 2010).

\section{Specific to NR1}

Glycine, 1-Serine, d-Serine, l-Alanine, d-Alanine, d-Cycloserine, HA 966, (+)-(1-hydroxy-3aminopyrrolidine-2-one, $\quad \beta$-Cl-d-Alanine, $\beta$-F-dl-Alanine, tri-F-dl-Alanine, ACPC, 1aminocyclopropane-1-carboxylic acid, ACBC, 1-aminocyclobutane-1-carboxylic acid, GLYX-13.

\section{Specific to NR2}

1-Glutamate, d-Glutamate, l-Aspartate, d-Aspartate, N-Methyl-1-aspartate, N-Methyl-d-aspartate, SYM208,1 1-Homocysteinsulfinate, d-Homocysteinsulfinate, 1-Homocysteate, d-Homocysteate, 1Cysteinesulfinate, 1-Cysteate, d-Cysteate, Homoquinolinate, Ibotenate, (R,S)-(Tetrazol-5yl)glycine, L-CCG-IV, (2S,3R,4S)-2-(carboxycyclopropyl)glycine, trans-ACBD, trans-1aminocyclobutane-1,3-dicarboxylate, cis-ADA, cis-azetidine-2,4-dicarboxylic acid, trans-ADC, azetidine-2,4-dicarboxylic acid, cis-ACPD, (1R,3R)-aminocyclopentane-cis-dicarboxylate, cis2,3-Piperidinedicarboxylic acid, (R)-NHP4G, 2-(N-hydroxylpyrazol-4-yl)glycine, (R,S)-EthylNHP5G, 2-(N-hydroxypyrazol-5-yl)glycine, (R)-Propyl-NHP5G, 2-(N-hydroxypyrazol-5yl)glycine.

Domoic acid (DomA) is structurally similar to kainic acid (KA) and both of them are analogues of the excitatory neurotransmitter L-glutamate. DomA induces excitotoxicity by an integrative action on ionotropic glutamate receptors at pre- and post-synaptic sides. DomA directly activates KA/AMPARs receptors followed by indirect activation of the NMDARs. Indeed, indirect activation of NMDARs by DomA is linked to the fact that KA and AMPA receptors activated by DomA induce increased levels of intracellular $\mathrm{Ca}^{2+}$ and $\mathrm{Na}^{+}$which, in turn, causes endogenous glutamate release that subsequently potentiates activation of NMDARs (Berman and Murray, 1997; Berman et al., 2002; Watanabe et al., 2011). DomA has been demonstrated through both in vitro and in vivo approaches to indirectly activate the NMDARs (reviewed in Pulido, 2008).

Glufosinate (GLF) ((RS)-2-amino-4-(hydroxy(methyl)phosphonoyl)butanoic acid, phosphinothricin) is a phosphorus containing amino acid herbicide that is naturally occurring as a component of the bacteria-derived bactericidal and fungicidal tripeptides bialaphos and phosalacine (Lanz et al., 2014). There are studies suggesting that convulsive and amnesic effects of GLF are mediated through direct binding and activation of NMDAR (Lantz et al., 2014; Matsumura et al., 2001). GLF agonist action at the NMDAR is expected to occur through direct interaction with the glutamate binding site and requires binding of the glycine co-agonist as well as release of the magnesium block from the channel pore. 


\section{References}

Barenberg, P., H. Strahlendorf and J. Strahlendorf (2001), Hypoxia induces an excitotoxic-type of dark cell degeneration in cerebellar Purkinje neurons, Journal of Neuroscience Research, Vol. 40. No 3, pp. 245-254.

Barria, A. and R.Malinow (2002), Subunit-specific NMDA receptor trafficking to synapses, Neuron, vol. 35, pp. 345-353.

Berman, F.W. and T. F. Murray (1997), Domoic acid neurotoxicity in cultured cerebellar granule neurons is mediated predominantly by NMDA receptors that are activated as a consequence of excitatory amino acid release, Journal of Neurochemistry, Vol. 69, pp. 693-703.

Berman, W.F., K. T. LePage, and T. F. Murray (2002), Domoic acid neurotoxicity in cultured cerebellar granule neurons is controlled preferentially by the NMDA receptor $\mathrm{Ca}^{2+}$ influx pathway, Brain Research, vol. 924, pp. 20-29.

Cohen, S. and M.E. Greenberg (2008), Communication between the synapse and the nucleus in neuronal development, plasticity, and disease, Annual Review of Cell and Developmental Biology, Vol. 24, pp. 183-209.

Daoudal, G., Debanne D, (2003), Long-term plasticity of intrinsic excitability: learning rules and mechanisms, Learning and Memory, vol. 10, no. 6, pp. 456-65.

Dingledine, R. et al., (1999), The glutamate receptor ion channels, Pharmacological Reviews, Vol. 51, pp. 7-61.

Evans, R.H. et al., (1982), The Effects of a Series of $\omega$-Phosphonic $\alpha$-Carboxylic Amino Acids on Electrically Evoked and Excitant Amino Acid-Induced Responses in Isolated Spinal Cord Preparations. British Journal of Pharmacology, Vol. 75, pp. 65-75.

Gill, S. et al., (2010), Cloning and characterization of glutamate receptors in Californian sea lions (Zalophus californianus). Marine Drugs, Vol. 8, pp. 1637-1649.

Glanzman, DL. (2005), Associative learning: Hebbian flies, Current Biology, Vol. 7, no. 15(11), R416-9.

Kürschner, V.C. (1998), Kainate and AMPA receptor binding in seizure-prone and seizure-resistant inbred mouse strains, Brain Research. Vol. 5, pp. 780-788.

Lantz, S.R. et al.,(2014), Glufosinate binds N-methyl-D-aspartate receptors and increases neuronal network activity in vitro, Neurotoxicology, Vol. 45, pp. 38-47.

Lefebvre, K.A. and A.Robertson (2010), Domoic acid and human exposure risks: a review. Toxicon, Vol. 56, pp. 218-30.

Luscher, C. and R.C. Malenka (2012), NMDA Receptor-Dependent Long-Term Potentiation and LongTerm Depression (LTP/LTD). Cold Spring Harb Perspect Biol, Vol. 4, a005710.

Matsumura, N. et al., (2001), Glufosinate ammonium induces convulsion through N-methyl-D-aspartate receptors in mice. Neurosci Letters, 2001, Vol. 304, pp. 123-5.

Mazumder, M.K. and A. Borah (2014), Piroxicam inhibits NMDA receptor-mediated excitotoxicity through allosteric inhibition of the GluN2B subunit: an in silico study elucidating a novel mechanism of action of the drug, Medical Hypotheses, Vol. 83, no. 6, pp. 740-6.

Morris, R. J. (1989), Synaptic Plasticity and Learning: Selective Impairment of Learning in Rats and Blockade of Long-Term Potentiation in vivo by the N-Methyl-D-Aspartate Receptor Antagonist AP5, Journal of Neuroscience, Vol. 9, pp. 3040-3057.

Mugnaini, M. et al., (1996), Regionally different N-methyl-D-aspartate receptors distinguished by ligand binding and quantitative autoradiography of [3H]-CGP 39653 in rat brain, British Journal of Pharmacology, Vol. 119, pp. 819-828.

Neville, K.R. and W.W. Lytton (1999), Potentiation of $\mathrm{Ca}^{2+}$ influx through NMDA channels by action potentials: a computer model, Neuroreport, Vol. 10, No. 17, pp. 3711-3716. 
Pulido, OM. (2008), Domoic acid toxicologic pathology: a review. Marine Drugs, Vol. 6, pp. 180-219.

Reynolds, I.J. and Palmer A.M. (1991) Regional variations in [3H]MK801 binding to rat brain N-methylD-aspartate receptors, Journal of Neurochemistry, Vol. 56, No. 5, pp. 1731-40.

Subramaniam, S. and P. McGonigle, (1991), Quantitative autoradiographic characterization of the binding of (+)-5-methyl-10,11-dihydro-5H-dibenzo[a,d]cyclohepten-5, 10-imine ([3H]MK-801) in rat brain: regional effects of polyamines, Journal of Pharmacology and Experimantal Theraupetics, Vol. 256, No. 2, pp. 811-819.

Tovar, K.R. and G L. Westbrook (1999), The incorporation of NMDA receptors with a distinct subunit composition at nascent hippocampal synapses in vitro, Journal of Neuroscience, vol. 19, pp. 4180 4188.

Traynelis, S. et al., (2010), Glutamate receptor ion channels: structure, regulation, and function. Pharmacological Reviews, Vol. 62, pp. 405-496.

Watanabe, K. H. et al., (2011), Defining and modeling known adverse outcome pathways: Domoic acid and neuronal signaling as a case study, Environmental Toxicology and Chemistry, Vol. 30, pp. 9-21.

Xia, S. and Chiang, A. S. (2009), NMDA Receptors in Drosophila. In: Van Dongen AM, editor. Biology of the NMDA Receptor, Boca Raton (FL): CRC Press, Chapter 10. Available from: http://www.ncbi.nlm.nih.gov/books/NBK5286/ 
Key events

\begin{tabular}{|l|}
\hline \multicolumn{1}{c|}{ Key Event } \\
\hline$\underline{\text { NMDARs, Overactivation }}$ \\
\hline$\underline{\text { Calcium influx, Increased }}$ \\
\hline$\underline{\text { Mitochondrial dysfunction, N/A }}$ \\
\hline$\underline{\text { Cell death, N/A }}$ \\
\hline$\underline{\text { Neurodegeneration, N/A }}$ \\
\hline$\underline{\text { Neuroinflammation, N/A }}$ \\
\hline$\underline{\text { Neuronal network function in adult brain, Decreased }}$ \\
\hline
\end{tabular}

\section{NMDARs, Overactivation}

AOPs including this Key Event

\begin{tabular}{|l|l|l|}
\hline \multicolumn{1}{|c|}{ AOP Name } & $\begin{array}{l}\text { Event } \\
\text { Type }\end{array}$ & Essentiality \\
\hline $\begin{array}{l}\text { Binding of agonists to ionotropic glutamate receptors in adult brain causes } \\
\text { excitotoxicity that mediates neuronal cell death, contributing to learning and } \\
\text { memory impairment. }\end{array}$ & KE & Moderate \\
\hline
\end{tabular}

How this Key Event works

\begin{tabular}{|l|}
\hline Level of biological organisation \\
\hline Molecular \\
\hline
\end{tabular}

Biological state: Please see MIE NMDARs, Binding of antagonist

Biological compartments: Please see MIE NMDARs, Binding of antagonist

General role in biology: Please see MIE NMDARs, Binding of antagonist

The above chapters belong to the AOP entitled: Chronic binding of antagonist to N-methyl-Daspartate receptors (NMDARs) during brain development induces impairment of learning and memory abilities since the general characteristic of the NMDA receptor biology is the same for both AOPs.

Additional text, specific for this AOP:

At resting membrane potentials, NMDA receptors are inactive. Depending on the specific impulse train received, the NMDA receptor activation triggers long term potentiation (LTP) or long-term depression (LTD) (Malenka and Bear, 2004; Luscher and Malenka, 2012). LTP (the opposing process to LTD) is the long-lasting increase of synaptic strength. For LTP induction both pre- and postsynaptic neurons need to be active at the same time because the postsynaptic neuron must be 
depolarized when glutamate is released from the presynaptic bouton to fully relieve the $\mathrm{Mg}^{2+}$ block of NMDARs that prevents ion flows through it. Sustained activation of AMPA or KA receptors by, for instance, a train of impulses arriving at a pre-synaptic terminal, depolarises the post-synaptic cell, releasing $\mathrm{Mg}^{2+}$ inhibition and thus allowing NMDA receptor activation. Unlike GluA2-containing AMPA receptors, NMDA receptors are permeable to calcium ions as well as being permeable to other ions. Thus NMDA receptor activation leads to a calcium influx into the post-synaptic cells, a signal that is instrumental in the activation of a number of signalling cascades (Calcium-dependent processes are describe in Key Event Calcium influx, increased). Postsynaptic $\mathrm{Ca}^{2+}$ signals of different amplitudes and durations are able to induce either LPT or LTD.

Conversely to LTP, LTD is induced by repeated activation of the presynaptic neuron at low frequencies without postsynaptic activity (Luscher and Malenka, 2012). Therefore, under physiological conditions LTD is one of several processes that serve to selectively weaken specific synapses in order to make constructive use of synaptic strengthening caused by LTP. This is necessary because, if allowed to continue increasing in strength, synapses would ultimately reach a ceiling level of efficiency, which would inhibit the encoding of new information (Purves, 2008).

LTD is an activity-dependent reduction in the efficacy of neuronal synapses lasting hours or longer following a long patterned stimulus. It has also been found to occur in different types of neurons. However, the most common neurotransmitter involved in LTD is L-glutamate that acts on the NMDARs, AMPAR, KARs and metabotropic glutamate receptors (mGluRs). It can result from strong synaptic stimulation (as occurs e.g. in the cerebellar Purkinje cells) or from persistent weak synaptic stimulation (as in the hippocampus) resulting mainly from a decrease in postsynaptic AMPA receptor density, although a decrease in presynaptic neurotransmitter release may also play a role. Moreover, cerebellar LTD has been hypothesised to be important for motor learning and hippocampal LTD may be important for the clearing of old memory traces (Nicholls et al., 2008; Mallere et al., 2010). The main molecular mechanism underlying-LTD is the phosphorylation of AMPA glutamate receptors and their synaptic elimination (Ogasawara et al., 2008).

It is now commonly understood in the field of spine morphology that long lasting NMDARdependent LTD causes dendritic spine shrinkage, reduces number of synaptic AMPA receptors (Calabrese et al., 2014), possibly leading to synaptic dysfunction, contributing to decreased neuronal network function and impairment of learning and memory processes.

\section{How it is Measured or Detected}

No OECD methods are available to measure the activation state of NMDA receptors.

The measurement of the activation or the inhibition of NMDA receptors is done indirectly by recording the individual ion channels that are selective to $\mathrm{Na}^{+}, \mathrm{K}^{+}$and $\mathrm{Ca}^{2+}$ by the patch clamp technique. This method relies on lack of measurable ion flux when NMDA ion channel is closed, whereas constant channel specific conductance is recorded at the open state of the receptor (Blanke and VanDongen, 2009). Furthermore, this method is based on the prediction that activation or inhibition of an ion channel results from an increase in the probability of being in the open or closed state, respectively (Ogdon and Stanfield, 2009; Zhao et al., 2009). 
The whole-cell patch clamp recording techniques have also been used to study synapticallyevoked NMDA receptor-mediated excitatory or inhibitory postsynaptic currents (EPSCs and IPSCs, respectively) in brain slices and neuronal cells, allowing the evaluation of the activated or inhibited state of the receptor.

Microelectrode array (MEA) recordings are used to measure mainly spontaneous network activity of cultured neurons (Keefer et al., 2001, Gramowski et al., 2000 and Gopal, 2003; Johnstone et al., 2010). However, using specific agonists and antagonists of a receptor, including NMDAR, MEA technology can be used to measure evoked activity, including glutamatergic receptor function (Lantz et al., 2014). For example it has been shown that MEA-coupled neuronal cortical networks are very sensitive to pharmacological manipulation of the excitatory ionotropic glutamatergic transmission (Frega et al., 2012). MEAs can also be applied in higher throughput platforms to facilitate screening of numerous chemical compounds (McConnell et al., 2012).

Excessive excitability can be also measured directly by evaluating the level of the extracellular glutamate using the enzyme-based microelectrode arrays. This technology is capable of detecting glutamate in vivo, to assess the effectiveness of hyperexcitability modulators on glutamate release in brain slices. Using glutamate oxidase coated ceramic MEAs coupled with constant voltage amperometry, it is possible to measure resting glutamate levels and synaptic overflow of glutamate after $\mathrm{K}(+)$ stimulation in brain slices (Quintero et al., 2011).

Neuronal network function can be also measured using optical detection of neuronal spikes both in vivo and in vitro (Wilt et al., 2013).

Drebrin immunocytochemistry: drebrin, a major actin-filament-binding protein localized in mature dendritic spines is a target of calpain mediated proteolysis under excitotoxic conditions induced by the overactivation of NMDARs. In cultured rodent neurons, degradation of drebrin was confirmed by the detection of proteolytic fragments, as well as a reduction in the amount of full-length drebrin. The NMDA-induced degradation of drebrin in mature neurons occurres concomitantly with a loss of f-actin. Biochemical analyses using purified drebrin and calpain revealed that calpain degraded drebrin directly in vitro. These findings suggest that calpainmediated degradation of drebrin is mediated by excitotoxicity, regardless of whether they are acute or chronic. Drebrin (A and E) regulates the synaptic clustering of NMDARs. Therefore, degradation of drebrin can be used as a readout for excitotoxicity induced by NMDAR overactivation. Degradation of drebrin can be evaluated quantitatively by Western blot analysis (mRNA evel) or by immunocytochemistry (at protein level) (Chimura et al., 2015: Sekino et al., 2006).

NMDAR overactivation-induced long lasting LTD can be measured by the dendritic spine shrinkage by quantification of cofilin and phospho-cofilin in neurons expressing eGFP and combined with immunocytochemical techniques (Calabrese et al., 2014). 
Evidence Supporting Taxonomic Applicability

\begin{tabular}{l|l|l|l|}
\hline Name & Scientific Name & Evidence & Links \\
\hline human & Homo sapiens & Strong & NCBI \\
\hline mouse & Mus sp. & Strong & NCBI \\
\hline rat & Rattus sp. & Strong & NCBI \\
\hline
\end{tabular}

It is important to note that in invertebrates the glutamatergic synaptic transmission has an inhibitory and not an excitatory role like in vertebrates. This type of neurotransmission is mediated by glutamate-gated chloride channels that are members of the 'cys-loop' ligand-gated anion channel superfamily found only in invertebrates. The subunits of glutamate-activated chloride channel have been isolated from C. elegans and from Drosophila (Blanke and VanDongen, 2009).

\section{References}

Blanke, M.L. and A.M.J. VanDongen (2009), Activation Mechanisms of the NMDA Receptor. In: Van Dongen AM, editor. Biology of the NMDA Receptor. Boca Raton (FL): CRC Press; Chapter 13. Available from: http://www.ncbi.nlm.nih.gov/books/NBK5274/.

Calabrese, B., J.M. Saffin and S. Halpain (2014), Activity-dependent dendritic spine shrinkage and growth involve downregulation of cofilin via distinct mechanisms. PLoS One, Vol. 16, No. 9(4): e94787.

Chimura, T., T. Launey and N. Yoshida (2015), Calpain-Mediated Degradation of Drebrin by Excitotoxicity In vitro and In vivo, PLoS One, |DOI:10.1371/journal.pone.0125119.

Frega, M. et al. (2012), Cortical cultures coupled to micro-electrode arrays: a novel approach to perform in vitro excitotoxicity testing. Neurotoxicology and Teratolology. Vol. 34, No. 1, pp.116-27.

Gopal, K. (2003), Neurotoxic effects of mercury on auditory cortex networks growing on microelectrode arrays: a preliminary analysis. Neurotoxicology and Teratolology, Vol. 25, pp. 69-76.

Gramowski, A., D. Schiffmann and G.W. Gross (2000), Quantification of acute neurotoxic effects of trimethyltin using neuronal networks cultures on microelectrode arrays. Neurotoxicology, Vol. 21, pp. 331-342.

Johnstone, A.F.M. et al. (2010), Microlelectrode arrays: a physiologically based neurotoxicity testing platform for the 21st century, Neurotoxicology, Vol, 31, pp. 331-350.

Keefer, E. et al. (2001), Acute toxicity screening of novel AChE inhibitors using neuronal networks on microelectrode arrays. Neurotoxicology, Vol. 22, pp. 3-12.

Lantz, S.R. et al. (2014), Glufosinate binds N-methyl-D-aspartate receptors and increases neuronal network activity in vitro. Neurotoxicology. Vol. 45, pp. 38-47.

Luscher, C. and R.C. Malenka (2012), NMDA Receptor-Dependent Long-Term Potentiation and LongTerm Depression (LTP/LTD). Cold Spring Harb Perspect Biol., 4:a005710.

Malenka R.C. and M.F. Bear (2004), LTP and LTD: An embarrassment of riches. Neuron, Vol. 44, pp. 521.

Malleret, G. et al. (2010), Bidirectional regulation of hippocampal long-term synaptic plasticity and its influence on opposing forms of memory. Journal of Neuroscience, Vol. 30, No. 10, pp. 3813-25. 
McConnell, E.R. et al. (2012), Evaluation of multi-well microelectrode arrays for neurotoxicity screening using a chemical training set. Neurotoxicology, Vol. 33, pp. 1048-1057.

Nicholls, R.E. et al. (2008), Transgenic mice lacking NMDAR-dependent LTD exhibit deficits in behavioral flexibility". Neuron, Vol. 58, No. 1, pp. 104-17.

Ogasawara, H,, T. Doi and M. Kawato (2008), Systems biology perspectives on cerebellar long-term depression. Neurosignals, Vol. 16, No. 4, pp. 300-17.

Ogdon, D. and P. Stanfield (1995) Patch clamp techniques for single channel and whole-cell recording. Chapter 4, pp. 5378, (http://www.utdallas.edu/ tres/microelectrode/microelectrodes_ch04.pdf).

Paradiso, M.A., M.F. Bear and B.W. Connors, (2007), Neuroscience: exploring the brain. 2007, Hagerstwon, MD: Lippincott Williams \& Wilkins. p. 718. ISBN 0-7817-6003-8.

Purves, D., Neuroscience (4th ed.). Sunderland, Mass: Sinauer., 2008, pp. 197-200. ISBN 0-87893-697-1.

Sekino, Y. et al., (2006), Activation of N-methyl-D-aspartate receptor induces a shift of drebrin distribution: disappearance from dendritic spines and appearance in dendritic shafts. Molecular Cellular Neuroscience, Volo. 31, No. 3, pp. 493-504.

Quintero, J.E. et al. (2011), Methodology for rapid measures of glutamate release in rat brain slices using ceramic-based microelectrode arrays: basic characterization and drug pharmacology. Brain Research, Vol. 1401, pp. 1-9.

Wilt, B.A., J.E. Fitzgerald and M.J. Schnitzer (2013), Photon shot noise limits on optical detection of neuronal spikes and estimation of spike timing. Biophysical Journal, Vol. 8, No. 104(1), pp. 51-62.

Zhao, Y. et al. (2009), Patch clamp techniques: review of the current state of art and potential contributions from nanoengineering. Proc. IMechE 222, Part N: Journal of Nanoengineering and Nanosystems, Vol. 149. DOI: $10.1243 / 17403499 J N N 149$.

\section{Intracellular Calcium overload, Increased}

AOPs including this Key Event

\begin{tabular}{|l|l|l|}
\hline \multicolumn{1}{|c|}{ AOP Name } & $\begin{array}{l}\text { Event } \\
\text { Type }\end{array}$ & Essentiality \\
\hline $\begin{array}{l}\text { Binding of agonists to ionotropic glutamate receptors in adult brain causes } \\
\text { excitotoxicity that mediates neuronal cell death, contributing to learning and } \\
\text { memory impairment. }\end{array}$ & KE & Moderate \\
\hline
\end{tabular}

How this Key Event works

\section{Level of biological organisation}

Cellular

For the relevant paragraphs below please see AOP entitled Chronic binding of antagonist to $N$ methyl-D-aspartate receptors (NMDARs) during brain development induces impairment of learning and memory abilities.

Biological state: KE Calcium influx, Decreased

Biological compartments: KE Calcium influx, Decreased

General role in biology: KE Calcium influx, Decreased 
The text specific for this AOP:

It is now well accepted that modest activation of NMDARs leading to modest increases in postsynaptic calcium are optimal for triggering LTD (Lledo et al. 1998; Bloodgood and Sabatin, 2007; Bloodgood et al. 2009), whereas much stronger activation of NMDARs leading to much larger increases in postsynaptic calcium are required to trigger LTP (Luscher and Malenka, 2012; Malenka 1994). Indeed, high-frequency stimulation causes a strong temporal summation of the excitatory postsynaptic potentials (EPSPs), and depolarisation of the postsynaptic cell is sufficient to relieve the $\mathrm{Mg}^{2+}$ block of the NMDAR and allow a large amount of calcium to enter into the postsynaptic cells. Therefore, intra-cellular calcium is measured as a readout for evaluation NMDAR stimulation.

\section{How it is Measured or Detected}

Please see KE Calcium influx, Decreased in the AOP entitled: Chronic binding of antagonist to $N$-methyl-D-aspartate receptors (NMDARs) during brain development induces impairment of learning and memory abilities.

\section{Evidence Supporting Taxonomic Applicability}

Please see KE Calcium influx, Decreasedin the AOP entitled Chronic binding of antagonist to $N$ methyl-D-aspartate receptors (NMDARs) during brain development induces impairment of learning and memory abilities.

\section{References}

Bloodgood, B.L. and B. L. Sabatini (2007), Nonlinear regulation of unitary synaptic signals by CaV2.3 voltage-sensitive calcium channels located in dendritic spines. Neuron, Vol. 53, pp. 249-260.

Bloodgood, B.L., A.J. Giessel, B.L. Sabatini (2009),Biphasic synaptic Ca influx arising from compartmentalized electrical signals in dendritic spines. PLoS Biol, Vol. 7: e1000190.

Lledo, P.M. et al. (1998), Postsynaptic membrane fusion and long-term potentiation. Science, Vol. 279, pp. 399-403.

Luscher, C. and R.C. Malenka (2012), Book: NMDA Receptor-Dependent Long-Term Potentiation and Long-Term Depression (LTP/LTD). Cold Spring Harb Perspect Biol., 2012, 4: a005710.

Malenka, R.C. (1994), Synaptic plasticity in the hippocampus: LTP and LTD. Cell, Vol. 78, pp. 535-538. 


\section{Mitochondrial dysfunction, N/A}

AOPs including this Key Event

\begin{tabular}{|l|l|l|}
\hline \multicolumn{1}{|c|}{ AOP Name } & $\begin{array}{l}\text { Event } \\
\text { Type }\end{array}$ & Essentiality \\
\hline $\begin{array}{l}\text { Binding of agonists to ionotropic glutamate receptors in adult brain causes } \\
\text { excitotoxicity that mediates neuronal cell death, contributing to learning and } \\
\text { memory impairment. }\end{array}$ & KE & Strong \\
\hline $\begin{array}{l}\text { Nicotinic acetylcholine receptor activation contributes to abnormal foraging and } \\
\text { leads to colony loss/failure }\end{array}$ & KE & \\
\hline $\begin{array}{l}\text { Nicotinic acetylcholine receptor activation contributes to abnormal roll change } \\
\text { within the worker bee caste leading to colony loss/failure }\end{array}$ & KE & \\
\hline $\begin{array}{l}\text { Nicotinic acetylcholine receptor activation contributes to impaired hive } \\
\text { thermoregulation and leads to colony loss/failure }\end{array}$ & KE & \\
\hline $\begin{array}{l}\text { Nicotinic acetylcholine receptor activation contributes to accumulation of damaged } \\
\text { mitochondrial DNA and leads to colony loss/failure }\end{array}$ & KE & \\
\hline $\begin{array}{l}\text { Nicotinic acetylcholine receptor activation contributes to abnormal foraging and } \\
\text { leads to colony loss/failure }\end{array}$ & KE & \\
\hline $\begin{array}{l}\text { Inhibition of Complex I of the mitochondrial respiration chain leading to } \\
\text { neurodegeneration. }\end{array}$ & KE & Strong \\
\hline Lysosomal damage leading to liver inflammation & Strong \\
\hline
\end{tabular}

How this Key Event works

\section{Level of biological organisation}

Cellular

Mitochondrial dysfunction is a consequence of inhibition of the respiratory chain leading to oxidative stress.

Mitochondria can be found in all cells and are considered the most important cellular consumers of oxygen. Furthermore, mitochondria possess numerous redox enzymes capable of transferring single electrons to oxygen, generating the superoxide $\left(\mathrm{O}_{2}{ }^{-}\right)$. Some mitochondrial enzymes that are involved in reactive oxygen species (ROS) generation include the electron-transport chain (ETC) complexes I, II and III; pyruvate dehydrogenase (PDH) and glycerol-3-phosphate dehydrogenase (GPDH). The transfer of electrons to oxygen, generating superoxide, happens mainly when these redox carriers are charged enough with electrons and the potential energy for transfer is elevated, like in the case of high mitochondrial membrane potential. In contrast, ROS generation is decreased if there are not enough electrons and the potential energy for the transfer is not sufficient (reviewed in Lin and Beal, 2006).

Cells are also able to detoxify the generated ROS due to an extensive antioxidant defence system that includes superoxide dismutases, glutathione peroxidases, catalase, thioredoxins, and 
peroxiredoxins in various cell organelles (reviewed in Lin and Beal, 2006). It is worth mentioning that, as in the case of ROS generation, antioxidant defences are also closely related to the redox and energetic status of mitochondria. If mitochondria are structurally and functionally healthy, an antioxidant defence mechanism balances ROS generation, and there is not much available ROS production. However, in case of mitochondrial damage, the antioxidant defence capacity drops and ROS generation takes over. Once this happens, a vicious cycle starts and ROS can further damage mitochondria, leading to more free-radical generation and further loss of antioxidant capacity. During mitochondrial dysfunction the availability of ATP also decreases, which is considered necessary for repair mechanisms after ROS generation.

A number of proteins bound to the mitochondria or endoplasmic reticulum (ER), especially in the mitochondria-associated ER membrane (MAM) are playing an important role of communicators between these two organelles (reviewed Mei et al., 2013). ER stress induces mitochondrial dysfunction through regulation of $\mathrm{Ca}^{2+}$ signaling and ROS production (reviewed Mei et al., 2013). Prolonged ER stress leads to release of $\mathrm{Ca}^{2+}$ at the MAM and increased $\mathrm{Ca}^{2+}$ uptake into the mitochondrial matrix, which induces $\mathrm{Ca}^{2+}$-dependent mitochondrial outer membrane permeabilisation and apoptosis. At the same, ROS are produced by proteins in the ER oxidoreductin 1 (ERO1) family. ER stress activates ERO1 and leads to excessive production of ROS, which, in turn, inactivates SERCA and activates inositol-1,4,5- trisphosphate receptors (IP3R) via oxidation, resulting in elevated levels of cytosolic $\mathrm{Ca}^{2+}$, increased mitochondrial uptake of $\mathrm{Ca}^{2+}$, and ultimately mitochondrial dysfunction. Just as ER stress can lead to mitochondrial dysfunction, mitochondrial dysfunction also induces ER Stress (reviewed Mei et al., 2013). For example, nitric oxide disrupts the mitochondrial respiratory chain and causes changes in mitochondrial $\mathrm{Ca}^{2+}$ flux which induce ER stress. Increased $\mathrm{Ca}^{2+}$ flux triggers loss of mitochondrial membrane potential (MMP), opening of mitochondrial permeability transition pore (MPTP), release of cytochrome $\mathrm{c}$ and apoptosis inducing factor (AIF), decreasing ATP synthesis and rendering the cells more vulnerable to both apoptosis and necrosis (Wang and Qin, 2010).

Summing up: Mitochondria play a pivotal role in cell survival and cell death because they are regulators of both energy metabolism and apoptotic/necrotic pathways (Fiskum, 2000; Wieloch, 2001; Friberg and Wieloch, 2002; Lee and Wei, 2012; Wang et al., 2011). The production of ATP via oxidative phosphorylation is a vital mitochondrial function (Kann and Kovács, 2007; Nunnari and Suomalainen, 2012). The ATP is continuously required for signalling processes (e.g. $\mathrm{Ca}^{2+}$ signalling), maintenance of ionic gradients across membranes, and biosynthetic processes (e.g. protein synthesis, heme synthesis or lipid and phospholipid metabolism) (Kang and Pervaiz, 2012), and (Green, 1998; McBride et al., 2006). Inhibition of mitochondrial respiration contributes to various cellular stress responses, such as deregulation of cellular $\mathrm{Ca}^{2+}$ homeostasis (Graier et al., 2007) and ROS production (Nunnari and Suomalainen, 2012; reviewed Mei et al., 2013; Li et al., 2003). It is well established in the existing literature that mitochondrial dysfunction may result in: (a) an increased ROS production and a decreased ATP level, (b) the loss of mitochondrial protein import and protein biosynthesis, (c) the reduced activities of enzymes of the mitochondrial respiratory chain and the Krebs cycle, (d) the loss of the mitochondrial membrane potential, (e) the loss of mitochondrial motility, causing a failure to relocalize to the sites with increased energy demands, (f) the destruction of the mitochondrial network, and $(\mathrm{g})$ increased mitochondrial $\mathrm{Ca}^{2+}$ uptake, causing $\mathrm{Ca}^{2+}$ overload (reviewed in Lin and Beal, 2006; Graier et al., 2007), (h) the rupture of the mitochondrial inner and outer membranes, leading to (i) the release of mitochondrial pro-death factors, including cytochrome $\mathrm{c}$ 
(Cyt. c), apoptosis-inducing factor, or endonuclease G (Braun, 2012; Martin, 2011; Correia et al., 2012; Cozzolino et al., 2013), which eventually leads to apoptotic, necrotic or autophagic cell death (Wang and Qin, 2010). Due to their structural and functional complexity, mitochondria present multiple targets for various compounds.

How it is Measured or Detected

Mitochondrial dysfunction can be detected using isolated mitochondria, intact cells or cells in culture as well as in vivo studies. Such assessment can be performed with a large range of methods (revised by Brand and Nicholls, 2011) for which some important examples are given. All approaches to assess mitochondrial dysfunction fall into two main categories: the first assesses the consequences of a loss-of-function, i.e. impaired functioning of the respiratory chain and processes linked to it. Some assays to assess this have been described for the KE NADHubiquinone oxidoreductase (complex I), Inhibition, with the limitation that they are not specific for complex I. In the context of overall mitochondrial dysfunction, the same assays provide useful information, when performed under slightly different assay conditions (e.g. without addition of complex III and IV inhibitors). The second approach assesses a 'non-desirable gain-of-function', i.e. processes that are usually only present to a very small degree in healthy cells, and that are triggered in a cell, in which mitochondria fail.

I. Mitochondrial dysfunction assays assessing a loss-of function.

1. Cellular oxygen consumption

See KE NADH-ubiquinone oxidoreductase (complex I), Inhibition for details of oxygen consumption assays. The oxygen consumption parameter can be combined with other endpoints to derive more specific information on the efficacy of mitochondrial function. One approach measures the ADP-to-O ratio (the number of ADP molecules phosphorylated per oxygen atom reduced (Hinkle, 1995; Hafner et al., 1990). The related P/O ratio is calculated from the amount of ADP added, divided by the amount of $\mathrm{O}$ consumed while phosphorylating the added ADP (Ciapaite et al., 2005; Diepart et al., 2010; Hynes et al., 2006; James et al., 1995; Heimburg et al., 2005).

\section{Mitochondrial membrane potential $(\Delta \psi \mathrm{m})$}

The mitochondrial membrane potential $(\Delta \psi \mathrm{m})$ is the electric potential difference across the inner mitochondrial membrane. It requires a functioning respiratory chain in the absence of mechanisms that dissipate the proton gradient without coupling it to ATP production. The classical and still most quantitative method uses a tetraphenylphosphonium ion (TPP+)-sensitive electrode on suspensions of isolated mitochondria. The $\Delta \psi \mathrm{m}$ can also be measured in live cells by fluorimetric methods. These are based on dyes which accumulate in mitochochondria because of $\Delta \psi \mathrm{m}$. Frequently used are tetramethylrhodamineethylester (TMRE), tetramethylrhodamine, methyl ester (TMRM) (Petronilli et al., 1999) or 5,5',6,6'-tetrachloro-1,1',3,3'-tetraethylbenzimidazole carbocyanide iodide (JC-1). Mitochondria with intact membrane potential concentrate JC-1, so that it forms red fluorescent aggregates, whereas de-energized mitochondria cannot concentrate JC-1 and the dilute dye fluoresces green (Barrientos and Moraes, 1999). Assays using TMRE or TMRM measure only at one wavelength (red fluorescence), and depending on the assay setup, de- 
energized mitochondria become either less fluorescent (loss of the dye) or more fluorescent (attenuated dye quenching).

3. Enzymatic activity of the electron transport system (ETS)

Determination of ETS activity can be determined following Owens and King's assay (1975). The technique is based on a cell-free homogenate that is incubated with NADH to saturate the mitochondrial ETS and an artificial electron acceptor [1 - (4 -iodophenyl) -3 - (4 -nitrophenyl) -5phenylte trazolium chloride (INT)] to register the electron transmission rate. The oxygen consumption rate is calculated from the molar production rate of INT-formazan which is determined spectrophotometrically (Cammen et al., 1990).

\section{ATP content}

For the evaluation of ATP levels, various commercially-available ATP assay kits are offered (e.g. Sigma, http://www.abcam.com/atp-assay-kit-colorimetricfluorometric-ab83355.html), based on luciferin and luciferase activity. For isolated mitochondria various methods are available to continuously measure ATP with electrodes (Laudet et al., 2005), with luminometric methods, or for obtaining more information on different nucleotide phosphate pools (e.g. Ciapaite et al., 2005).

II. Mitochondrial dysfunction assays assessing a gain-of function.

1. Mitochondrial permeability transition pore opening (PTP)

The opening of the PTP is associated with a permeabilization of mitochondrial membranes, so that different compounds and cellular constituents can change intracellular localisation. This can be measured by assessment of the translocation of cytochrome c, adenylate kinase or AIF from mitochondria to the cytosol or nucleus. The translocation can be assessed biochemically in cell fractions, by imaging approaches in fixed cells or tissues or by life-cell imaging of GFP fusion proteins (Single et al., 1998; Modjtahedi et al., 2006). An alternative approach is to measure the accessibility of cobalt to the mitochondrial matrix in a calcein fluorescence quenching assay in live permeabilized cells (Petronilli et al., 1999).

2. mtDNA damage as a biomarker of mitochondrial dysfunction

Various quantitative polymerase chain reaction (QPCR)-based assays have been developed to detect changes of DNA structure and sequence in the mitochondrial genome. mtDNA damage can be detected in blood after low-level rotenone exposure, and the damage persists even after CI activity has returned to normal. With a more sustained rotenone exposure, mtDNA damage is also detected in skeletal muscle. These data support the idea that mtDNA damage in peripheral tissues in the rotenone model may provide a biomarker of past or ongoing mitochondrial toxin exposure (Sanders et al., 2014a and 2014b).

\section{Generation of ROS and resultant oxidative stress}

a. general approach Electrons from the mitochondrial ETS may be transferred 'erroneously' to molecular oxygen to form superoxide anions. This type of side reaction can be strongly enhanced upon mitochondrial damage. As superoxide may form hydrogen peroxide, hydroxyl radicals or other reactive oxygen species, a large number of direct ROS assays and assays assessing the effects of ROS (indirect ROS assays) are available (Adam-Vizi, 2005; Fan and Li 2014). Direct assays are based on the chemical modification of fluorescent or luminescent reporters by ROS species. Indirect assays assess cellular metabolites, the concentration of which is changed in the 
presence of ROS (e.g. glutathione, malonaldehyde, isoprostanes,etc.) At the animal level the effects of oxidative stress are measured from biomarkers in the blood or urine.

b. Measurement of the cellular glutathione (GSH) status GSH is regenerated from its oxidized form $(\mathrm{GSSH})$ by the action of an NADPH dependent reductase (GSSH + NADPH + H+ à 2 GSH $+\mathrm{NADP}+$ ). The ratio of GSH/GSSG is therefore a good indicator for the cellular $\mathrm{NADH}+$ /NADPH ratio (i.e. the redox potential). GSH and GSSH levels can be determined by HPLC, capillary electrophoresis, or biochemically with DTNB (Ellman's reagent). As excess GSSG is rapidly exported from most cells to maintain a constant GSH/GSSG ratio, a reduction of total glutathione (GSH/GSSG) is often a good surrogate measure for oxidative stress.

c. Quantification of lipid peroxidation Measurement of lipid peroxidation has historically relied on the detection of thiobarbituric acid (TBA)-reactive compounds such as malondialdehyde generated from the decomposition of cellular membrane lipid under oxidative stress (Pryor et al., 1976). This method is quite sensitive, but not highly specific. A number of commercial assay kits are available for this assay using absorbance or fluorescence detection technologies. The formation of F2-like prostanoid derivatives of arachidonic acid, termed F2-isoprostanes (IsoP) has been shown to be more specific for lipid peroxidation. A number of commercial ELISA kits have been developed for IsoPs, but interfering agents in samples requires partial purification before analysis. Alternatively, GC/MS may be used, as robust (specific) and sensitive method.

d. Detection of superoxide production Generation of superoxide by inhibition of complex I and the methods for its detection are described by Grivennikova and Vinogradov (2014). A range of different methods is also described by BioTek (http://www.biotek.com/resources/articles/reactiveoxygen-species.html). The reduction of ferricytochrome $\mathrm{c}$ to ferrocytochrome $\mathrm{c}$ may be used to assess the rate of superoxide formation (McCord and Fidovich, 1968). Like in other superoxide assays, specificity can only be obtained by measurements in teh absence and presence of superoxide dismutase. Chemiluminescent reactions have been used for their increased sensitivity. The most widely used chemiluminescent substrate is lucigenin. Coelenterazine has also been used as a chemiluminescent substrate. Hydrocyanine dyes are fluorogenic sensors for superoxide and hydroxyl radical, and they become membrane impermeable after oxidation (trapping at sit of formation). The best characterised of these probes are Hydro-Cy3 and Hydro-Cy5. generation of superoxide in mitochondria can be visualized using fluorescence microscopy with MitoSOX ${ }^{\mathrm{TM}}$ Red reagent (Life Technologies). MitoSOX ${ }^{\mathrm{TM}}$ Red reagent is a cationic derivative of dihydroethidium that permeates live cells and accumulates in mitochondria.

e. Detection of hydrogen peroxide $\left(\mathrm{H}_{2} \mathrm{O}_{2}\right)$ production. There are a number of fluorogenic substrates, which serve as hydrogen donors that have been used in conjunction with horseradish peroxidase (HRP) enzyme to produce intensely fluorescent products in the presence of hydrogen peroxide (Zhou et al., 1997; Ruch et al., 1983). The more commonly used substrates include diacetyldichloro-fluorescein, homovanillic acid, and Amplex ${ }^{\circledR}$ Red. In these examples, increasing amounts of $\mathrm{H} 2 \mathrm{O} 2$ form increasing amounts of fluorescent product (Tarpley et al., 2004).

Summing up mitochondrial dysfunction can be measured by: • ROS production: superoxide (O2-), and hydroxyl radicals $\left(\mathrm{OH}^{-}\right)$- Nitrosative radical formation such as $\mathrm{ONOO}-$ or directly by: • Loss of mitochondrial membrane potential (MMP) - Opening of mitochondrial permeability transition pores (MPTP) $-\mathrm{ATP}$ synthesis $\cdot$ Increase in mitochondrial $\mathrm{Ca}^{2+} \cdot$ Cytochrome $\mathrm{c}$ release 
- AIF (apoptosis inducing factor) release from mitochondria - Mitochondrial Complexes enzyme activity - Measurements of mitochondrial oxygen consumption - Ultrastructure of mitochondria using electron microscope and mitochondrial fragmentation measured by labelling with DsRedMito expression (Knott et al., 2008) Mitochondrial dysfunction-induced oxidative stress can be measured by: - Reactive carbonyls formations (proteins oxidation) - Increased 8-oxo-dG immunoreactivity (DNA oxidation) $・$ Lipid peroxidation (formation of malondialdehyde (MDA) and 4- hydroxynonenal (HNE) - 3-nitrotyrosine (3-NT) formation, marker of protein nitration • Translocation of Bid and Bax to mitochondria - Measurement of intracellular free calcium concentration $\left(\left[\mathrm{Ca}^{2+}\right] \mathrm{i}\right)$ : Cells are loaded with $4 \mu \mathrm{M}$ fura-2/AM). - Ratio between reduced and oxidized form of glutathione (GSH depletion) (Promega assay, TB369; Radkowsky et al., 1986) • Neuronal nitric oxide synthase (nNOS) activation that is $\mathrm{Ca}^{2+}$-dependent All above measurements can be performed as the assays for each readout are well established in the existing literature (e.g. Bal-Price and Brown, 2000; Bal-Price et al., 2002; Fujikawa, 2015; Walker et al., 1995).

Evidence Supporting Taxonomic Applicability

\begin{tabular}{l|l|l|l|}
\hline Name & Scientific Name & Evidence & Links \\
\hline human & Homo sapiens & Strong & NCBI \\
\hline mouse & Mus musculus & Strong & NCBI \\
\hline rat & Rattus norvegicus & Strong & NCBI \\
\hline
\end{tabular}

Mitochondrial dysfunction is a universal event occurring in cells of any species (Farooqui and Farooqui, 2012). Many invertebrate species (drosophila, C. elegans) are considered as potential models to study mitochondrial function (Sanchez-Paz et al., 2012; Tahira and Farooqui, 2012). New data on marine invertebrates, such as molluscs and crustaceans and non-Drosophila species, are emerging (Martinez-Cruz, 2012). Mitochondrial dysfunction can be measured in animal models used for toxicity testing (Winklhofer and Haass, 2010; Waerzeggers et al., 2010) as well as in humans (Winklhofer and Haass, 2010).

\section{References}

Adam-Vizi, V. (2005), Production of reactive oxygen species in brain mitochondria: contribution by electron transport chain and non-electron transport chain sources, Antioxidants and Redox Signaling, Vol. (9-10), pp. 1140-1149.

Bal-Price, A. and G. C. Brown (2000), Nitric-oxide-induced necrosis and apoptosis in PC12 cells mediated by mitochondria. Journal of Neurochemistry, Vol. 75, pp. 1455-1464.

Bal-Price, A., A. Matthias, G.C. Brown (2002), Stimulation of the NADPH oxidase in activated rat microglia removes nitric oxide but induces peroxynitrite production, Journal of Neurochemistry, Vol. 80, pp. 73-80.

Brand, M,D. and D.G. Nicholls (2011), Assessing mitochondrial dysfunction in cells. Biochemical Journal, Vol. 15. no. 435, pp. 297-312.

Braun, R.J. (2012), Mitochondrion-mediated cell death: dissecting yeast apoptosis for a better understanding of neurodegeneration. Frontiers in Oncology, Vol. 2, pp. 182-195. 
Barrientos, A. and C.T. Moraes (1999), Titrating the Effects of Mitochondrial Complex I. Impairment in Cell Physiology, Vol. 274, No. 23, pp. 16188-16197.

Cammen, M., S. Corwin, J.P. Christensen (1990), Electron transport system (ETS) activity as a measure of benthic macrofaunal metabolism. Marine Ecology Progress Series, Vol. 65, pp. 171-182.

Ciapaite et al., (2005), Modular Kinetic Analysis of the Adenine Nucleotide Translocator-Mediated Effects of Palmitoyl-CoA on the Oxidative Phosphorylation in Isolated Rat Liver. Mitochondria Diabetes, Vol. 54, no. 4, pp. 944-951.

Correia et al., (2012), Mitochondrial importance in Alzheimer's, Huntington's and Parkinson's diseases. Advances in Experimental Medicine and Biology, Vol. 1724, pp. 205 - 221.

Cozzolino et al., (2013), Mitochondria and ALS: implications from novel genes and pathways. Molecular and Cellular Neuroscience, Vol. 55, pp. $44-49$.

Diepart et al., (2010), Comparison of methods for measuring oxygen consumption in tumor cells in vitro. Analytical Biochemistry, Vol. 396, pp. 250-256.

Fan, L.M. and J.M. Li (2014), Evaluation of methods of detecting cell reactive oxygen species production for drug screening and cell cycle studies. Journal of Pharmacological and Toxicological Methods, Vol. 70, no. 1, pp. 40-47.

Farooqui, T. and A. Farooqui (2012), Oxidative stress in Vertebrates and Invertebrate: molecular aspects of cell signalling. Wiley-Blackwell, Chapter 27, pp. 377- 385.

Fiskum G. (2000), Mitochondrial participation in ischemic and traumatic neural cell death. J Neurotrauma, Vol. 17, no. 10, pp. 843-55.

Friberg, H and T. Wieloch (2002), Mitochondrial permeability transition in acute neurodegeneration. Biochimie, Vol. 84, pp. 241-250.

Fujikawa, D.G. (2015), The Role of Excitotoxic Programmed Necrosis in Acute Brain Injury. Computational and Structural Biotechnology Journal, Vol. 13, pp. 212-221.

Graier, W.F., M. Frieden, R. Malli (2007), Mitochondria and $\mathrm{Ca}^{2+}$ signaling: old guests, new functions. Pflügers Archiv, Vol. 455, pp. 375-396.

Green, D.R. (1998), Apoptotic pathways: the roads to ruin. Cell, Vol. 94, pp. 695-698.

Grivennikov, V.G and A.D. Vinogradov (2006), Generation of superoxide by the mitochondrial Complex I. Biochimica et Biophysica Acta, Vol. 1757, No. 5-6, pp. 553-61.

Hafner, R.P., G.C. Brown and M.D Brand (1990), Analysis of the control of respiration rate, phosphorylation rate, proton leak rate and protonmotive force in isolated mitochondria using the 'top-down' approach of metabolic control theory. European Journal of Biochemistry, Vol. 188, pp. $313-319$.

Hajnóczky G. et al. (2006), Mitochondrial calcium signalling and cell death: approaches for assessing the role of mitochondrial $\mathrm{Ca}^{2+}$ uptake in apoptosis. Cell Calcium, Vol. 40, pp. 553-560.

Heimburg, D. et al. (2005), Oxygen consumption in undifferentiated versus differentiated adipogenic mesenchymal precursor cells, Respiratory Physiology \& Neurobiology, Vol. 146, pp. 107-116.

Hinkle, P. C. (1995), Measurement of ADP/O ratios. In Bioenergetics: A Practical Approach. Brown GC, Cooper CE, Eds. Oxford, U.K., IRL Press, pp.5 -6.

Hynes, J. et al. (2006), Investigation of drug-induced mitochondrial toxicity using fluorescence-based oxygen-sensitive probes, Toxicological. Sciences. Vol. 92, pp. 186-200.

James, P.E. (1995) The effects of endotoxin on oxygen consumption of various cell types in vitro: an EPR oximetry study, Free Radical Biology\& Medicine, Vol 18, pp. 641-647.

Kang, J. and S. Pervaiz (2012), Mitochondria: Redox Metabolism and Dysfunction. Biochemistry Research International, Vol 2012, 896751. 
Kann, O. and Kovács R. (2007). Mitochondria and neuronal activity. American Journal of Physiology. Cell physiology, Vol. 292, pp. C641-576.

Knott, A. et al. (2008), Mitochondrial fragmentation in neurodegeneration. Nature Reviews Neuroscience, Vol. 229, pp. 505-518.

Llaudet, E. et al. (2005), Microelectrode biosensor for real-time measurement of ATP in biological tissue. Analitical Chemistry, Vol. 77, No. 10, pp. 3267-73.

Lee, H.C. and Y.H. Wei (2012), Mitochondria and aging. Advances in Experimental Medicine and Biology, Vol. 942, pp. 311-327.

Li N. et al. (2003), Mitochondrial complex I inhibitor rotenone induces apoptosis through enhancing mitochondrial reactive oxygen species production. Journal of Biological Chemistry, Vol. 278, pp. $8516-8525$.

Lin, M.T. and M.F. Beal (2006), Mitochondrial dysfunction and oxidative stress in neurodegenerative diseases. Nature, Vol. 443, pp. 787-795.

Martin, L.J. (2011), Mitochondrial pathobiology in ALS. Journal of Bioenergetics and Biomembranes, Vol. 43, pp. $569-579$.

Martinez-Cruz O. (2012), Invertebrates Mitochondrial Function and Energetic Challenges (www.intechopen.com), Bioenergetics, Edited by Dr Kevin Clark, ISBN 978-953-51-0090-4, Publisher InTech, pp. 181-218.

McBride, H.M., M. Neuspiel M. and S. Wasiak (2006), Mitochondria: more than just a powerhouse. Current Biology, Vol. 16, pp. R551-560.

McCord, J.M. and I. Fidovich (1968), The Reduction of Cytochrome C by Milk Xanthine Oxidase. Journal of Biological Chemistry, Vol. 243, pp. 5733-5760.

Mei, Y., et al. (2013), Endoplasmic Reticulum Stress and Related Pathological Processes. Journal of Pharmaceutical and Biomedical Analysis, Vol. 1, pp. 100-107.

Modjtahedi N. et al. (2006), Apoptosis-inducing factor: vital and lethal. Trends Cell Biology, Vol. 16, No. 5, pp. 264-72.

Nunnari J. and A. Suomalainen (2012), Mitochondria: in sickness and in health. Cell, Vol. 148, pp. 11451159.

Owens R.G. and F.D. King (1975), The measurement of respiratory lectron-transport system activity in marine zooplankton. Marine Biology, Vol. 30, pp. 27-36.

Petronilli V., et al. (1999), Transient and long-lasting openings of the mitochondrial permeability transition pore can be monitored directly in intact cells by changes in mitochondrial calcein fluorescence. Biophysical Journal, Vol. 76, pp. 725-734.

Promega GSH-Glo Glutathione Assay Technical Bulletin, TB369, Promega Corporation, Madison, WI.

Pryor, W.A., J.P. Stanley, and E. Blair. (1976), Autoxidation of polyunsaturated fatty acids: II. A Suggested mechanism for the Formation of TBA-reactive materials from prostaglandin-like Endoperoxides. Lipids, Vol. 11, pp. 370-379.

Radkowsky, A.E. and E.M. Kosower (1986), Bimanes $17 . \quad$ (Haloalkyl)-1,5diazabicyclo[3.3.O]octadienediones (halo-9,10- dioxabimanes): reactivity toward the tripeptide thiol, glutathione, J Am Chem Soc, Vol. 108, pp. 4527-4531.

Ruch, W., P.H. Cooper, and M. Baggiollini (1983), Assay of $\mathrm{H} 2 \mathrm{O} 2$ production by macrophages and neutrophils with Homovanillic acid and horseradish peroxidase. Journal of Immunological Methods, Vol. 63, pp. 347-357.

Sanchez-Paz, M.O. et al. (2012), Invertebrates Mitochondrial Function and Energetic Challenges (www.intechopen.com), Bioenergetics, Edited by Dr Kevin Clark, ISBN 978-953-51-0090-4, Publisher InTech, pp. 181-218. 
Sanders, L.H., et al. (2014a), Mitochondrial DNA damage: molecular marker of vulnerable nigral neurons in Parkinson's disease. Neurobiology of Disease, Vol. 70, pp. 214-23.

Sanders, L.H. et al. (2014b), Mitochondrial DNA damage as a peripheral biomarker for mitochondrial toxin exposure in rats. Toxicological Sciences. Vol. 142, No. 2, pp. 395-402.

Single, B., M. Leist, P. Nicotera (1989, Simultaneous release of adenylate kinase and cytochrome c in cell death. Cell Death and Differentiation, Vol. 5, No. 12. pp.1001-3.

Tahira, F. and A. A. Farooqui (2012), Oxidative stress in Vertebrates and Invertebrate: molecular aspects of cell signalling. Wiley-Blackwell,Chapter 27, pp:377- 385.

Tarpley, M.M., D.A. Wink, and M.B. Grisham (2004), Methods for detection of reactive Metabolites of Oxygen and Nitrogen: in vitro and in vivo considerations, American Journal of Physiology Regulatory, Integrative and Comparative Physiology, Vol. 286, pp. R431-R444.

Waerzeggers, Y. et al. (2010), Mouse models in neurological disorders: Applications of non-invasive imaging. Biochimica et Biophysica Acta (BBA), - Molecular Basis of Disease, Vol. 1802, No.10, pp. 819-839.

Walker, J,E,, Skehel J,M. and S.K. Buchanan (1995), Structural analysis of NADH: ubiquinone oxidoreductase from bovine heart mitochondria, Methods in Enzymology, Vol. 260, pp. 14-34.

Wang A. et al., (2011), Parkinson's disease risk from ambient exposure to pesticides, European Journal of Epidemiology, Vol. 26, pp. 547-555.

Wang Y., and Z.H Qin (2010), Molecular and cellular mechanisms of excitotoxic neuronal death, Apoptosis, Vol. 15, pp. 1382-1402.

Wieloch, T. (2001), Mitochondrial involvement in acute neurodegeneration, IUBMB Life. Vol. 52, No. 35, pp. 247-54.

Winklhofer, K. and C. Haass (2010), Mitochondrial dysfunction in Parkinson's disease, Biochimica et Biophysica Acta (BBA) - Molecular Basis of Disease, Vol. 1802, pp. 29-44.

Zhou, M. et al. (1997), A Stable nonfluorescent derivative of resorufin for the fluorometric determination of trace hydrogen peroxide: application in detecting the activity of phagocyte NADPH oxidase and other oxidases, Analitical Biochemistry, Vol. 253, pp. 162-168. 


\section{Cell injury/death, N/A}

AOPs including this Key Event

\begin{tabular}{|l|l|l|}
\hline \multicolumn{1}{|c|}{ AOP Name } & $\begin{array}{l}\text { Event } \\
\text { Type }\end{array}$ & Essentiality \\
\hline $\begin{array}{l}\text { Binding of agonists to ionotropic glutamate receptors in adult brain causes } \\
\text { excitotoxicity that mediates neuronal cell death, contributing to learning and } \\
\text { memory impairment. }\end{array}$ & KE & Strong \\
\hline $\begin{array}{l}\text { Chronic binding of antagonist to N-methyl-D-aspartate receptors (NMDARs) } \\
\text { during brain development induces impairment of learning and memory abilities }\end{array}$ & KE & Strong \\
\hline Protein Alkylation leading to Liver Fibrosis & KE & Strong \\
\hline $\begin{array}{l}\text { Binding of antagonist to N-methyl-D-aspartate receptors (NMDARs) during brain } \\
\text { development can trigger neuroinflammation and lead to neurodegeneration }\end{array}$ & KE & Moderate \\
\hline Lysosomal damage leading to liver inflammation & KE & Strong \\
\hline
\end{tabular}

How this Key Event works

\section{Level of biological organisation}

Cellular

Two types of cell death can be distinguished by morphological features, although it is likely that these are two ends of a spectrum with possible intermediate forms. Apoptosis involves shrinkage, nuclear disassembly, and fragmentation of the cell into discrete bodies with intact plasma membranes. These are rapidly phagocytosed by neighbouring cells. An important feature of apoptosis is the requirement for adenosine triphosphate (ATP) to initiate the execution phase. In contrast, necrotic cell death is characterised by cell swelling and lysis. This is usually a consequence of profound loss of mitochondrial function and resultant ATP depletion, leading to loss of ion homeostasis, including volume regulation, and increased $\mathrm{Ca}^{2+}$. The latter activates a number of nonspecific hydrolases (i.e., proteases, nucleases, and phospholipases) as well as calcium dependent kinases. Activation of calpain $\mathrm{I}$, the $\mathrm{Ca}^{2+}$-dependent cysteine protease cleaves the death-promoting Bcl-2 family members Bid and Bax which translocate to mitochondrial membranes, resulting in release of truncated apoptosis-inducing factor (tAIF), cytochrome $\mathrm{c}$ and endonuclease in the case of Bid and cytocrome $\mathrm{c}$ in the case of Bax. tAIF translocates to cell nuclei, and together with cyclophilin $\mathrm{A}$ and phosphorylated histone $\mathrm{H} 2 \mathrm{AX}(\gamma \mathrm{H} 2 \mathrm{AX})$ is responsible for DNA cleavage, a feature of programmed necrosis. Activated calpain I has also been shown to cleave the plasma membrane $\mathrm{Na}^{+}-\mathrm{Ca}^{2+}$ exchanger, which leads to build-up of intracellular $\mathrm{Ca}^{2+}$, which is the source of additional increased intracellular $\mathrm{Ca}^{2+}$. Cytochrome $\mathrm{c}$ in cellular apoptosis is a component of the apoptosome.

DNA damage activates nuclear poly(ADP-ribose) polymerase-1(PARP-1), a DNA repair enzyme. PARP-1 forms poly(ADP-ribose) polymers, to repair DNA, but when DNA damage is extensive, PAR accumulates, exits cell nuclei and travels to mitochondrial membranes, where it, like calpain $\mathrm{I}$, is involved in AIF release from mitochondria. A fundamental distinction between necrosis and apoptosis is the loss of plasma membrane integrity; this is integral to the former but not the latter. 
As a consequence, lytic release of cellular constituents promotes a local inflammatory reaction, whereas the rapid removal of apoptotic bodies minimizes such a reaction. The distinction between the two modes of death is easily accomplished in vitro but not in vivo. Thus, although claims that certain drugs induce apoptosis have been made, these are relatively unconvincing. DNA fragmentation can occur in necrosis, leading to positive TUNEL staining. Conversely, when apoptosis is massive, it can exceed the capacity for rapid phagocytosis, resulting in the eventual appearance of secondary necrosis.

Two alternative pathways - either extrinsic (receptor-mediated) or intrinsic (mitochondriamediated) - lead to apoptotic cell death. The initiation of cell death begins either at the plasma membrane with the binding of TNF or FasL to their cognate receptors or within the cell. The latter is due to the occurrence of intracellular stress in the form of biochemical events such as oxidative stress, redox changes, covalent binding, lipid peroxidation, and consequent functional effects on mitochondria, endoplasmic reticulum, microtubules, cytoskeleton, or DNA. The intrinsic mitochondrial pathway involves the initiator, caspase-9, which, when activated, forms an "apoptosome" in the cytosol, together with cytochrome c, which translocates from mitochondria, Apaf- 1 and dATP. The apoptosome activates caspase-3, the central effector caspase, which in turn activates downstream factors that are responsible for the apoptotic death of a cell (Fujikawa, 2015). Intracellular stress either directly affects mitochondria or can lead to effects on other organelles, which then send signals to the mitochondria to recruit participation in the death process (Fujikawa, 2015; Malhi et al., 2010). Constitutively expressed nitric oxide synthase (nNOS) is a $\mathrm{Ca}^{2+}$-dependent cytosolic enzyme that forms nitric oxide (NO) from L-arginine, and NO reacts with the free radical such as superoxide $\left(\mathrm{O}^{2-}\right)$ to form the very toxic free radical peroxynitrite $(\mathrm{ONOO}-)$. Free radicals such as $\mathrm{ONOO}^{-}, \mathrm{O}^{-}$and hydroxyl radical $\left(\mathrm{OH}^{-}\right)$damage cellular membranes and intracellular proteins, enzymes and DNA (Fujikawa, 2015; Malhi et al., 2010; Kaplowitz, 2016; Kroemer et al., 2009).

\section{How it is Measured or Detected}

\section{Necrosis:}

LDH is a soluble cytoplasmic enzyme that is present in almost all cells and is released into extracellular space when the plasma membrane is damaged. To detect the leakage of LDH into cell culture medium, a tetrazolium salt is used in this assay. In the first step, LDH produces reduced nicotinamide adenine dinucleotide (NADH) when it catalyzes the oxidation of lactate to pyruvate. In the second step, a tetrazolium salt is converted to a colored formazan product using newly synthesised NADH in the presence of an electron acceptor. The amount of formazan product can be colorimetrically quantified by standard spectroscopy. Because of the linearity of the assay, it can be used to enumerate the percentage of necrotic cells in a sample (Chan et al., 2013).

The MTT assay is a colorimetric assay for assessing cell viability. NAD(P)H-dependent cellular oxidoreductase enzymes may reflect the number of viable cells present. These enzymes are capable of reducing the tetrazolium dye MTT 3-(4,5-dimethylthiazol-2-yl)-2,5diphenyltetrazolium bromide to its insoluble formazan, which has a purple color. Other closely related tetrazolium dyes including XTT, MTS and the WSTs. Tetrazolium dye assays can also be used to measure cytotoxicity (loss of viable cells) or cytostatic activity (shift from proliferation to 
quiescence) of potential medicinal agents and toxic materials. MTT assays are usually done in the dark since the MTT reagent is sensitive to light (Berridge et al., 2005).

Propidium iodide (PI) is an intercalating agent and a fluorescent molecule used to stain necrotic cells. It is cell membrane impermeant so it stains only those cells where the cell membrane is destroyed. When PI is bound to nucleic acids, the fluorescence excitation maximum is $535 \mathrm{~nm}$ and the emission maximum is $617 \mathrm{~nm}$ (Moore et al., 1998).

\section{Apoptosis:}

TUNEL is a common method for detecting DNA fragmentation that results from apoptotic signalling cascades. The assay relies on the presence of nicks in the DNA which can be identified by terminal deoxynucleotidyl transferase or TdT, an enzyme that will catalyze the addition of dUTPs that are secondarily labeled with a marker. It may also label cells that have suffered severe DNA damage.

Caspase activity assays measured by fluorescence. During apoptosis, mainly caspase- 3 and -7 cleave PARP to yield an $85 \mathrm{kDa}$ and a $25 \mathrm{kDa}$ fragment. PARP cleavage is considered to be one of the classical characteristics of apoptosis. Antibodies to the $85 \mathrm{kDa}$ fragment of cleaved PARP or to caspase-3 both serve as markers for apoptotic cells that can be monitored using immunofluorescence (Li et al., 2004).

Hoechst 33342 staining: Hoechst dyes are cell-permeable and bind to DNA in live or fixed cells. Therefore, these stains are often called supravital, which means that cells survive a treatment with these compounds. The stained, condensed or fragmented DNA is a marker of apoptosis (Loo, 2002; Kubbies and Rabinovitch, 1983).

Evidence Supporting Taxonomic Applicability

\begin{tabular}{l|l|l|l|}
\hline \multicolumn{1}{c|}{ Name } & Scientific Name & Evidence & \multicolumn{1}{c|}{ Links } \\
\hline human & Homo sapiens & Strong & NCBI \\
\hline human and other cells in culture & & Strong & Error! Hyperlink reference not valid. \\
\hline Rattus norvegicus & Rattus norvegicus & Strong & NCBI \\
\hline mouse & Mus musculus & Strong & NCBI \\
\hline
\end{tabular}

Cell death is a universal event occurring in cells of any species (Fink and Cookson, 2005).

\section{References}

Berridge, M.V., P.M. Herst and A.S. Tan (2005), Tetrazolium dyes as tools in cell biology: new insights into their cellular reduction. Biotechnology Annual Review, Vol. 11, pp 127-152.

Chan, F.K., K. Moriwaki and M.J. De Rosa (2013), Detection of necrosis by release of lactate dehydrogenase (LDH) activity, Methods in Molecular Biology, Vol. 979, pp. 65-70.

Fink, S.L. and B.T. Cookson (2005), Apoptosis, pyroptosis, and necrosis: mechanistic description of dead and dying eukaryotic cells, Infection and Immunity, Vol. 73, No. 4, pp.1907-1916. 
Fujikawa, D.G. (2015), The role of excitotoxic programmed necrosis in acute brain injury, Computational and Structural Biotechnology Journal, Vol. 13, pp. 212-221.

Kaplowitz, N. (2016), Biochemical and Cellular Mechanisms of Toxic Liver Injury, Seminars in Liver Disease, Vol. 22, No. 2, http://www.medscape.com/viewarticle/433631.

Kroemer, G. et al., (2009), Classification of cell death: recommendations of the Nomenclature Committee on Cell Death, Cell Death and Differentiation, Vol. 16, No. 1, pp. 3-11.

Kubbies, M. and P.S. Rabinovitch (1983), Flow cytometric analysis of factors which influence the BrdUrdHoechst quenching effect in cultivated human fibroblasts and lymphocytes, Cytometry, Vol. 3, No. 4, pp. 276-281.

Li, P. et al. (2004), Mitochondrial activation of apoptosis, Cell, Vol. 116, No. 2 Suppl,pp. S57-59, 2 p following S59.

Loo, D.T. (2002), TUNEL Assay an overview of techniques, Methods in Molecular Biology, Vol. 203: In Situ Detection of DNA Damage, chapter 2, Didenko VV (ed.), Humana Press Inc.

Malhi, H. et al. (2010), Hepatocyte death: a clear and present danger, Physiologivcal Reviews, Vol. 90, No. 3, pp. 1165-1194.

Moore, A, et al.(1998), Simultaneous measurement of cell cycle and apoptotic cell death, Methods in Cell Biology, Vol. 57, pp. 265-278.

\section{Neurodegeneration, N/A}

AOPs including this Key Event

\begin{tabular}{|l|l|l|}
\hline \multicolumn{1}{|c|}{ AOP Name } & $\begin{array}{l}\text { Event } \\
\text { Type }\end{array}$ & Essentiality \\
\hline $\begin{array}{l}\text { Binding of antagonist to N-methyl-D-aspartate receptors (NMDARs) during brain } \\
\text { development can trigger neuroinflammation and lead to neurodegeneration }\end{array}$ & AO & \\
\hline $\begin{array}{l}\text { Binding to SH/selen-proteins can trigger neuroinflammation leading to } \\
\text { neurodegeneration }\end{array}$ & AO & \\
\hline $\begin{array}{l}\text { Binding of agonists to ionotropic glutamate receptors in adult brain causes } \\
\text { excitotoxicity that mediates neuronal cell death, contributing to learning and } \\
\text { memory impairment. }\end{array}$ & KE trong \\
\hline
\end{tabular}

How this Key Event works

\section{Level of biological organisation}

Tissue

The term neurodegeneration is a combination of two words - "neuro," referring to nerve cells and "degeneration," referring to progressive damage. The term "neurodegeneration" can be applied to several conditions that result in the loss of nerve structure and function including death of neurons. Neurodegeneration occurs in a large number of diseases that come under the umbrella of "neurodegenerative diseases" including, Huntington's, Alzheimer's and Parkinson's diseases. All of these conditions lead to progressive brain damage and neurodegeneration. 
Alzheimer's disease is characterised by loss of neurons and synapses in the cerebral cortex and certain subcortical regions, with gross atrophy of the affected regions; symptoms include memory loss. Parkinson's disease (PD) results from the death of dopaminergic neurons in the midbrain substantia nigra pars compacta; symptoms include bradykinesia, rigidity, and resting tremor.

Several observations suggest correlative links between environmental exposure and neurodegenerative diseases, but only few suggest causative links:

In the brain, the cerebral cortex is highly sensitive to heavy metal exposure. This may be due to differential accumulation, such as observed following high concentrations of mercury (Hamilton et al, 2011), or to differential vulnerability. The hippocampus is the most affected structure following exposure to trimethyltin (TMT) (Dey et al., 1997; Fiedorowicz et al, 2008; Robertson et al, 1987), or mercury exposure during the developmental period (Falluel-Morel et al, 2012). $\mathrm{Pb}^{2+}$ affects the hippocampus and the frontal cortex (Schneider et al., 2012). In these sensitive regions, a decrease of synapses or cellular loss is observed (Corvino et al., 2013; Dey et al, 1997). Changes in genes involved in the amyloid cascade related to Alzheimer's disease were observed in the cortex of monkeys following $\mathrm{Pb}^{2+}$ exposure early in life (Zawia and Basha, 2005 ; Wu et al., 2008). In addition, aggregation of the amyloid peptide $\beta$ was particularly enhanced in these monkeys after re-exposure to $\mathrm{Pb}^{2+}$ (Basha et al, 2005). These epigenetic modifications may be due to DNA methylation mediated in part through lead-induced dysregulation of methyltransferases (Schneider et al, 2013). The particular sensitivity of cortical areas to heavy metal exposure together with the increase of amyloid peptide deposition suggest a link between heavy metal exposure and Alzheimer's pathology (Castoldi et al., 2008; Mutter et al., 2004). Paraquat and rotenone induce specific lesions in the substantia nigra (Costello et al., 2009; Wu et al., 2013), suggesting that these toxicants may be causally associated with Parkinson's disease.

Only an extremely small proportion (less than 5\%) of neurodegenerative diseases are caused by genetic mutations. The remainders are thought to be caused by the following:

- A build up of toxic proteins in the brain (Lansbury et al., 2006; Majd et al., 2015; Zaltieri et al., 2015)

- A loss of mitochondrial function that leads to the oxidative stress and creation of neurotoxic molecules that trigger cell death (apoptotic, necrotic or autophagy) (Lin and Beal, 2006; Braun, 2012; Betarbet et al.,2000; Zhu and Chu, 2010)

- Changes in the levels and activities of neurotrophic factors (Zuccato and Cattaneo, 2009; Michalski et al., 2015)

- Variations in the activity of neural networks (Palop et al., 2006; Kann, 2015; Sala-Llonch et al., 2014).

Protein aggregation: the correlation between neurodegenerative disease and protein aggregation in the brain has long been recognised, but a causal relationship has not been unequivocally established (Lansbury and Lashuel, 2006). However, the causative link between mitochondrial dysfunction and its relationship to protein degradation and intracellular transport is well documented (Zaltieri et al., 2015). The dynamic nature of protein aggregation means that, despite progress towards understanding aggregation, its relationship to disease is difficult to determine in the laboratory. Nevertheless, drug candidates that inhibit aggregation are now being tested in the clinic. These have the potential to slow the progression of Alzheimer's disease, Parkinson's disease and related disorders and could, if administered pre-symptomatically, reduce the incidence of these diseases (Gerard et al., 2010; McFarland and Okun, 2013). 
Loss of mitochondrial function: many lines of evidence suggest that mitochondria have a central role in neurodegenerative diseases (Lin and Beal, 2006). Mitochondria are critical regulators of cell death, a key feature of neurodegeneration. Dysfunction of mitochondria induces oxidative stress, production of free radicals, calcium overload, and mutations in mitochondrial DNA that contribute to neurodegenerative diseases. In all major examples of neurodegenerative diseases there is strong evidence that mitochondrial dysfunction occurs early and acts causally in disease pathogenesis (Zaltieri et al., 2015). Moreover, an impressive number of disease-specific proteins interact with mitochondria. Thus, therapies targeting basic mitochondrial processes, such as energy metabolism or free-radical generation hold some promise (Kaidery et al., 2013).

Decreased level of neurotrophic factors: decreased levels and activities of neurotrophic factors, such as brain-derived neurotrophic factor (BDNF), have been described in a number of neurodegenerative disorders, including Huntington disease, Alzheimer's disease and Parkinson's disease (Zuccato and Cattaneo, 2009; Michalski et al., 2015)). These studies have led to the development of experimental strategies aimed at increasing BDNF levels in the brains of animals that have been genetically altered to mimic neurodegenerative human diseases, with a view to ultimately influencing the clinical treatment of these conditions. Therefore BDNF treatment is often used as a beneficial and feasible therapeutic approach in the clinic setting (Bai et al., 2013; Nagahara and Tuszynski, 2011; Bradley 1999).

Variations in the activity of neural networks: Patients with various neurodegenerative disorders show remarkable fluctuations in neurological functions, even during the same day (Palop et al., 2006). These fluctuations cannot be caused by sudden loss or gain of nerve cells. Instead, it is likely that they reflect variations in the activity of neural networks and, perhaps, chronic intoxication by abnormal proteins that the brain is temporarily able to overcome. Variations in neuronal network activity are implicated in many brain diseases (Kann, 2015) as well as in aging (Sala-Llonch et al., 2014).

\section{How it is Measured or Detected}

The assays for measurements of necrotic or apoptotic cell death are described in the Key Event: Cell injury/Cell death.

Recent neuropathological studies have shown that Fluoro-Jade, an anionic fluorescent dye, is a good marker of degenerating neurons. Fluoro-Jade and Fluoro-Jade B were found to stain all degenerating neurons, regardless of specific insult or mechanism of cell death (Schmued et al., 2005). More recently, Fluoro-Jade $\mathrm{C}$ was shown to be highly resistant to fading and compatible with virtually all histological processing and staining protocols (Schmued et al., 2005). In addition, Fluoro-Jade $\mathrm{C}$ is a good tool for detecting acutely and chronically degenerating neurons (Ehara and Ueda, 2009).

\section{Evidence Supporting Taxonomic Applicability}

The necrotic and apoptotic cell death pathways are quite well conserved throughout taxa (Blackstone and Green, 1999, Aravind et al., 2001). It has been widely suggested that apoptosis is also conserved in metazoans, although despite conservation of Bcl-2 proteins, APAF-1, and caspases there is no biochemical evidence of the existence of the mitochondrial pathway in either C. elegans or Drosophila apoptosis (Baum et al., 2007; Blackstone and Green, 1999). 


\section{References}

Aravind, L., Dixit, V. M. and Koonin, E. V. (2001), Apoptotic Molecular Machinery: Vastly Increased Complexity in Vertebrates Revealed by Genome Comparisons. Science, Vol. 291: pp. 1279-1284.

Bai, L.U. et al. (2013), Guhan Nagappan, Xiaoming Guan, Pradeep J. Nathan , Paul Wren., BDNF-based synaptic repair as a disease-modifying strategy for neurodegenerative diseases. Nature Reviews Neuroscience, Vol. 14, pp. 401-416.

Basha, M.R. et al. (2005), Lead (Pb) exposure and its effect on APP proteolysis and Abeta aggregation. FASEB J., Vol. 19, pp. 2083-2084.

Baum, J. S. et al. (2007), The Drosophila caspases Strica and Dronc function redundantly in programmed cell death during oogenesis. Cell Death \& Differentiation, Vol. 14, pp. 1508-1517.

Betarbet, R. et al. (2000), Chronic systemic pesticide exposure reproduces features of Parkinson's disease. Nature Neuroscience, vol. 3, pp. 1301-1306.

Blackstone, N. W., and D.R. Green (1999), The evolution of a mechanism of cell suicide. Bioessays, Vol. 21, pp. 84-88.

Bradley, W. G. (1999), A controlled trial of recombinant methionyl human BDNF in ALS Neurology, Vol. 52, No. 7, pp. 1427-1439.

Braun, R.J. (2012), Mitochondrion-mediated cell death: dissecting yeast apoptosis for a better understanding of neurodegeneration. Frontiers in Oncology, Vol. 2, pp. 182-194.

Castoldi, A.F. et al. (2008), Human developmental neurotoxicity of methylmercury: impact of variables and risk modifiers. Regul Toxicol Pharmacol, Vol. 51, pp. 201-214.

Corvino, V. et al. (2013), Neuroprotective strategies in hippocampal neurodegeneration induced by the neurotoxicant trimethyltin. Neurochemistry Research, Vol. 38, pp. 240-253.

Costello, S. et al. (2009), Parkinson's disease and residential exposure to maneb and paraquat from agricultural applications in the central valley of California. American Journal of Epidemiology, Vol. 169, pp. 919-926.

Dey, P. M. et al. (1997), Altered expression of polysialylated NCAM in mouse hippocampus following trimethyltin administration. Neurotoxicology, Vol. 18, pp. 633-643.

Ehara, A. and S. Ueda (2009), Application of Fluoro-Jade C in acute and chronic neurodegeneration models: utilities and staining differences. Acta Histochemica et Cytochemica, Vol. 42, pp. 171-179.

Falluel-Morel, A. et al. (2012), N-acetyl cysteine treatment reduces mercury-induced neurotoxicity in the developing rat hippocampus. Journal of Neuroscience Research, Vol. 90, pp. 743-750.

Fiedorowicz, A. et al. (2008), Trimethyltin-evoked apoptosis of murine hippocampal granule neurons is accompanied by the expression of interleukin-1beta and interleukin-1 receptor antagonist in cells of ameboid phenotype, the majority of which are NG2-positive. Brain Research Bulletin, Vol. 77, pp. 19-26.

Gerard, M. et al. (2010), Inhibition of FK506 binding proteins reduces alpha-synuclein aggregation and Parkinson's disease-like pathology. Journal of Neuroscience, Vol. 30, pp. 2454-63.

Hamilton, M., A. Scheuhammer and N. Basu (2011), Mercury, selenium and neurochemical biomarkers in different brain regions of migrating common loons from Lake Erie, Canada. Ecotoxicology, Vol. 20, pp. 1677-1683.

Kaidery N. A. et al. (2013), Targeting Nrf2-mediated gene transcription by extremely potent synthetic triterpenoids attenuate dopaminergic neurotoxicity in the MPTP- mouse model of Parkinson's disease. Antioxid Redox Signal, Vol. 18, No. 2, pp. 139-57. 
Kann, O. (2016), The interneuron energy hypothesis: Implications for brain disease. Neurobiology of Diseases, Vol. 90, pp. 75-85.

Lansbury, P.T. and H.A Lashuel (2006), Review Article A century-old debate on protein aggregation and neurodegeneration enters the clinic. Nature, Vol. 443, pp. 774-779.

Lin, M.T. and M.F. Beal (2006), Review Article Mitochondrial dysfunction and oxidative stress in neurodegenerative diseases. Nature, Vol. 443, pp. 787-795.

Majd, S., J.H. Power and H.J. Grantham (2015), Neuronal response in Alzheimer's and Parkinson's disease: the effect of toxic proteins on intracellular pathways. BMC Neuroscience, Vol. 23, pp.16-69.

McFarland, N.R. and M.S. Okun (2013), Advancing research towards novel therapeutic approaches. Natture Reviews Neurology, Vol. 9, pp. 70-1.

Michalski, B. et al. (2015), Brain-derived neurotrophic factor and TrkB expression in the "oldest-old," the 90+ Study: correlation with cognitive status and levels of soluble amyloid-beta. Neurobiology of Aging, Vol. 36, No. 12, pp. 3130-9.

Mutter, J. et al. (2004), Alzheimer disease: mercury as pathogenetic factor and apolipoprotein E as a moderator. Neuro Endocrinology Letters, Vol. 25, pp. 331-339.

Nagahara, A.H. and M. H. Tuszynski (2011), Potential therapeutic uses of BDNF in neurological and psychiatric disorders. Nature Reviews Drug Discovery, Vol. 10, pp. 209-219.

Palop, J.J., J. Chin and L. Mucke (2006), Review Article A network dysfunction perspective on neurodegenerative diseases. Nature, Vol. 443, pp. 768-773.

Robertson, D. G. et al. (1987), Quantitative assessment of trimethyltin induced pathology of the hippocampus. Toxicologic Pathology, Vol. 15, pp. 7-17.

Sala-Llonch, R. et al. (2014), Changes in whole-brain functional networks and memory performance in aging. Neurobiology of Aging, Vol. 35, pp. 2193-202.

Schmued, L.C. et al. (2005), Fluoro-Jade C results in ultra high resolution and contrast labeling of degenerating neurons. Brain Research, Vol. 1035, No. 1, pp. 24-31.

Schneider, J.S. et al., (2012), Effects of developmental lead exposure on the hippocampal transcriptome: influences of sex, developmental period, and lead exposure level. Toxicological Sciences, Vol. 129, pp. 108-125

Schneider, J. S. et al. (2013), Influence of developmental lead exposure on expression of DNA methyltransferases and methyl cytosine-binding proteins in hippocampus. Toxicological Letters, Vol. 217, No. 1, pp. 75-81.

Wu, J. et al. (2008), Alzheimer's disease (AD)-like pathology in aged monkeys after infantile exposure to environmental metal lead $(\mathrm{Pb})$ : evidence for a developmental origin and environmental link for $\mathrm{AD}$. Journal of Neuroscience, Vol. 28, pp. 3-9.

Wu, B. et al. (2013), Central nervous system damage due to acute paraquat poisoning: an experimental study with rat model. Neurotoxicology, Vol. 35, pp. 62-70.

Zaltieri, M. et al. (2015), Mitochondrial Dysfunction and $\alpha$-Synuclein Synaptic Pathology in Parkinson's Disease: Who's on First? Parkinson's Disorders, Vol. 15, pp. 108- 129.

Zawia, N.H. and M.R. Basha (2005), Environmental risk factors and the developmental basis for Alzheimer's disease. Reviews in the Neurosciences, Vol. 16, pp. 325-337.

Zhu, J. and C. T. Chu (2010), Mitochondrial dysfunction in Parkinson's disease, Journal of Alzheimer's Disease, Vol. 20, No.2, pp. S325-S334.

Zuccato, C. and E. Cattaneo (2009), Brain-derived neurotrophic factor in neurodegenerative diseases. Nature Reviews Neurology, Volo. 5, pp. 311-322. 


\section{Neuroinflammation, N/A}

AOPs including this Key Event

\begin{tabular}{|c|c|c|}
\hline AOP Name & $\begin{array}{l}\text { Event } \\
\text { Type }\end{array}$ & Essentiality \\
\hline $\begin{array}{l}\text { Binding to } \mathrm{SH} / \text { selen-proteins } \text { can trigger neuroinflammation leading to } \\
\text { neurodegeneration }\end{array}$ & $\mathrm{KE}$ & Strong \\
\hline $\begin{array}{l}\text { Binding of antagonist to N-methyl-D-aspartate receptors (NMDARs) during brain } \\
\text { development can trigger neuroinflammation and lead to neurodegeneration }\end{array}$ & $\mathrm{KE}$ & Moderate \\
\hline $\begin{array}{l}\text { Binding of agonists to ionotropic glutamate receptors in adult brain causes } \\
\text { excitotoxicity that mediates neuronal cell death, contributing to learning and } \\
\text { memory impairment. }\end{array}$ & $\mathrm{KE}$ & Weak \\
\hline $\begin{array}{l}\text { Inhibition of Complex I of the mitochondrial respiration chain leading to } \\
\text { neurodegeneration. }\end{array}$ & KE & Mo \\
\hline
\end{tabular}

How this Key Event works

\section{Level of biological organisation}

Tissue

Neuroinflammation or brain inflammation differs from peripheral inflammation in that the vascular response and the role of peripheral bone marrow-derived cells are less conspicuous. The most-easily detectable feature of neuroinflammation is the activation of microglial cells and astrocytes. It is evidenced by changes in shape, increased expression of certain antigens, and accumulation and proliferation of these glial cells in affected regions (Aschner, 1998; Graeber and Streit, 1990; Monnet-Tschudi et al., 2007; Streit et al., 1999; Kraft and Harry, 2011; Claycomb et al., 2013). Upon stimulation by cytokines or inflammogens (e.g. from pathogens or from damaged neurons), both glial cell types activate inflammatory signalling pathways, which result in increased expression and/or release of inflammatory mediators such as cytokines, eicosanoids, and metalloproteinases (Dong and Benveniste, 2001), as well as in the production of reactive oxygen (ROS) and nitrogen species (RNS) (Brown and Bal-Price, 2003). Different types of activation states are possible for microglia and astrocytes, resulting in different responses concerning pro-inflammatory/anti-inflammatory signalling and other cellular functions (such as phagocytosis) (Streit et al., 1999; Nakajima and Kohsaka, 2004). Therefore, neuroinflammation can have both neuroprotective/neuroreparative and neurodegenerative consequences (Carson et al., 2006 ; Monnet-Tschudi et al., 2007; Aguzzi et al., 2013 ; Glass et al., 2010). Under normal physiological conditions, microglial cells scan the nervous system for neural integrity (Nimmerjahn et al., 2005) and for invading pathogens (Aloisi, 2001; Kreutzberg, 1995; Kreutzberg, 1996; Rivest, 2009). They are the first type of cell activated (first line of defence), and can subsequently lead to astrocyte activation (Falsig, 2008). Two distinct states of microglial activation have been described (Gordon, 2003; Kigerl et al., 2009; Maresz et al., 2008; Mosser and Edwards, 2008; Perego et al; Ponomarev et al., 2005): The M1 state is classically triggered by interferon-gamma and/or other pro-inflammatory cytokines, and this state is characterised by increased expression of integrin alpha $\mathrm{M}$ (Itgam) and CD86, as well as the release of pro- 
inflammatory cytokines (TNF-alpha, IL-1beta, IL-6), and it is mostly associated with neurodegeneration. The M2 state is triggered by IL-4 and IL-13 (Maresz et al., 2008; Perego et al., 2011; Ponomarev et al., 2007) and induces the expression of mannose receptor 1 (MRC1), arginase1 (Arg 1) and Ym1/2; it is involved in repair processes. The activation of astrocytes by microglia-derived cytokines or TLR agonists resembles the microglial M1 state (Falsig, 2006).

\section{How it is Measured or Detected}

Neuroinflammation, i.e. the activation of glial cells can be measured by quantification of cellular markers (most commonly), or of released mediators (less common). As multiple activation states exist for the two main cell types involved, it is necessary to measure several markers of neuroinflammation:

1. Microglial activation can be detected based on the increased numbers of labeled microglia per volume element of brain tissue (due to increase of binding sites, proliferation, and immigration of cells). A specific microglial marker, used across different species, is CD11b. Alternatively, various specific carbohydrate structures can be stained by lectins (e.g. IB4). Beyond that, various well-established antibodies are available to detect microglia in mouse tissue (F4/80), phagocytic microglia in rat tissue (ED1) or more generally microglia across species (Iba1). Transgenic mice are available with fluorescent proteins under the control of the CD11b promoter to easily quantify microglia without need for specific stains. 1 . The most frequently used astrocyte marker is GFAP (99\% of all studies) (Eng et al., 2000). This protein is highly specific for astrocytes in the brain, and good clinically-validated antibodies are available for immunocytochemical detection. In neuroinflamatory brain regions, the stain becomes more prominent, due to an upregulation of the protein, a shape change/proliferation of the cells, or better accessibility of the antibody. Various histological quantification approaches can be used. Occasionally, alternative astrocytic markers, such as vimentin of the S100beta protein have been used for staining of astrocytes (Struzynska et al., 2007). 2. All immunocytochemical methods can also be applied to cell culture models. 3. In patients, microglial accumulation can be monitored by PET imaging, using [11C]-PK 11195 as microglial marker (Banati et al., 2002). 4. Activation of glial cells can be assessed in tissue or cell culture models also by quantification of sets of activation markers. This can for instance be done by PCR quantification of inflammatory factors, of by measurement of the respective mediators, e.g. by ELISA-related immuno-quantification. Such markers include: - Pro- and antiinflammatory cytokine expression (IL-1 $\beta$; TNF- $\alpha$, Il-6, IL-4); or expression of immunostimmulatory proteins (e.g. MHC-II) - Itgam, CD86 expression as markers of M1 microglial phenotype - Arg1, MRC1, as markers of M2 microglial phenotype (for description of techniques, see Falsig, 2004; Lund, 2006 ; Kuegler, 2010; Monnet-Tschudi et al., 2011; Sandström et al., 2014; von Tobel et al., 2014)

Regulatory examples using the KE:

Measurement of glial fibrillary acidic protein (GFAP), whose increase is a marker of astrocyte reactivity, is required by the US EPA for fuel additives (40 CFR 79.67), but is optional for other toxicant evaluation. 
Evidence Supporting Taxonomic Applicability

\begin{tabular}{l|l|l|l|}
\hline \multicolumn{1}{l|}{ Name } & Scientific Name & Evidence & Links \\
\hline rat & Rattus sp. & Strong & NCBI \\
\hline mouse & Mus musculus & Strong & NCBI \\
\hline human & Homo sapiens & Moderate & NCBI \\
\hline
\end{tabular}

Neuroinflammation is observed in humans, monkey, rat, mouse and zebrafish associated to neurodegeneration or following toxicant exposure. Some references (not exhaustive list) are given below for illustration: in humans: Vennetti et al., 2006 in monkey (Macaca fascicularis): Charleston et al., 1994, 1996 in rat: Little et al., 2012; Eskes et al., 2002 in mouse: Liu et al., 2012 in zebrafish: Xu et al., 2014

\section{References}

Aschner, M. (1998), Immune and inflammatory responses in the CNS: modulation by astrocytes. Toxicogical Letters, 103: 283-287.

Banati, R. B. (2002), Visualising microglial activation in vivo. Glia , Vol. 40, pp. 206-217.

Brown, G.C. and A. Bal-Price (2003), Inflammatory neurodegeneration mediated by nitric oxide, glutamate, and mitochondria. Molecular Neurobiology, Vol. 27, pp. 325-355.

Charleston, J.S. et al. (1996), Changes in the number of astrocytes and microglia in the thalamus of the monkey Macaca fascicularis following long-term subclinical methylmercury exposure. NeuroToxicology, Vol. 17, pp. 127-138.

Charleston, J.S. et al. (1994), Increases in the number of reactive glia in the visual cortex of Macaca fascicularis following subclinical long-term methyl mercury exposure. Toxicology and Applied Pharmacology, Vol. 129, pp. 196-206.

Dong, Y. and E.N. Benveniste (2001), Immune Function of Astrocytes. Glia , Vol. 36, pp.180-190

Eng, L.F. and R.S. Ghirnikar and Y.L. Lee (2000), Glial Fibrillary Acidic Protein: GFAP-Thirty-One Years (1969-2000). Neurochem Research, Vol. 25, pp. 1439-1451.

Eskes, C. et al. (2002), Microglial reaction induced by noncytotoxic methylmercury treatment leads to neuroprotection via interactions with astrocytes and IL-6 release. Glia, Vol. 37, No. 1, pp. 43-52.

Falsig, J., M. Latta and M. Leist (2004), Defined inflammatory states in astrocyte cultures correlation with susceptibility towards CD95-driven apoptosis. Journal of Neurochemistry, Vol. 88, No. 1, pp. 18193.

Falsig, J. et al. (2006), The inflammatory transcriptome of reactive murine astrocytes and implications for their innate immune function. Journal of Neurochemistry, Vol. 96, No. 23, pp. 893-907.

Falsig, J. et al. (2008), Molecular basis for detection of invading pathogens in the brain. $J$ Neuroscience Reserch, Vol. 86, No. 7, pp. 1434-47.

Glass, C.K. et al. (2010), Mechanisms underlying inflammation in neurodegeneration. Cell, Vol. 140, No. 6, pp. 918-934.

Gordon, S. (2003), Alternative activation of macrophages. Nature Reviews Immunology, Vol. 3, pp. 23-35.

Graeber, M.B. and W.J. Streit (1990), Microglia: immune network in the CNS. Brain Patholology, Vol. 1, pp. 2-5. 
Kigerl, K.A. et al. (2009), Identification of two distinct macrophage subsets with divergent effects causing either neurotoxicity or regeneration in the injured mouse spinal cord. Journal of Neuroscience, Vol. 29, pp. 13435-13444.

Kreutzberg, G.W. (1995), Microglia, the first line of defence in brain pathologies. Arzneimttelforsch, Vol. 45, pp. 357-360.

Kreutzberg, G.W. (1996), Microglia: a sensor for pathological events in the CNS. Trends in Neuroscience, Vol. 19, pp. 312-318.

Kuegler, P.B. et al. (2010), Markers of murine embryonic and neural stem cells, neurons and astrocytes: reference points for developmental neurotoxicity testing. ALTEX, Vol. 27, No. 1, pp. 17-42.

Little, A.R. et al. (2012), Trimethyltin-induced neurotoxicity: gene expression pathway analysis, q-RTPCR and immunoblotting reveal early effects associated with hippocampal damage and gliosis. Neurotoxicology and Teratology, Vol, 34, No. 1, pp. 72-82.

Liu, Y. et al. (2012), alpha7 nicotinic acetylcholine receptor-mediated neuroprotection against dopaminergic neuron loss in an MPTP mouse model via inhibition of astrocyte activation. $J$ Neuroinflammation, Vol. 9, pp. 98-114.

Lund, S. et al. (2006), The dynamics of the LPS triggered inflammatory response of murine microglia under different culture and in vivo conditions. Journal of Neuroimmunology, Vol. 180, No. 1-2, pp. 71-87.

Maresz, K. et al. (2008), IL-13 induces the expression of the alternative activation marker Ym1 in a subset of testicular macrophages. Journal of Reproductive Immunology, Vol. 78, pp. 140-148.

Monnet-Tschudi, F., M.G. Zurich, P. Honegger (2007), Neurotoxicant-induced inflammatory response in three-dimensional brain cell cultures. Human and Experimental Toxicology, Vol. 26, pp. 339-346.

Monnet-Tschudi, F. et al. (2011), Methods to assess neuroinflammation. Current Protocols in Toxicology, Chapter 12: Unit12 19.

Mosser, D.M. and J.P. Edwards (2008), Exploring the full spectrum of macrophage activation. Nature Reviews Immunology, Vol. 8, pp. 958-969.

Nakajima, K. and S. Kohsaka (2004), Microglia: Neuroprotective and neurotrophic cells in the central nervous system. Current Drug Targets-Cardiovasc and Haematol Disorders, Vol. 4, pp. 65-84.

Perego, C., S. Fumagalli, M.G. De Simoni (2011), Temporal pattern of expression and colocalization of microglia/macrophage phenotype markers following brain ischemic injury in mice. Journal of Neuroinflammation, Vol. 8, pp. 174-188.

Ponomarev, E.D. et al. (2007), CNS-derived interleukin-4 is essential for the regulation of autoimmune inflammation and induces a state of alternative activation in microglial cells. Journal of Neuroscience, Vol. 27, pp. 10714-10721.

Ponomarev, E.D. et al. (2005), Microglial cell activation and proliferation precedes the onset of CNS autoimmunity. Journal of Neuroscience Research, Vol. 81, pp. 374-389.

Sandstrom von Tobel, J. et al. (2014), Immediate and delayed effects of subchronic Paraquat exposure during an early differentiation stage in 3D-rat brain cell cultures. Toxicological Letters, Vol. 230, No. 2, pp. 188-97.

Struzynska, L. et al. (2007), Inflammation-Like Glial Response in Lead-Exposed Immature Rat Brain. Toxicological Sciences, Vol. 95, pp. 156-162.

von Tobel, J. S. et al. (2014), Repeated exposure to Ochratoxin A generates a neuroinflammatory response, characterized by neurodegenerative M1 microglial phenotype. Neurotoxicology, Vol. 44C, pp. 6170.

Venneti, S., B.J. Lopresti and C.A. Wiley (2006), The peripheral benzodiazepine receptor (Translocator protein 18kDa) in microglia: from pathology to imaging. Progress in Neurobiology, Vol. 80, No. 6, pp. 308-322. 
$\mathrm{Xu}$, D.P. et al. (2014), A novel tetramethylpyrazine bis-nitrone (TN-2) protects against 6hydroxyldopamine-induced neurotoxicity via modulation of the NF-kappaB and the PKCalpha/PI3K/Akt pathways. Neurochemistry International, Vol. 78, pp. 76-85.

Zurich, M.G. et al. (2002), Maturation-dependent neurotoxicity of lead acetate in vitro: Implication of glial reactions. Journal of Neuroscience Research, Vol. 70, pp. 108-116.

\title{
7. Neuronal network function in adult brain, Decreased
}

\author{
Key Event Overview
}

AOPs including this Key Event

\begin{tabular}{|l|l|l|}
\hline AOP Name & $\begin{array}{l}\text { Event } \\
\text { Type }\end{array}$ & Essentiality \\
\hline $\begin{array}{l}\text { Binding of agonists to ionotropic glutamate receptors in adult brain causes } \\
\text { excitotoxicity that mediates neuronal cell death, contributing to learning and } \\
\text { memory impairment. }\end{array}$ & KE & Moderate \\
\hline
\end{tabular}

\section{How this Key Event works}

\section{Biological state:}

In the brain, neurons never work alone. They create a network where the activity of one cell directly influences many others. Each neuron is a specialised cell and when activated, it fires an electrochemical signal along the axon. A neuron fires only if the total signal received at the cell body from the dendrites exceeds a certain level (the firing threshold). The strength of the signal received by a neuron (and therefore its chances of firing) critically depends on the efficacy of the synapses. Each synapse actually contains a synaptic cleft with neurotransmitter that transmits a signal across the gap. During synaptic transmission neurotransmitters are released by a presynaptic neuron and bind to and activate the receptors of the postsynaptic neuron in response to a threshold of action potential. Synaptic transmission relies on: the availability of the neurotransmitter; the release of the neurotransmitter by exocytosis; the binding of the postsynaptic receptor by the neurotransmitter; the functional response of the postsynaptic cell; and the subsequent removal or deactivation of the neurotransmitter. Neurons form complex networks of synapses through which action potentials travel. When the nerve impulse arrives at the synapse, it may cause the release of neurotransmitters, which influence another (postsynaptic) neuron. The postsynaptic neurons receive inputs from many additional neurons, both excitatory and inhibitory. The excitatory and inhibitory influences are summed (neural summation) resulting in inhibition or "firing" (i.e., generate an action potential) if the threshold potential has been reached. The voltage at which an action potential is triggered happens if enough voltage-dependent sodium channels are activated and the net inward sodium current exceeds all outward currents (Kolb and Whishaw, 2003). Therefore, at the beginning of the action potential, the $\mathrm{Na}^{+}$channels open and $\mathrm{Na}^{+}$moves into the axon, causing depolarisation. Re-polarisation occurs when the $\mathrm{K}^{+}$channels open and $\mathrm{K}^{+}$ moves out of the axon. This creates a change in polarity between the outside of the cell and the inside. The impulse travels down from the axon hillock in one direction only, to the axon terminal. Here, the neurotransmitter is released releasing neurotransmitter at the synaptic cleft to pass along information to another adjacent neuron. Excitatory inputs bring a neuron closer to a firing threshold, while inhibitory inputs bring the neuron farther from threshold. An action 
potential is an "all-or-none" event; neurons whose membranes have not reached threshold will not fire, while those that do, will fire. One of the most influential researchers into neurological systems (Donald Hebb) postulated that learning consisted principally in altering the "strength" of synaptic networking. Recent research in cognitive science, in particular in the area of nonconscious information processing, have further demonstrated the enormous capacity of the human mind to learn simple input-output co-variations from extremely complex stimuli. Consequently, the neurodegeneration and cell death disrupt the natural rhythms of brain network communication. Cognitive disorders are primarily associated with dysfunction of the neurons of the prefrontal cortex, hippocampus and with changes mainly in NMDARs function (Wang and Arnsten, 2015).

\section{Biological compartments:}

The interface through which neurons interact with their neighbours usually consists of several axon terminals connected via synapses to dendrites on other neurons. If the hippocampal or cortical neurons are damaged or killed by the over-activation of receptors for the excitatory neurotransmitter glutamate, such as the NMDA, kainate and AMPA receptors, the neuronal networking and number of synapses are decreased. Indeed, it has been proved that lesions of the hippocampus in humans prevent the acquisition of new episodic memories suggesting that hippocampus-dependent memory is mediated, at least in part, by hippocampal synaptic plasticity that is a prominent feature of hippocampal synapses of the neuronal network (Neves et al., 2008). Since the finding that the hippocampus plays a pivotal role in long-term memory consolidation (dogma, well established fact in the literature, described in the text books; e.g. Andersen et al., 2007; Byrne, 2008; Eichenbaum, 2002), many proposals have been made regarding its specific role. A prominent view of the mechanisms underlying consolidation of episodic memories involves fast formation (e.g., via Hebbian mechanisms) of strong associations between hippocampal sparse patterns of activity and distributed neocortical representations. Recent research on the primate prefrontal cortex discovered that the pyramidal cell circuits that generate the persistent firing underlying spatial working memory communicate through synapses on spines containing NMDARs with NR2B subunits (GluN2B) in the post-synaptic density. This contrasts with synapses in the hippocampus and primary visual cortex, where GluN2B receptors are both synaptic and extrasynaptic. Cholinergic stimulation of nicotinic $\alpha 7$ receptors within the glutamate synapse is necessary for NMDAR actions (Wang and Arnsten, 2015).

\section{General role in biology: \\ Glutamatergic neurotransmission (NMDA, AMPA and KA receptors)}

The network of glutamatergic neurons is heavily involved in long-term synaptic plasticity, the main process linked to learning and memory. At the same time over-activation of these neurons (excitotoxicity) leads to neuronal cell death that can be mediated by increased levels of extracellular glutamate or a molecule that behaves as its analogue. Glutamate acts at a variety of ionotropic receptors, including AMPARs, kainate receptors, and NMDARs. The NMDARs have been of particular interest due to their unique properties. They require neuronal depolarisation to relieve their $\mathrm{Mg}^{++}$block, and are permeable to $\mathrm{Ca}^{++}$that can initiate second-messenger signalling events, such as mediating neuroplasticity or negative feedback through $\mathrm{Ca}^{++}$-sensitive $\mathrm{K}^{+}$ channels. There have been extensive studies on the glutamate NMDAR and AMPAR mechanisms underlying long-term synaptic plasticity in the primary visual cortex and in CA1 neurons of the hippocampus (Liu et al., 2004; Cho et al., 2009; Lüscher and Malenka, 2012). Neuronal network function and long-term plasticity is also regulated by the levels of AMPAR expression as the number of AMPARs inserted into the post-synaptic density can mediate the degree of spine 
depolarisation and thus the NMDAR opening. Synaptic plasticity in the mature visual cortex appears to be governed by GluN2A subunits, which have faster kinetics than GluN2B. GluN2B receptors are expressed in synapses early in development, but many move to extra-synaptic locations in the mature visual cortex and hippocampus (Goebel-Goody et al., 2009). The actions of NMDARs on the dorsolateral prefrontal cortex neuronal circuitry network underlying spatial working memory in primates and it mechanism is described in detail by Wang and Arnsten (2015). In the hippocampus, there is some evidence that long-term potentiation (LTP) is mediated by synaptic GluN2A, while long-term depression is mediated by extrasynaptic GluN2B receptors (Liu et al., 2004). Kainate receptors (KARs) also play an important role in neuronal network function. They play a major function in the pre-synaptic terminal, in particular in the hippocampus. Activation of kainate receptors in have been shown to regulate glutamate release (Jane et al., 2009) and to both depress and factilitate transmission in different synapses. Presynaptic kainate receptors in the hippocampus facilitate AMPA and NMDA receptor-mediated transmission at mossy fibre-CA3 synapses (Lauri et al., 2005). Activation of post-synaptic KARs facilitates activation of NMDARs as it has been described in the context of DomA exposure.

\section{Role of other neurotransmitters}

It is important to stress that other classical neurotransmitter systems also play an important role in learning and memory processes (Blokland, 1996). The role of the most critical neurotransmitters has been evaluated in a meta-analysis based on studies of four behavioral tasks relevant for evaluation of rat cognitive functions such as Morris water maze, radial maze, passive avoidance, and spontaneous alternation (Myhrer, 2003). Calculation of impact factors (percentage of significant effects of chemical agents like agonists, antagonists, neurotoxins) showed that glutamate was ranking highest (93), followed by GABA (81), dopamine (81), acetylcholine (81), serotonin (55), and norepinephrine (48).

GABA-ergic receptors: indeed, presynaptic GABA B receptors mediate GABA-dependent inhibition of glutamate release, impacting plasticity of hippocampal synapses and hippocampusdependent memory function (Vigot et al., 2006). A critical link between GABABR heterodimer conformational dynamics and local regulation of release probability at hippocampal synapses has been recently proved (Laviv et al., 2010).

5-Hydroxytrytamine (serotonin) type $3 \mathrm{~A}$ receptors (5-HT3ARs), as the only ligand-gated ion channels in the serotonin receptor family, are known to regulate neuronal excitation and release of GABA in hippocampal interneurons, playing also an important role in glutamatergic synaptic plasticity. Deletion of the 5-HT3AR gene in transgenic mice abolished NMDAR-dependent longterm depression (LTD) induced by low-frequency stimulation (LFS) in hippocampal CA1 synapses in slices. In addition, 5-HT3ARs disruption inhibited AMPARs internalization, without altering basal surface levels of AMPARs. These observations revealed an important role of 5HT3ARs in NMDAR-dependent long-term depression, which is critical for learning behaviours (Yu et al., 2014).

The cholinergic hypothesis claims that the decline in cognitive functions in dementia is predominantly related to a decrease in cholinergic neurotransmission. This hypothesis has led to great interest in the putative involvement of the cholinergic neurotransmission in learning and memory processes (Blokland, 1996; Bracco et al., 2014). 
Dopamine plays diverse roles in human behaviour and cognition but it is mainly involved in motivation, decision-making, reward processing, attention, working memory and learning (Steinberg and Janak, 2012; Labudda et al., 2010).

Noradrenaline is associated with memory processing as it induces lasting changes in the brain that could sustain memories over time (Gazarini et al., 2013). As confirmed later on its neurotransmission indeed strengthens memory-related synaptic plasticity such as long-term potentiation, allowing memories to be formed and maintained in a more intense and enduring manner, a notion particularly valid for those with emotional content (Joëls et al., 2011). Like other types of memory, an emotional memory has to be consolidated to allow its later retrieval. Accumulating evidence has indicated that noradrenaline acts during these gradual stages to finetune the strength and/or persistence of a memory (Guzmán-Ramos, 2012; Gazarini et al., 2013).

\section{How it is Measured or Detected}

Neuronal network activity is fundamental to brain function and now can be measured using in vitro and in vivo techniques such as:

1. Two-photon imaging of cell populations in vivo that are labelled with fluorescent calcium indicators. Two-photon imaging relies on fluorescence excitation and, in general, necessitates staining of cells with fluorescent dyes. Various staining methods have been developed for in vivo calcium measurements. Single cells can be filled with membrane-impermeable calcium indicators via intracellular recording electrodes or by single-cell electroporation. The basic aspects of in vivo calcium imaging and recent developments that allow evaluation of the neural circuits activity are described by Göbel et al., (2007a). With new imaging technology, scientists are now better able to visualize neural circuits connecting brain regions in humans. Advances in genetic engineering, microscopy, and computing are enabling scientists to begin to map the connections between individual nerve cells.

2. Optical detection of neuronal spikes both in vivo and in vitro. Assuming action potential (AP) as the only trigger of calcium influx, spike patterns are directly reflected in the trains of calcium transients. Each fluorescence trace is the convolution of the spike train with the single AP-evoked calcium transient plus added noise. The temporal resolution will be limited by the acquisition rate of the network scanning approach. In addition, the signal-to-noise ratio of fluorescence signals will be a decisive factor for the accuracy of the reconstruction.

3. Microelectrode array (MEA) recordings in primary cultures. Glutamate analogues effects on neuronal network activity can be assessed (Lantz et al., 2014) and neuronal spontaneous activity evaluation is already used for screening purposes (Valdivia et al., 2014).

4. To understand the function of a neural circuit, it is important to discriminate its sub-network components. This is possible through counterstaining of specific neuronal and glial cell types, especially in bulk loaded tissue where markers need not be calcium sensitive. In addition, transgenic mice with fluorescent protein expression in specific neuronal subsets, allow separation of functional signals into different neuronal subtypes (Göbel et al., 2007b). 
5. Combined positron emission tomography (PET) and magnetic resonance imaging (MRI) is a new tool to study functional processes in the brain, including the response to a stimulus simultaneously using PET. Functional MRI (fMRI), is used to assesses at the same time fast vascular and oxygenation changes during activation. These results demonstrate the feasibility of combined PET-MRI for the simultaneous study of the brain at activation and rest, revealing comprehensive and complementary information to further decode brain function and brain networks (Wehrl et al., 2013).

6. Seed-based correlative analysis of [18F]fluorodeoxyglucose (FDG)-PET (FDG-PET) differences in images (resting state minus activation) is suitable to identify cerebral networks in rats. Using awake and freely moving animals enables functional network analysis of complex behavioral paradigms (Rohleder et al., 2015).

Although most experiments at present are carried out in anesthetized animals, several approaches for imaging in awake behaving animals have been devised that ultimately aim at directly correlating neuronal network dynamics with behaviour (Dombeck et al., 2007, Arenkiel et al., 2007). Finally, through expression of light-activated channel proteins, it might become possible in the future to not only read-out but also control neuronal networks in vivo (Garaschuk et al., 2006)since with the development of X-ray, CT, and MRI, deep neural networks involved in learning and memory processes can be studied in vivo (Cheng et al., 2014).

7. NMDAR overactivation-induced LTD that decrease number of spine density can be measured in vitro using GFP technology and by cofilin-F-actin quantification (Calabrese et al., 2014).

Current behavioural tests used for evaluating neural network function:

1. The Morris water maze: this test is developed to measure spatial orientation in rats. The rat has to swim around the pool to search for a platform onto which he can escape from the water. In one condition, the platform is visible, rising $1 \mathrm{~cm}$ above the water surface. In a Second condition the rat has to learn to find the hidden platform provided it remains in the fixed position relative to distal room cues.

2. Radial maze: In the T-maze version of working memory, the animal has to remember only a single item for each trial. In the radial arm version of the working memory procedure rats have to learn multiple items.

3. Passive avoidance: fear-motivated avoidance tests are usually based on electric current as source of punishment.

4. Spontaneous alternation: spontaneous alternation is spatial alternation and represents a tendency to avoid stimulus re-exposure during exploratory behaviour. T-maze (simple or multiple), Y-maze, and radial maze are used to quantify an innate, unlearned response in rats.

These four behavioural tests are described in detail in the review by Myhrer (Myhrer et al., 2003).

\section{Evidence Supporting Taxonomic Applicability}

The ability to process complex spatiotemporal information through neuronal networking is a fundamental process underlying the behaviour of all higher organisms. The most studied are the neuronal networks of rodents (e.g. Reig et al., 2015) and primates (e.g. Wang and Arnsten, 2015) and extremely large amount of the published data exist to support this topic. Invertebrates hold neural circuitries in various degrees of complexity and there are studies describing how neurons are organized into functional networks to generate behaviour (Wong and Wong, 2004; Marder, 1994). 


\section{References}

Andersen, P., R.Morris, D. Amaral, T. Bliss and J. O'Keefe, eds., The Hippocampus, Book: Oxford University Press. ISBN, 2007, 978-0-19-510027-3.

Arenkiel, B.R. et al. (2007), In vivo light-induced activation of neural circuitry in transgenic mice expressing channelrhodopsin-2. Neuron, Vol. 54, p. 205-218.

Blokland, A. (1996), Acetylcholine: a neurotransmitter for learning and memory? Brain Research Reviews, Vol. 21, pp. 285-300.

Bracco, L. et al. (2014), Do cholinesterase inhibitors act primarily on attention deficit? A naturalistic study in Alzheimer's disease patients. Journal of Alzheimer's Disorders. Vol. 40, No. 3, pp. 737-42.

Byrne, J. H, ed. (2008), Book: Learning and Memory: A comprehensive reference. Elsevier., ISBN 978-012-370509-9.

Calabrese, B., J.M. Saffin and S.H. Halpain (2014), Activity-Dependent Dendritic Spine Shrinkage and Growth Involve Downregulation of Cofilin via Distinct Mechanisms, PLos One, DOI: 10.1371/journal.pone.0094787

Cheng, D.A., Z. Haixian, S. Yongsheng (2014), Brain CT Image Classification with Deep Neural Networks, Chapter from Proceedings of the 18th Asia Pacific Symposium on Intelligent and Evolutionary Systems, 2014, Volume 1 of the series Proceedings in Adaptation, Learning and Optimization. Pp. 653-662.

Cho, K.K. et al. (2009), The ratio of NR2A/B NMDA receptor subunits determines the qualities of ocular dominance plasticity in visual cortex. Proceedings of the National Academy of Sciences of the USA, Vol. 106, pp. 5377-5382.

Dombeck, D.A. et al. (2007), Imaging large scale neural activity with cellular resolution in awake mobile mice. Neuron, Vol. 56, pp. 43-57.

Eichenbaum H. (2002), The Cognitive Neuroscience of Memory. Oxford University Press US. 2002, ISBN 978-0-19-514175-7.

Garaschuk, O. et al., (2006), Optical monitoring of brain function in vivo: from neurons to networks. Pflügers Archiv, Vol. 453, pp. 385-396.

Gazarini, L. et al. (2013), Enhanced noradrenergic activity potentiates fear memory consolidation and reconsolidation by differentially recruiting $\alpha 1$ - and $\beta$-adrenergic receptors. Current Issue Learning Memory, Vol. 20, pp. 210-219.

Göbel, W. and F. Helmchen (2007a), In Vivo Calcium Imaging of Neural Network Function, Physiology, Vol. 22, pp. 358-365.

Göbel, W. and F. Helmchen (2007b) New Angles on Neuronal Dendrites In Vivo, Journal of Neurophysiology, Vol. 98, pp. 3770-3779.

Goebel-Goody, S.M. et al. (2009), Phospho-regulation of synaptic and extrasynaptic N-methyl-d-aspartate receptors in adult hippocampal slices. Neuroscience, Vol. 158, pp. 1446-1459.

Guzmán-Ramos, K. (2012), Post-acquisition release of glutamate and norepinephrine in the amygdala is involved in taste-aversion memory consolidation. Learn Mem., Vol. 19, pp. 231-238.

Jane, D.E., D. Lodge, and G.L. Collingridge (2009), Kainate receptors: pharmacology, function and therapeutic potential. Neuropharmacology, Vol. 56. No.1, pp. 90-113.

Joëls, M., G. Fernandez and B. Roozendaal (2011), Stress and emotional memory: A matter of timing. Trends in Cognitive Sciences, Vol. 15, pp. 280-288.

Kolb, B. and I. Q Whishaw (2003), Fundamentals of Human Neuropsychology (5th ed.). Worth. pp. 102104. ISBN 978-0-7167-5300-1. 
Labudda, K. et al., (2010), Decision making under risk condition in patients with Parkinson's disease: A behavioural and fMRI study. Behavioral Neurology, Vol. 23, No. 3, pp. 131-143.

Lantz, S.R. et al. (2014), Glufosinate binds N-methyl-D-aspartate receptors and increases neuronal network activity in vitro, Neurotoxicology, Vol. 45, pp. 38-47.

Lauri, S.E. et al. (2005), Endogenous Activation of Kainate Receptors Regulates Glutamate Release and Network Activity in developing Hippocampus. The Journal of Neuroscience, Vol. 25, No. 18, pp. 4473-4484.

Laviv, T. et al., (2010), Basal GABA Regulates GABABR Conformation and Release Probability at Single Hippocampal Synapses. Neuron, Vol. 67, pp. 253-267.

Liu, L. et al. (2004), Role of NMDA receptor subtypes in governing the direction of hippocampal synaptic plasticity. Science, Vol. 304, pp. 1021-1024.

Lüscher, C. and R.C. Malenka (2012), NMDA receptor-dependent longterm potentiation and long-term depression (LTP/LTD). Book, Cold Spring Harb Perspect Biol 2012, 4: pii: a005710.

Marder, E. (1994), Invertebrate neurobiology. Polymorphic neural networks. Current Biology, Vol. 4, pp. $752-4$.

Myhrer, T. (2003), Neurotransmitter systems involved in learning and memory in the rat: a meta-analysis based on studies of four behavioral tasks. Brain Research Reviews, Vol. 41, No. 2-3, pp. 268-87.

Neves, G. et al. (2008), Synaptic plasticity, memory and the hippocampus: a neural network approach to causality. Nature Reviews Neuroscience, Vol. 9, pp. 65-75.

Reig, R. et al. (2015), Gain modulation of synaptic inputs by network state in auditory cortex in vivo. Journal of Neuroscience, Vol. 35, No. 6, pp. 2689-702.

Rohleder, C.F. et al. (2015), Characterization of functional neural networks using [18F]fluorodeoxyglucose (FDG)-PET in awake rats. Journal of Nuclear Medicine, Vol. 56, No. 3, pp. 1542-1563.

Steinberg, E.E. and P.H. Janak 82012), Establishing causality for dopamine in neural function and behavior with optogenetics. Brain Research, Vol. 9, pp. 52-63.

Valdivia, P. et al. (2014), Multi-well microelectrode array recordings detect neuroactivity of ToxCast compounds, NeuroToxicology, Vol. 44, pp. 204-217.

Vigot, R. et al., (2006), Differential compartmentalization and distinct functions of GABAB receptor variants. Neuron, Vol. 50, pp. 589-601.

Wang, M., and A. F. T.Arnsten (2015), Contribution of NMDA receptors to dorsolateral prefrontal cortical networks in primates, Neuroscience Bulletin, Vol. 31, No. 2, pp. 191-197.

Wehrl, H.F. et al. (2013), Simultaneous PET-MRI reveals brain function in activated and resting state on metabolic, hemodynamic and multiple temporal scales. Nature Medicine, Vol. 19, pp. 1184-1189.

Wong, Y.H. and J.T.Y. Wong (2004), Invertebrate Neural Networks, Neuro-Signals, Vol. 13, pp. 1-2.

$\mathrm{Yu}$, Y. et al. (2014), 5-HT3A receptors are required in long-term depression and AMPA receptor internalization. Neuroscience, Vol. 278, pp. 105-12. 


\section{Adverse Outcome}

\begin{tabular}{c|c|}
\hline \multicolumn{1}{c}{ Adverse Outcome } \\
\hline Learning and memory, Impairment \\
\hline
\end{tabular}

\section{Learning and memory, Impairment}

AOPs including this Key Event

\begin{tabular}{l|l|l|l|}
\hline \multicolumn{1}{|c|}{ AOP Name } & Event \\
\hline $\begin{array}{l}\text { Chronic binding of antagonist to N-methyl-D-aspartate receptors (NMDARs) } \\
\text { during brain development induces impairment of learning and memory abilities }\end{array}$ & AO \\
\hline $\begin{array}{l}\text { Binding of agonists to ionotropic glutamate receptors in adult brain causes } \\
\text { excitotoxicity that mediates neuronal cell death, contributing to learning and } \\
\text { memory impairment. }\end{array}$ & AO \\
\hline $\begin{array}{l}\text { Inhibition of Na+/I- symporter (NIS) decreases TH synthesis leading to learning } \\
\text { and memory deficits in children }\end{array}$ & AO \\
\hline $\begin{array}{l}\text { Nicotinic acetylcholine receptor activation contributes to abnormal foraging and } \\
\text { leads to colony loss/failure }\end{array}$ & KE \\
\hline $\begin{array}{l}\text { Nicotinic acetylcholine receptor activation contributes to abnormal roll change } \\
\text { within the worker bee caste leading to colony loss/failure }\end{array}$ & KE \\
\hline $\begin{array}{l}\text { Nicotinic acetylcholine receptor activation contributes to abnormal foraging and } \\
\text { leads to colony loss/failure }\end{array}$ & KE \\
\hline $\begin{array}{l}\text { Nicotinic acetylcholine receptor activation contributes to abnormal foraging and } \\
\text { leads to colony loss/failure }\end{array}$ & KE \\
\hline $\begin{array}{l}\text { Nicotinic acetylcholine receptor activation contributes to abnormal foraging and } \\
\text { leads to colony loss/failure }\end{array}$ & KE \\
\hline $\begin{array}{l}\text { Nicotinic acetylcholine receptor activation contributes to abnormal roll change } \\
\text { within the worker bee caste leading to colony loss/failure }\end{array}$
\end{tabular}

How this Key Event works

\section{Level of biological organisation}

Individual

Learning can be defined as the process by which new information is acquired to establish knowledge by systematic study or by trial and error (Ono, 2009). Two types of learning are considered in neurobehavioral studies: a) associative learning and b) non-associative learning.

Associative learning is learning by making associations between different events. In associative learning, a subject learns the relationship among two different stimuli or between the stimulus and the subject's behaviour. Classical conditioning, operant conditioning and category learning are 
some examples of associative learning. On the other hand, non-associative learning can be defined as an alteration in the behavioural response that occurs over time in response to a single type of stimulus. Habituation and sensitization are some examples of non-associative learning. Another important type of learning is emotional learning and the simplest form of emotional regulation is extinction (Quirk and Mueller, 2008). During extinction, conditioned response to a stimulus decreases when the reinforcer is omitted and fear conditioning experiments help to elucidate the underlined mechanism.

The memory to be formed requires acquisition, retention and retrieval of information in the brain, which is characterised by the non-conscious recall of information (Ono, 2009; Gilbert et al., 2012). Memory is considered very important as it allows the subjects to access the past, to form experience and consequently to acquire skills for surviving purposes. There are three main categories of memory, including sensory memory, short-term or working memory (up to a few hours) and long-term memory (up to several days or even much longer). At the cellular level the storage of long-term memory is associated with increased gene expression and protein synthesis as well as formation of novel synaptic connections (Lynch, 2004).

Learning-related processes require neural networks to detect correlations between events in the environment and store these as changes in synaptic strength (Abbott and Nelson, 2000). Longterm potentiation (LTP) and long-term depression (LTD) are two fundamental processes involved in cognitive functions (Abbott and Nelson, 2000; Malenka and Bear, 2004), which respectively, strengthen synaptic inputs that are effective at depolarizing the postsynaptic neuron and weaken inputs that are not, thus reinforcing useful pathways in the brain. Synapses that are strengthened become more effective at depolarizing the postsynaptic neuron, eventually driving neuronal activity to saturation (Abbott and Nelson, 2000). As correlated activity of presynaptic and postsynaptic neurons drives strengthening of specific synapses, the postsynaptic neuron will be driven more strongly, and so presynaptic inputs that were initially only poorly correlated with postsynaptic firing will be better able to trigger firing of the postsynaptic neuron. This implies that nervous systems must have a matching set of plasticity mechanisms that counteract these destabilizing forces. The cortical and hippocampal pyramidal neurons have a target firing rate, and synaptic strengths are regulated to maintain these rates relatively constant in the face of perturbations in input channel (Burrone et al., 2002). This provides a robust mechanism for generating stability in network function in the face of learning-related changes in synaptic input. In principle, neurons could maintain stable firing rates through homeostatic regulation of many aspects of neuronal excitability. These possibilities include balancing inward and outward voltage-dependent conductances that determine firing properties generally called "intrinsic excitability" (Marder and Goaillard, 2006; Zhang and Linden 2003), regulating inhibitory and/or excitatory synaptic strength (Turrigiano, 2011) or synapse number (Kirov et al., 1999) or by adjusting the ease with which other forms of plasticity can be induced, so-called "metaplasticity" (Abraham and Bear, 1996). Evidence suggests that all of these mechanisms can contribute to the homeostatic regulation of neuronal firing rates in central circuits. Activity-dependent alteration in synaptic strength is a fundamental property of the vertebrate central nervous system and is thought to underlie learning and memory.

A major expression mechanism of synaptic scaling is changes in the accumulation of synaptic glutamate receptors. Central synapses typically cluster both AMPA receptors and NMDA receptors. AMPA receptors are ionotropic and carry out the majority of excitatory synaptic current 
in the central nervous system; NMDA receptors are also ionotropic but open as a function of voltage, flux calcium, and mediate a number of calcium-dependent forms of synaptic plasticity (Malenka and Bear, 2004). Synaptic scaling results in postsynaptic changes in both types of glutamate receptors (Stellwagen and Malenka, 2006; Watt et al., 2000) and can therefore be monitored by measuring changes in receptor accumulation at synapses.

The best characterised form of LTP occurs in the CA1 region of the hippocampus, in which LTP is initiated by transient activation of receptors and is expressed as a persistent increase in synaptic transmission through AMPA receptors followed by activation of NMDARs. This increase is due, at least in part, to a postsynaptic modification of AMPA-receptor function; this modification could be caused by an increase in the number of receptors, their open probability, their kinetics or their single-channel conductance. Summing up activity-dependent alteration in synaptic strength is a fundamental property of the vertebrate central nervous system that underlies learning and memory processes.

It is appropriate to state that while much emphasis has been given on the key role of the hippocampus in memory, it would probably be simplistic to attribute memory deficits solely to hippocampal damage (Barker and Warburton, 2011). There is substantial evidence that fundamental memory functions are not mediated by hippocampus alone but require a network that includes, in addition to the hippocampus, anterior thalamic nuclei, mammillary bodies cortex, cerebellum and basal ganglia (Aggleton and Brown, 1999; Doya, 2000; Mitchell et al., 2002, Toscano and Guilarte, 2005). Each of these brain structures can be potentially damaged leading to more or less severe impairment of learning and memory.

Amnesia is defined as the impairment or loss of memory. Depending on the cause amnesia can be characterised as functional, organic amnesia or infantile amnesia. Dementia, is a brain disease that causes a long term and often gradual decrease in the ability to think and remember as well as problems with language, and a decrease in motivation (Solomon and Budson, 2011). It is an intellectual impairment observed mainly in elderly people due to the progress of a neudegenerative disease. In younger people this type of impairment is known as presenile dementia. The most common affected areas include memory, visual-spatial, language, attention, and executive function (problem solving). Therefore, very often, short-time memory, mind, speech and motor skills are affected. Certain forms of dementia can be treated, to some extent. The most common form of dementia is Alzheimer's disease, which accounts for between 50 and 60 percent of all cases. Other types include vascular dementia and Lewy body dementia (Burns and Iliffe, 2009).

In the past, the study of infant memory has relied in models and tests used in adults and more specific amnesic patients with hippocampal damage. For this reason, the infant memory has been distinguished to declarative or explicit memory and nondeclarative or implicit memory. However, in recent years this distinction such as explicit/implicit are no longer accepted especially in relation to hippocampal function as new theories have been emerged (reviewed in Mullally and Maguire, 2014). Furthermore, there are findings that even very young infants have a more adept and flexible memory system than was previously thought and neurobiological data derived from non-humans provide support to the new hypotheses about hippocampal development that would facilitate to interpret infant memory data from humans. 


\section{How it is Measured or Detected}

In humans: The neuropsychological tests have been used for neurosensory assessment of humans including identification of altered neurobehaviours in vulnerable populations such as children (Rohlman et al., 2008). Intelligence tests, perceptual motor tests, planning tests, and logical, spatial, short term, long term, and working memory tasks can be used in neurobehavioral studies to assess learning and memory. The same test is also used to identify risks from occupational exposure to chemicals.

In laboratory animals: Current behavioural tests used for evaluating learning and memory processes in rats such as the Morris water maze, Radial maze, Passive avoidance and Spontaneous alternation are characterised in the KE Decreased Neuronal Network Function.

Cognitive function including learning and memory is an important endpoint required by the US EPA and OECD Developmental Neurotoxicity (DNT) Guidelines (OCSPP 870.6300 or OECD 426). The methods applied to assess learning and memory have been reviewed (Markis et al., 2009) and discussed in the OECD Series on testing and assessment number 20, Guidance document for Neurotoxicity Testing (2004). This document is considered an essential supplement to a substantial number of already existing OECD Test Guidelines relevant for neurotoxicity testing.

Evidence Supporting Taxonomic Applicability

\begin{tabular}{l|l|l|l|}
\hline \multicolumn{1}{c|}{ Name } & \multicolumn{1}{c|}{ Scientific Name } & Evidence & Links \\
\hline human & Homo sapiens & Strong & NCBI \\
\hline rat & Rattus norvegicus & Strong & NCBI \\
\hline fruit fly & Drosophila melanogaster & Strong & NCBI \\
\hline zebrafish & Danio rerio & Strong & NCBI \\
\hline gastropods & Physa heterostropha & Strong & NCBI \\
\hline
\end{tabular}

Learning and memory have been studied in invertebrates such as gastropod molluscs and drosophila and vertebrates such as rodents and primates. Recently, larval zebrafish has also been suggested as a model for the study of learning and memory (Roberts et al., 2013).

\section{References}

Abbott, L.F. and S.B. Nelson (2000), Synaptic plasticity: Taming the beast. Nature Neuroscience, Vol. 3, pp. 1178-1183.

Abraham, H.A.J. and M.F. Bear (1996), Bidirectional modification of CA1 synapses in the adult hippocampus in vivo. Nature, Vol. 381, No. 6578, pp. 163-176.

Aggleton, J.P. and M.W. Brown (1999), Episodic memory, amnesia, and the hippocampal-anterior thalamic axis. Behavioral and Brain Sciences, Vol. 22, pp. 425-489.

Barker, G.R. and E. C. Warburton (2011), When is the hippocampus involved in recognition memory? Journal of Neuroscience, Vol. 31, pp. 10721-10731. 
Burns, A. and S. Iliffe (2009), Dementia. BMJ, Clinical Research, Vol. 338, b75.

Burrone, J, M. O'Byrne and V.N. Murthy (2002), Multiple forms of synaptic plasticity triggered by selective suppression of activity in individual neurons. Nature, Vol. 420, pp. 414-418.

Doya, K. (2000), Complementary roles of basal ganglia and cerebellum in learning and motor control. Current Opinion in Neurobiology, Vol. 10, pp. 732-739.

Gilbert, M.E. et al. (2012), Developmental thyroid hormone disruption: prevalence, environmental contaminants and neurodevelopmental consequences. Neurotoxicology, Vol. 33, pp. 842-52.

Kirov, S.A., K.E. Sorra and K.M. Harris (1999), Slices have more synapses than perfusion-fixed hippocampus from both young and mature rats. Journal of Neuroscience, Vol. 19, pp. 2876-2886.

Lynch, M.A. (2004), Long-term potentiation and memory. Physiological Reviews, Vol. 84, pp. 87-136.

Makris, S.L. et al. (2009), A retrospective performance assessment of the developmental neurotoxicity study in support of OECD test guideline 426. Environ Health Perspectives, Vol. 117, pp. 17-25.

Malenka, R.C. and M.F. Bear (2004). LTP and LTD: An embarrassment of riches. Neuron, Vol. 44, pp. 521.

Marder, E.and J.M. Goaillard (2006), Variability, compensation and homeostasis in neuron and network function. Nature Reviews Neuroscience, Vol. 7, pp. 563-574.

Mitchell, A.S., J.C. Dalrymple-Alford and M.A. Christie (2002), Spatial working memory and the brainstem cholinergic innervation to the anterior thalamus. Journal of Neuroscience, Vol. 22, pp. 1922-1928.

Mullally, S.L. and E.A. Maguire (2014), Learning to remember: the early ontogeny of episodic memory. Devopmental Cognitive Neuroscience, Vol. 9, pp. 12-29.

OECD (2004), Series on testing and assessment number 20, Guidance document for neurotoxicity testing.

OECD (2007), Test Guideline 426. OECD Guideline for Testing of Chemicals. Developmental Neurotoxicity Study. http://www.oecd.org/document/55/0,3343,en_2649_34377_2349687_1_1_ $1 \_1,00 . h t m l$

OECD (2008), Nr 43 GUIDANCE DOCUMENT ON MAMMALIAN REPRODUCTIVE TOXICITY TESTING AND ASSESSMENT. ENV/JM/MONO(2008)16

Ono, T. (2009), Learning and Memory. Encyclopedia of neuroscience. M D. Binder, N. Hirokawa and U. Windhorst (Eds). Springer-Verlag GmbH Berlin Heidelberg, pp. 2129-2137.

Quirk, G.J. and D. Mueller (2008), Neural mechanisms of extinction learning and retrieval. Neuropsychopharmacology, Vol. 33, pp. 56-72.

Roberts, A.C., B.R. Bill and D.L. Glanzman (2013), Learning and memory in zebrafish larvae. Frontiers in Neural Circuits, Vol. 7, pp. 126-134.

Rohlman, D.S. et al., (2008), Neurobehavioral testing in human risk assessment. Neurotoxicology, Vol. 29, pp. 556-567.

Solomon, A.E. and P.R. Budson, (2011), Memory loss : a practical guide for clinicians. Elsevier Saunders. ISBN 9781416035978.

Stellwagen, D. and R.C. Malenka (2006), Synaptic scaling mediated by glial TNF- $\alpha$. Nature, Vol. 440, pp. $1054-1059$.

Toscano, C.D. and T.R. Guilarte (2005), Lead neurotoxicity: From exposure to molecular effects. Brain Research Reviews, Vol. 49, pp. 529-554.

Turrigiano, G. (2011), Too many cooks? Intrinsic and synaptic homeostatic mechanisms in cortical circuit refinement. Annual Review of Neuroscience, Vol. 34, pp. 89-103.

Watt, A.J. et al. (2000), Activity coregulates quantal AMPA and NMDA currents at neocortical synapses. Neuron, Vol. 26, pp. 659-670. 
Zhang, W. and D.J Linden (2003), The other side of the engram: Experience-driven changes in neuronal intrinsic excitability. Nature Reviews Neuroscience, Vol. 4, pp. 885-900.

\section{Key Event Relationships: Scientific evidence supporting the linkages in the AOP}

\begin{tabular}{|c|c|c|}
\hline Event & Description & Triggers \\
\hline $\begin{array}{l}\text { Inotropic glutamate receptors, Binding of } \\
\text { agonist }\end{array}$ & $\begin{array}{l}\text { Directly Leads } \\
\underline{\text { to }}\end{array}$ & $\underline{\text { NMDARs, Overactivation }}$ \\
\hline NMDARs, Overactivation & $\begin{array}{ll}\text { Directly Leads } \\
\text { to }\end{array}$ & Calcium influx, Increased \\
\hline$\underline{\text { Calcium influx, Increased }}$ & $\begin{array}{l}\text { Indirectly Leads } \\
\underline{\text { to }}\end{array}$ & Mitochondrial dysfunction, N/A \\
\hline Mitochondrial dysfunction, N/A & $\begin{array}{l}\text { Indirectly Leads } \\
\underline{\text { to }}\end{array}$ & $\underline{\text { Cell death, N/A }}$ \\
\hline Cell death, N/A & $\begin{array}{ll}\text { Directly Leads } \\
\underline{\text { to }}\end{array}$ & Neurodegeneration, N/A \\
\hline Cell death, N/A & $\underline{\text { Indirectly Leads }}$ & Neuroinflammation, N/A \\
\hline Neurodegeneration, N/A & $\begin{array}{l}\text { Directly Leads } \\
\underline{\text { to }}\end{array}$ & Neuroinflammation, N/A \\
\hline Neuroinflammation, N/A & $\begin{array}{l}\text { Directly Leads } \\
\text { to }\end{array}$ & Neurodegeneration, N/A \\
\hline$\underline{\text { Neurodegeneration, N/A }}$ & 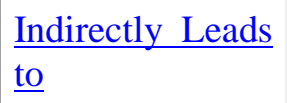 & $\begin{array}{l}\text { Neuronal network function in adult brain, } \\
\text { Decreased }\end{array}$ \\
\hline $\begin{array}{l}\text { Neuronal network function in adult brain, } \\
\text { Decreased }\end{array}$ & $\begin{array}{l}\text { Indirectly Leads } \\
\underline{\text { to }}\end{array}$ & Learning and memory, Impairment \\
\hline
\end{tabular}

\section{Inotropic glutamate receptors, Binding of agonist leads to NMDARs, Overactivation}

How Does This Key Event Relationship Work

NMDARs can be activated indirectly through initial activation of KA/AMPARs as it happens in the case of DomA exposure. DomA is an agonist of presynaptic and postsynaptic KARs and sustained activation of these receptors by DomA results in massive ion flux and excessive release of glutamate from excitatory terminals causing depolarisation of the postsynaptic neuron (as descibed in MIE). Upon this depolarisation the $\mathrm{Mg}^{2+}$ block is removed from the pore of NMDARs, resulting in their activation allowing sodium, potassium, and, importantly, calcium ions to enter into a cell. The sustained exposure to DomA causes pathological overactivation of 
NMDARs. In the case of exposure to glufosinate NMDARs activation is triggered by direct, sustained binding of glufosinate to the NMDARs.

Weight of Evidence

Biological Plausibility

NMDARs are unique among ligand-gated ion channels in that their activation requires binding of two co-agonists, glycine and endogenous neurotransmitter, L-glutamate. Physiologically, however, glycine and glutamate have distinct functions. While L-glutamate is released from specific presynaptic terminals, low concentrations of ambient glycine present at the synapse are thought to be sufficient to allow receptor activation. There is a clear understanding that binding of glutamate or its analogue will activate NMDA receptor (accepted dogma). The prolonged activation of NMDARs will lead to a pathological over-activation of a receptor leading to excitotoxicity (minor role of KA/AMPARs), allowing high levels of calcium ions to enter the cell. However, KA/AMPARs play an important role for indirect NMDAR activation since (almost always) an initial activation of these receptors triggers depolarisation of postsynaptic neurons that relieves the block of the channel pore by $\mathrm{Mg}^{2+}$, resulting in NMDAR activation. NMDA receptors are formed by a ligand binding domain (LBD) and an ion channel that are considered the core structural and functional elements of the receptors. There is a clear understanding of how agonist binding leads to channel opening that relies on structural (e.g. crystallography or NMR) and functional (e.g. UV and IR spectrometric measurements) experimental studies of the watersoluble LBD combined with functional studies of the intact receptor. After the initial agonist binding, a conformational change - so-called clam shell closure - that prevents agonist dissociation occurs followed by a conformational change in the ion channel that is tightly coupled to that in the LBD (reviewed in Traynelis et al., 2010). Consequently it can be stated that there is a clear structural and functional mechanistic understanding in this KER between MIE (Binding of agonist to glutamate ionotropic receptors) and KE1, NMDAR overactivation that, as explained above, can be triggered by direct binding to NMDAR or indirectly, through initial activation of KA/AMPARs as it happens in the case of exposure to glufosinate and DomA respectively, two stressors described in this AOP.

Indeed, domoic acid has a very strong affinity for the ionotropic glutamate receptors, the activation of which results in excitotoxicity, initiated by an integrative action of ionotropic receptors at both sides of the synapse blocking the channel from rapid desensitisation. It has a synergistic effect with endogenous glutamate and it acts mainly as an agonist for presynaptic and postsynaptic kainate receptors. Activation of ionotropic receptors leads to the influx of $\mathrm{Na}^{+}, \mathrm{K}^{+}$ and $\mathrm{Ca}^{2+}$, particulary after activation of NMDARs. In combination with the inhibitory GABA neurotransmitter, glutamate contributes to the control of overall neuronal excitability.

Gufosinate (GLF) triggers alterations in glutamatergic signaling through direct binding and activation of NMDARs (Lantz et al., 2014: Matsumura et al., 2001). GLF agonist action at the NMDAR is expected to occur through interaction with the glutamate binding site and requires binding of the glycine co-agonist as well as release of the magnesium block from the channel pore. Additionally, the possible inhibition by GLF of the high affinity glutamate re-uptake transporter, especially GLT-I was studied to determine whether GLF could increase the levels of endogenous glutamate at the synaptic cleft, resulting in over activation of NMDARs. Such 
mechanism was excluded by Lantz (Lantz et al., 2014) but suggested by other studies (Watanabe and Sano, 1998).

\section{Empirical support for linkage}

There is well established understanding of NMDAR activation by endogenous agonist glutamate that happens in the absence of the $\mathrm{Mg}^{2+}$ block under conditions of depolarized post-synaptic membrane (accepted dogma) (Blanke et al., 2009a and b; Enoki R, et al., 2004).

Single channel behavior of NMDARs from hippocampal CA1 neurons was studied using very low glutamate concentrations to improve temporal resolution of individual glutamate binding events. Openings resulting from individual receptor activations showed surprising complexity: they consist of a long cluster of bursts of openings. Furthermore, the NMDARs appeared to have different gating modes, occasionally entering periods of very high open probability (Gibb and Colquhoun, 1991). Single channel analysis also provided insight in how NMDARs function at the synapse. In response to a brief pulse of glutamate, mimicking synaptic release, NMDARs activate slowly over hundreds of milliseconds and continue activating long after all glutamate has been removed from the synaptic cleft, thereby briefly "memorising" the occurrence of a synaptic input. Single channel analysis of NR1 and NR2A receptors indicates that after a brief pulse of glutamate, receptors enter a high affinity closed state from which either channel opening or agonist unbinding occurs with approximately equal probability (Popescu et al., 2004). A single synaptic event is therefore expected to only partially activate NMDARs. Consequently, a closely spaced second pulse of agonist is able to further increase the open probability, endowing the NMDAR with an ability to decode synaptic input frequency.

Domoic acid is an agonist for presynaptic and postsynaptic kainate receptors, however indirectly also activates NMDA receptors. Kainate receptors are localised both at presynaptic and postsynaptic sites. At presynaptic sites, they directly affect transmitter release from both excitatory and inhibitory neuron terminals. At postsynaptic sites, kainate receptors lead to cell depolarisation, which would bring the neuron closer to its spike firing threshold. By having this dual localisation, kainate receptors help in the control of neuronal excitability. However, sustained activation of postsynaptic kainate receptors by domoic acid results in massive ion flux and excessive release of glutamate from excitatory terminals. The released glutamate in turn activates NMDA receptors, which have lost their physiologic $\mathrm{Mg}^{2+}$ block because of domoic acid-induced depolarisation. The final event is an increase of NMDA-mediated $\mathrm{Ca}^{2+}$ flux and subsequent activation of intracellular pro-oxidative cascades and ion imbalances, eventually leading to excitotoxicity-mediated neuronal death (Babot et al., 2005; Giordano et al., 2006).

Kainate receptors are widely expressed in the hippocampus. Glutamatergic granule cells in the hippocampus express these receptors, suggesting that cell death found after domoic acid intoxication may be produced by hyperstimulation of NMDA receptor after glutamate is released in excess. In agreement with this hypothesis, the seriously damaged CA3 area of the hippocampus receives projections from hippocampal granule cells. Qiu and Curras-Collazo (Qiu et al., 2006a) elegantly demonstrated that domoic acid first targets kainate receptors in the hippocampus by blocking its effects in vivo with a kainate receptor antagonist. The sequential involvement of distinct glutamate receptors was confirmed and further elucidated in rat mixed cortical cell and hippocampal slice cultures (Jakobsen et al., 2002; Qiu et al., 2006b). 
Using primary cultures of rodent cerebellar granule cells, an in vitro model mainly constituted by glutamatergic neurons that express both NMDA and kainate receptors it was proved that domoic acid increased glutamate release, intracellular calcium, and cell death, which were prevented by kainate and NMDA receptor antagonists (Berman and Murray, 1997; Vale-Gonzalez et al., 2006) confirming that DomA toxicity is mediated by both KA and NMDARs.

Glufosinate (GLF) and its primary metabolite N-acetylglufosinate (NAcGLF) interaction with NMDARs was studied in the primary culture of rat cortical neurons by performing [3H]CGP 39653 binding experiments. The results showed that their binding affinity to NMDAR (IC50, GLF $668 \mathrm{uM}$ and NAcGLF approximately $100 \mathrm{uM}$ ) corresponded to the concentration that produce the highest increase of mean firing rate. Furthermore, they produced biphasic MFR profile, specific to NMDAR agonists. The obtained results suggest that GLF and NAcGLF can produce both effects, excitatory and inhibitory on network activity through direct activation of NMDARs (Lantz et al., 2014).

Direct activation of NMDARs by GLF is also suggested by in vivo studies where three NMDA receptor antagonists, dizocilpine, LY235959, and Compound 40, and AMPA/KA antagonist, NBQX, were co-administrated with glufosinate ammonium $(80 \mathrm{mg} / \mathrm{kg}$, intraperitoneally) in mice. Statistical analyses showed that the NMDA receptor antagonists markedly inhibited the GLFinduced convulsions, while the AMPA/KA receptor antagonist had no effect. These results suggest that the convulsion caused by glufosinate ammonium were mediated through activation of NMDA receptors (Matsumura et al., 2001).

\section{Uncertainties or Inconsistencies}

The increase in MFR induced by GLF in neuronal networks was significantly blocked by MK-801 but not entirely suggesting that GLF can increase activity in the MEA system through nonsynaptic NMDARs, since these are not blocked by MK-801. It is not entirely clear whether GLF can work through an inhibition of the glutamate reuptake transporter, GLT-I, increasing the concentration of endogenous glutamate at the synaptic cleft and subsequently resulting in over activation of NMDARs (Lantz et al., 2014: Watanabe and Sano, 1998). Further studies are necessary to determine whether this alternative mechanism of GLF-induced NMDAR overactivation takes place. Additionally GLF also modulates glutamine synthetase (GS) activity. Since, astrocytic GS in the brain participates in the metabolic regulation of glutamate (endogenous agonist of NMDAR) it is not clear if this pathway contributes to NMDAR activation too.

\section{Quantitative Understanding of the Linkage}

To predict how potent an agonist can be, it is usually based on the half maximal effective concentration (EC50) that induces the currents through NMDA receptors of brain slices and cells (or in recombinantly expressed proteins of these receptors). Traynelis et al. (2010) summarised the IC50 values for agonists of the different NMDA receptor subunits. The activation effect (efficacy) of agonist on NMDA receptor have been found to be dependent on: -the type of subunits that form the NMDA receptor -the chemical structure of the agonist -the binding site of a receptor that the agonist prefers -how tightly an agonist binds to the receptor (affinity) Glufosinate 
and its primary metabolite $\mathrm{N}$-acetylglufosinate NAcGLF bind to the NMDAR with the following affinity: the IC50 value for GLF was $668 \mathrm{mM}$ and for NAcGLF was about $100 \mathrm{mM}$.

\section{Evidence Supporting Taxonomic Applicability}

Various studies suggest the existence of functional NMDA-like receptors in invertebrates (Xia et al., 2005). Fly and rodent NMDARs exhibit several important differences (Murphy and Glanzman, 1997). The expression and function of NMDA receptors in rodent and primates is well characterised in the existing literature.

\section{References}

Babot, Z., R. Cristofol, and C. Sunol (2005), Excitotoxic death induced by released glutamate in depolarized primary cultures of mouse cerebellar granule cells is dependent on GABAA receptors and niflumic acidsensitive chloride channels. European Journal of Neuroscience, Vol. 21, pp. 103112.

Berman, F.W. and T.F. Murray (1997), Domoic acid neurotoxicity in cultured cerebellar granule neurons is mediated predominantly by NMDA receptors that are activated as a consequence of excitatory amino acid release. Journal of Neurochemistry, Vol. 69, pp. 693-703.

Blanke, M.L., and A.M.J. VanDongen (2009a) Activation Mechanisms of the NMDA Receptor. In: Van Dongen AM, editor. Biology of the NMDA Receptor. Boca Raton (FL): CRC Press; Chapter 13. Frontiers in Neuroscience.

Blanke, M.L. and A.M.J. VanDongen (2009b), Activation Mechanisms of the NMDA Receptor in Biology of the NMDA Receptor, Chapter 13, Van Dongen AM, editor. Boca Raton (FL): CRC Press.

Enoki, R. et al. (2004), NMDAR-mediated depolarizing after-potentials in the basal dendrites of CA1 pyramidal neurons. Neuroscience Research, 2004, Vol. 48, pp. 325-337.

Gibb, A.J. and D. Colquhoun (1991), Glutamate activation of a single NMDAR-channel produces a cluster of channel openings. Proceedings of the Royal Society ofLondon. (Biological Sciences), Vol. 243, pp. 39-47.

Giordano, G. et al. (2006), Neurotoxicity of domoic Acid in cerebellar granule neurons in a genetic model of glutathione deficiency. Molecular Pharmacology, Vol. 70, pp. 2116-2126.

Jakobsen, B. A. Tasker and J. Zimmer (2002), Domoic acid neurotoxicity in hippocampal slice cultures. Amino Acids, Vol.23, pp. 37-44.

Lantz, S.R et al. (2014), Glufosinate binds to N-methyl-D-aspartate receptors and increases neuronal network activity in vitro. NeuroToxicology, Vol. 45, pp. 38-47.

Matsumura, N. et al. (2001), Glufosinate ammonium induces convulsion through N-methyl-D-aspartate receptors in mice. Neurosci Letters., Vol. 304, No. 1-2, pp. 123-5.

Murphy, G.G. and D.L. Glanzman (1997), Mediation of classical conditioning in Aplysia californica by long-term potentiation of sensorimotor synapses. Science, Vol. 278, pp. 467-78.

Popescu G, et al. (2004), Reaction mechanism determines NMDAR response to repetitive stimulation. Nature, Vol. 430, pp. 790-799.

Qiu, S. and M.C. Curras-Collazo (2006a), Histopathological and molecular changes produced by hippocampal microinjection of domoic acid. Neurotoxicology and Teratolology, Vol. 28, pp. 354362.

Qiu, S., C.W. Pak and M.C. Curras-Collazo (2006b), Sequential involvement of distinct glutamate receptors in domoic acid-induced neurotoxicity in rat mixed cortical cultures: Effect of multiple 
dose/duration paradigms, chronological age, and repeated exposure. Toxicological Sciences, Vol. 89, pp. 243-256.

Traynelis, S.F. et al. (2010), Glutamate receptor ion channels: structure, regulation, and function. Pharmacological Reviews. Vol. 62, No.3, pp. 405-96.

Vale-Gonzalez, C. et al. (2006), Role of the plasma membrane calcium adenosine triphosphatase on domoate-induced intracellular acidification in primary cultures of cerebellar granule cells. Journal of Neuroscience Research, Vol. 84, pp. 326-337.

Watanabe, T. and T. Sano (1998), Neurological effects of glufosinate poisoning with a brief review. Human \& Experimental Toxicology, Vol. 17, pp. 35-9.

Xia, S. et al. (2005), NMDARs mediate olfactory learning and memory in Drosophila. Current Biology, Vol. 15, pp. 603-618.

\section{NMDARs, Overactivation leads to Calcium influx, Increased}

\section{How Does This Key Event Relationship Work}

The NMDA receptor is distinct from the other glutamate receptors in two ways: first, it is both ligand-gated and voltage-dependent; second, it requires co-activation by two ligands: glutamate (GLU) and either glycine or D-serine. Following membrane depolarisation, the co-agonists, Lglutamate and glycine must bind to their respective sites on the receptor to open the channel. On activation, the NMDA receptor allows the influx of extracellular calcium ions into the postsynaptic neuron and neurotransmission occurs (reviewed in Higley and Sabatini, 2012). Calcium flux through NMDA receptors is also thought to be critical in synaptic plasticity, a cellular mechanism for learning and memory. Indeed, NMDA receptor-dependent synaptic potentiation (LTP) and depression (LTD) are two forms of activity-dependent long-term changes in synaptic efficacy that are believed to represent cellular correlates of learning and memory processes. The best characterised form of NMDA receptor-dependent LTP and LTD occurs between CA3 and CA1 pyramidal neurons of the hippocampus (Luscher and Malenka, 2012). It is now well established that modest activation of NMDARs leads to modest increases in postsynaptic calcium, triggering LTD, whereas much stronger activation of NMDARs leading to much larger increases in postsynaptic calcium are required to trigger LTP (Luscher and Malenka, 2012). The high-frequency stimulation causes a strong temporal summation of the excitatory postsynaptic potentials, and depolarisation of the postsynaptic cell is sufficient to relieve the $\mathrm{Mg}^{2+}$ block of the NMDAR and allow a large amount of calcium to enter into the post-synaptic cells.

Weight of Evidence

Biological Plausibility

There is structural and functional mechanistic understanding supporting this relationship between KE NMDARs, Overactivation and KE Calcium influx, Increased.

This relationship is plausible as the expression of the functional NMDA receptors is commonly carried out or assessed by $\mathrm{Ca}^{2+}$ imaging method. Calcium imaging techniques have been extensively utilised in the literature to investigate the potential interactions between NMDAevoked $\mathrm{Ca}^{2+}$ influx and NMDA receptor activation. Approximately $15 \%$ of the current through NMDA receptors is mediated by $\mathrm{Ca}^{2+}$ under physiological conditions (Higley and Sabatini, 2012). 
It has been shown that less than five and, occasionally, only a single NMDA receptor opens under physiological conditions, causing a total $\mathrm{Ca}^{2+}$ influx of about 6000 ions into a spine head reaching a concentration of $\sim 10 \mu \mathrm{m}$ (Higley and Sabatini, 2012). However, the majority of the ions are rapidly eliminated by binding to $\mathrm{Ca}^{2+}$ proteins, reaching $\sim 1 \mu \mathrm{M}$ of free $\mathrm{Ca}^{2+}$ concentration (Higley and Sabatini, 2012).

It has been shown that in rat primary forebrain cultures the intracellular $\mathrm{Ca}^{2+}$ increases after activation of the NMDA receptor through administration of NMDA but this increase in $\mathrm{Ca}^{2+}$ is blocked when the cells are cultured under $\mathrm{Ca}^{2+}$ free conditions, demonstrating that the NMDAevoked increase in intracellular $\mathrm{Ca}^{2+}$ derives from extracellular and not intracellular sources (Liu et al., 2013).

Indirect mechanism of domoic acid (DA) induced overactivation of NMDARs that result in $\mathrm{Ca}^{2+}$ overload: depolarisation of the pre-synaptic cell activates the release of endogenous $\mathrm{Ca}^{2+}$ which mobilises vesicles containing GLU to the membrane surface. Glutamate is then released into the synaptic cleft by exocytosis where it is able to interact with cell surface receptors. Exogenous DA can interact within the synaptic cleft with each of the three ionotropic receptor subtypes including the kainate, AMPA, and NMDA receptors on cell membranes. Activation of the kainate and AMPA receptors results in release of $\mathrm{Ca}^{2+}$ via coupled ion channels, into the post-synaptic cell. DA is also able to bind to NMDA receptors that are linked to both $\mathrm{Ca}^{2+}$ and $\mathrm{Na} / \mathrm{K}^{+}$ion channels and results in a cellular influx of both $\mathrm{Na}^{+}$and $\mathrm{Ca}^{2+}$. Unlike GLU, DA induces prolonged receptor activation causing a constant influx of cations into the cell and the appropriate chemical cues for desensitization are blocked. The excess intracellular $\mathrm{Ca}^{2+}$ causes disruption of cellular function, cell swelling and ultimately cell death (Lefebvre and Robertson, 2010).

Glufosinate (GLF) is the methylphosphinate analog of glutamate that directly can activate NMDARs (Lantz et al., 2014, Matsumura et al., 2001, Faro et al., 2013) (as described in KE: NMDARs, Binding of agonist). It is well established in the existing literature that activation of NMDARs leads to the intra-cellular $\mathrm{Ca}^{2+}$ overload and based on this assumption it can be suggested that an exposure to GLF leads to increased intra-cellular calcium levels.

Empirical support for linkage

\section{Domoic acid (DomA)}

- Treatment of mouse cerebellar granule neurons (CGNs) with 1 or $10 \mu \mathrm{M}$ DomA causes increase of intracellular $\mathrm{Ca}^{2+}$ by approximately 5 or 8 fold compared to controls, respectively (Giordano et al., 2006). Interestingly, when the cells are exposed simultaneously to DomA and the NMDA receptor antagonist MK-801, the $\mathrm{Ca}^{2+}$ levels measured are close to control levels, indicating that the $\mathrm{Ca}^{2+}$ elevation evoked by DomA involves activation of NMDA receptors (Giordano et al., 2006).

- The same research group has performed a time course study by applying a high and a low DomA concentration and using CGNs from Gclm $(+/+)$ and Gclm $(-/-)$ mice lacking glutathione (Giordano et al., 2007). The low DomA dose $(0.1 \mu \mathrm{M})$ causes a small and delayed increase in intracellular $\mathrm{Ca}^{2+}$ concentration with a full recovery by $20 \mathrm{~min}$. When 
the experiment is performed in the absence of extracellular calcium, this increase of intracellular $\mathrm{Ca}^{2+}$ levels in the presence of DomA is abolished, indicating that this change in homeostasis of $\mathrm{Ca}^{2+}$ is due to ion entry from outside the cell. However, this recording of intracellular $\mathrm{Ca}^{2+}$ is antagonised only by NBQX (AMPA receptor antagonist), but not by MK-801 (NMDA receptor antagonist). On the other hand, the higher DomA concentration $(10 \mu \mathrm{M})$ causes a rapid and robust increase in intracellular $\mathrm{Ca}^{2+}$, which lasts even after 25 min. This effect is antagonized by both NBQX and MK-801, suggesting that not only AMPA but also NMDA receptors are involved in $\mathrm{Ca}^{2+}$ elevation evoked by DomA at high doses (Giordano et al., 2007).

- In an earlier study, the time course and concentration dependence of the increase in intracellular $\mathrm{Ca}^{2+}$ stimulated by DomA has been examined in 10-13 day-in-culture CGNs (Berman et al., 2002). DomA produces a rapid and concentration-dependent increase in intracellular $\mathrm{Ca}^{2+}$, showing the maximal increase at $10 \mu \mathrm{M}$ DomA (Berman et al., 2002). At this concentration, fluo-3 fluorescence that is used to measure $\mathrm{Ca}^{2+}$ elevates rapidly during the first $40 \mathrm{~s}$ of exposure, increases more slowly before peaking at $3.5 \mathrm{~min}$, after which the signal diminishes steadily over the 30 min course of the experiment to $55 \%$ of peak values. The EC50 for DomA-induced increase in intracellular $\mathrm{Ca}^{2+}$ is $0.61 \mu \mathrm{M}$. In the same study, the NMDA receptor antagonist MK-801 significantly reduced both peak and final plateau of intracellular $\mathrm{Ca}^{2+}$ by 30 and $70 \%$, respectively (Berman et al., 2002).

- These three studies (Giordano et al., 2006; 2007; Berman et al., 2002) do not provide a simultaneous measurement of NMDA receptor activation by DomA and intracellular $\mathrm{Ca}^{2+}$ levels. However, they do provide indirect evidence of NMDA receptor activation involvement in increased intracellular $\mathrm{Ca}^{2+}$ concentrations induced by DomA as they have used known antagonists of the NMDA receptors that reverses the situation in both KEs (blocking upstream KE will block downstream KE).

- In an in vivo study it was indirectly shown that the microinjection to adult male Sprague Dawley rats of $10 \mu \mathrm{M}$ DomA increased intracellular $\mathrm{Ca}^{2+}$ levels. A significant upregulation of phosphorylated CaMKII and phosphorylated CREB levels was recorded, possibly due to increased intracellular $\mathrm{Ca}^{2+}$ levels induced by DomA (Qiu and CurrásCollazo, 2006).

In CGNs, the co-treatment with $10 \mu \mathrm{M}$ DomA and the kainate/AMPA receptor antagonist NBQX maintains $\mathrm{Ca}^{2+}$ levels near to control levels, suggesting that the $\mathrm{Ca}^{2+}$ elevation evoked by DomA is mediated by the activation of both AMPA/kainate and of NMDA receptors (Giordano et al., 2006).

The voltage-sensitive $\mathrm{Ca}^{2+}$ channel (VSCC) blocker nifedipine $(5 \mu \mathrm{M})$ and NBQX $(10 \mu \mathrm{M})$, a competitive AMPA/kainate receptor antagonist reduces the peak and final intracellular $\mathrm{Ca}^{2+}$ concentration in CGNs (Berman et al., 2002), strengthening the view that the increase of $\mathrm{Ca}^{2+}$ influx is not only mediated by NMDA receptors but also by AMPA/kainate receptors and VSCCs. 


\begin{tabular}{|c|c|c|c|c|c|c|c|c|c|c|c|}
\hline Stressor & $\begin{array}{c}\text { Experimental } \\
\text { Model }\end{array}$ & $\begin{array}{c}\text { Tested } \\
\text { concentrations }\end{array}$ & $\begin{array}{c}\text { Exposure } \\
\text { route }\end{array}$ & $\begin{array}{l}\text { Exposure } \\
\text { duration }\end{array}$ & \begin{tabular}{|c|} 
Overactivation \\
of NMDAR \\
(KE up)
\end{tabular} & \begin{tabular}{|c|} 
Increased \\
intracellular Ca \\
levels (KE down) \\
\end{tabular} & References & $\begin{array}{c}\text { Temporal } \\
\text { Relationship }\end{array}$ & \begin{tabular}{|c|} 
Dose- \\
response \\
relationship
\end{tabular} & Incidence & Comments \\
\hline DomA & \begin{tabular}{|l} 
Mouse \\
cerebellar \\
granule \\
neurons \\
(CGNs) from \\
Gclm (+/+) and \\
Gclm $(-/-)$ \\
mice
\end{tabular} & 0.01 to $10 \mu \mathrm{M}$ & & $\begin{array}{l}\text { Time } \\
\text { course }(15 \\
\text { to } 120 \\
\text { min })\end{array}$ & & $\begin{array}{l}5 \text { and } 8 \text { fold } \\
\text { increase of }\left[\mathrm{Ca}^{2+}\right] \mathrm{i} \\
\text { compared to } \\
\text { controls. }\end{array}$ & $\begin{array}{l}\text { Giordano et } \\
\text { al., } 2006\end{array}$ & & & & $\begin{array}{l}\text { The cells were exposed } \\
\text { simultaneously to DA } \\
\text { and the NMDA } \\
\text { receptor antagonist } \\
\text { MK- } 801 \text { and the } \mathrm{Ca}^{2+} \\
\text { levels were found to be } \\
\text { close to control levels, } \\
\text { indicating that the Ca }{ }^{2+} \\
\text { elevation evoked by } \\
\text { DA involves activation } \\
\text { of NMDA receptors. }\end{array}$ \\
\hline DomA & $\begin{array}{l}\text { CGNs from } \\
\operatorname{Gclm}(+/+) \text { and } \\
\operatorname{Gclm}(-/-) \\
\text { mice }\end{array}$ & 0.01 to $10 \mu \mathrm{M}$ & & $\left|\begin{array}{l}\text { Time } \\
\text { course }(0 \\
\text { to } 25 \mathrm{~min})\end{array}\right|$ & & $\begin{array}{l}0.1 \mu \mathrm{M} \text { domoic acid } \\
\text { caused a small and } \\
\text { delayed increase }(4 \\
\text { fold) in }\left[\mathrm{Ca}^{2+}\right] \mathrm{i}, \text { with } \\
\text { a full recovery by } \\
20 \text { min.In contrast, } \\
\text { the higher } \\
\text { concentration of } \\
\text { domoic acid }(10 \mu \mathrm{M}) \\
\text { caused a rapid and } \\
\text { robust increase ( } 8 \\
\text { fold) in }\left[\mathrm{Ca}^{2+}\right] \mathrm{i}, \\
\text { which was still } \\
\text { elevated after } 25 \\
\text { min. } \\
0.1 \mu \mathrm{M} \text { DA } \\
\left.\text { increases [Ca }{ }^{2+}\right] \mathrm{M} \\
\text { by about } 3 \text { fold, } \\
\text { with a delay of } \\
\text { about } 15 \text { min. In } \\
\text { contrast, no changes } \\
\text { in }\left[\text { Ca }{ }^{2+}\right] \mathrm{M} \text { were } \\
\text { observed following } \\
10 \mu \mathrm{M} \text { of DA. } \\
\end{array}$ & $\begin{array}{l}\text { Giordano et } \\
\text { al., } 2007\end{array}$ & & & & $\begin{array}{l}\text { At the low } \\
\text { concentration }(0.1 \mu \mathrm{M}) \text {, } \\
\text { the recording of } \\
\text { intracellular } \mathrm{Ca}^{2+} \text { was } \\
\text { antagonized only by } \\
\text { NBQX (AMPA } \\
\text { receptor antagonist), } \\
\text { but not by MK-801 } \\
\text { (NMDA receptor } \\
\text { antagonist). On the } \\
\text { other hand, the higher } \\
\text { DA concentration } \\
(10 \mu \mathrm{M}) \text { caused a rapid } \\
\text { and robust increase in } \\
\text { intracellular Ca }{ }^{2+} \text {. This } \\
\text { effect was antagonized } \\
\text { by both NBQX and } \\
\text { MK-801, suggesting the } \\
\text { importance of NMDA } \\
\text { receptors in Ca }{ }^{2+} \\
\text { elevation evoked by } \\
\text { DA but only at high } \\
\text { doses }\end{array}$ \\
\hline
\end{tabular}




\begin{tabular}{|c|c|c|c|c|c|c|c|}
\hline DomA & \begin{tabular}{|l|}
$10-13$ DIV \\
CGNs obtained \\
from 8-day-old \\
Sprague- \\
Dawley rats
\end{tabular} & 0.1 to $30 \mu \mathrm{M}$ & & $\left|\begin{array}{l}\text { Time } \\
\text { course }(0 \\
\text { to } 45 \text { min })\end{array}\right|$ & $\begin{array}{l}\text { EC50 for DA- } \\
\text { induced increase in } \\
\text { intracellular } \mathrm{Ca}^{2+} \\
\text { was } 0.61 \mu \mathrm{M}\end{array}$ & $\begin{array}{l}\text { Berman et } \\
\text { al., } 2002\end{array}$ & $\begin{array}{l}\text { The NMDA receptor } \\
\text { antagonist MK-801 } \\
\text { significantly reduced } \\
\text { both peak and final } \\
\text { plateau of intracellular } \\
\mathrm{Ca}^{2+} \text { by } 30 \text { and } 70 \%, \\
\text { respectively } \\
\end{array}$ \\
\hline DomA & \begin{tabular}{|l} 
Adult male \\
Sprague \\
Dawley rats
\end{tabular} & $10 \mu \mathrm{M}$ & $\begin{array}{l}\text { Brain } \\
\text { microinjection }\end{array} \mid$ & & \begin{tabular}{|l} 
Increased \\
phosphorylated \\
CaMKII and \\
phosphorylated \\
CREB levels \\
\end{tabular} & \begin{tabular}{|l} 
Qiu and \\
Currás- \\
Collazo, \\
2006 \\
\end{tabular} & \\
\hline
\end{tabular}




\section{Glufosinate (GLF)}

There are no data showing that an exposure to GLF causes an increase in intra-cellular calcium. Such assumption can be proposed based on a fact that GLF directly activates NMDR as described in the MIE and other relevant KEs of this AOP.

\section{Uncertainties or Inconsistencies}

A case of a 59-yr-old woman who ingested a herbicide containing glufosinate was suffering from severe intoxication of this herbicide, however, she did not develop convulsions, which experimentally occurs in rats treated with glufosinate (Koyama et al., 1994) and is described in other human cases (Watanabe and Sano 1998).

\section{Quantitative Understanding of the Linkage}

The experiments describing semi-quantitative effects for these KERs are described in the table above.

\section{Evidence Supporting Taxonomic Applicability}

Data not available

\section{References}

Berman, F.W., K.T. LePage and T.F. Murray (2002), Domoic acid neurotoxicity in cultured cerebellar granule neurons is controlled preferentially by the NMDA receptor $\mathrm{Ca}(2+)$ influx pathway, Brain Research, Vol. 924, pp. 20-29.

Faro, L.R. et al. (2013), Role of glutamate receptors and nitric oxide on the effects of glufosinate ammonium, an organophosphate pesticide, on in vivo dopamine release in rat striatum, Toxicology, Vol. 311, pp. 154-161.

Giordano, G. et al. (2006), Neurotoxicity of domoic Acid in cerebellar granule neurons in a genetic model of glutathione deficiency, Molecular Pharmacology, Vol. 70, pp. 2116-2126.

Giordano, G. et al. (2007), Glutathione levels modulate domoic acid-induced apoptosis in mouse cerebellar granule cells, Toxicological Sciences, Vol. 100, pp. 433-444.

Higley, M.J. and B.L. Sabatini (2012), Calcium signalling in dendritic spines, Cold Spring Harbor Perspectives in Biology, Vol. 4, pp. a005686.

Koyama, K. et al. (1994), Delayed and severe toxicities of a herbicide containing glufosinate and a surfactant, Veterinary and human toxicology, Vol. 36, pp. 17-18.

Lantz, S.R. et al. (2014), Glufosinate binds N-methyl-D aspartate receptors and increases neuronal network activity in vitro, Neurotoxicology, Vol. 45, pp. 38-47.

Lefebvre, K.A. and A. Robertson (2010), Domoic acid and human exposure risks: a review, Toxicon, Vol. 56, No. 2, pp. 218-230.

Liu, F. et al. (2013), Ketamine-induced neuronal damage and altered N-methyl-D-aspartate receptor function in rat primary forebrain culture, Toxicological Sciences, Vol. 131, pp. 548-557.

Luscher, C. and R.C. Malenka (2012), NMDA Receptor-Dependent Long-Term Potentiation and LongTerm Depression (LTP/LTD), Cold Spring Harbor Perspectives in Biology, Vol. 4, pp. a005710.

Matsumura, N. et al. (2001), Glufosinate ammonium induces convulsion through N-methyl-D-aspartate receptors in mice, Neuroscience Letters, Vol. 304, No. 1-2, pp. 123-125. 
Qiu, S. and M.C. Currás-Collazo (2006), Histopathological and molecular changes produced by hippocampal microinjection of domoic acid, Neurotoxicology and Teratology, Vol. 28, pp. 354-362.

Watanabe, T. and T. Sano (1998), Neurological effects of glufosinate poisoning with a brief review, Human and Experimental Toxicology, Vol. 17, pp. 35-39.

\section{Calcium influx, Increased leads to Mitochondrial dysfunction, N/A}

\section{How Does This Key Event Relationship Work}

One of the mitochondrial functions is to buffer intracellular $\mathrm{Ca}^{2+}$ levels facilitating the maintenance of $\mathrm{Ca}^{2+}$ homeostasis in the cell. In the case of $\mathrm{Ca}^{2+}$ overload, mitochondria are not able to buffer the excess of $\mathrm{Ca}^{2+}$ that leads to mitochondrial dysfunction measured by the increased generation of reactive oxygen species (ROS), triggering mitochondrial permeability transition pore opening (Choi et al., 2013) and reduced ATP production (reviewed in Gleichmann and Mattson, 2011).

\section{Weight of Evidence}

\section{Biological Plausibility}

There is functional and structural mechanistic understanding supporting the relationship between $\mathrm{KE}$ "Ca ${ }^{2+}$ influx, increased" and KE "Mitochondrial dysfunction".

The increase in cytoplasmic $\mathrm{Ca}^{2+}$ can cause the activation of plasma membrane and endoplasmic reticulum (ER) $\mathrm{Ca}^{2+}$-ATPases that results in higher ATP demand. At the same time elevated $\mathrm{Ca}^{2+}$ can cause reduced levels of ATP by the direct uptake of the cation into the matrix that utilises the proton circuit and directly competes with mitochondrial ATP synthesis (reviewed in Nicholls, 2009).

$\mathrm{Ca}^{2+}$ overload besides of being detrimental to mitochondrial energy production can also induce mitochondrial ROS generation. A number of possible mechanisms have been suggested by which $\mathrm{Ca}^{2+}$ overload can increase ROS production including: 1) stimulated increase of metabolic rate by $\mathrm{Ca}^{2+}, 2$ ) stimulated nitric oxide production by $\left.\mathrm{Ca}^{2+}, 3\right) \mathrm{Ca}^{2+}$ induced cytochrome c dissociation, 4) $\mathrm{Ca}^{2+}$ induced cardiolipin peroxidation, 5) $\mathrm{Ca}^{2+}$ induced mitochondrial permeability transition pore (MPTP) opening with release of cytochrome c (leading to apoptosome formation and caspase-3 activation)and apoptosis inducing factor (AIF), decreased level of reduced glutathione (GSH), the antioxidative enzymes, and 6) $\mathrm{Ca}^{2+}$-calmodulin dependent protein kinase activation (reviewed in Peng and Jou, 2010; Gleichmann and Mattson, 2011). It is worth mentioning that mitochondrial ROS increase is capable of modulating $\mathrm{Ca}^{2+}$ dynamics causing further increase of $\mathrm{Ca}^{2+}$ levels.

The cytoplasmic and mitochondrial $\mathrm{Ca}^{2+}$ levels, the oxidative stress and the energy production are very closely inter-related. For example, decreased (or lack) of ATP production can affect the function of plasma membrane $\mathrm{Ca}^{2+}$ pump activity causing $\mathrm{Ca}^{2+}$ overload, oxidative stress and further restriction in ATP generating capacity (reviewed in Nicholls, 2009). Prolonged oxidative stimuli cause further mitochondrial dysfunction, including the decrease of mitochondrial transmembrane potential $(\Delta \Psi \mathrm{m})$, further overload of mitochondrial calcium, and opening of mitochondrial permeability transition pore (MPTP) (Choi et al., 2013). 
Mitochondria within dendrites are elongated and perform extensive directional and lateral movement at physiological conditions. Under an excitotoxic exposure to glutamate, mitochondrial movement has been found to be inhibited and mitochondria change morphology becoming rounded and swollen. Although blocking mitochondrial ATP production is sufficient to inhibit mitochondrial movement (Rintoul et al., 2003), research has shown that the collapse of mitochondrial structure requires extracellular $\mathrm{Ca}^{2+}$ influx via NMDA receptors (Rintoul et al., 2003; Pivovarova et al., 2004; Shalbuyeva et al., 2006), suggesting that structural, mechanistic understanding is also available supporting this KER.

In neurons, the high mitochondrial content in axons and dendrites closely correlates with the high energy demand in these structures that is needed to pump the ions that underlie the generation of action potentials mediated by the electrochemical gradients (Attwell and Laughlin, 2001).

Empirical support for linkage

\section{Domoic acid (DomA)}

- DomA has been shown to cause a significant time- and concentration-dependent increase of ROS production in mouse cerebellar granule neurons (CGNs) and the maximal effect ( 2.5 fold increase) has been recorded $1 \mathrm{~h}$ after exposure (Giordano et al., 2006). The time course involved the measurement of oxidant-sensitive fluorescent dye DCFH2-DA from 15 to $120 \mathrm{~min}$ and the concentrations assessed are 1 and $10 \mu \mathrm{M}$ DomA (Giordano et al., 2006). ROS production is higher in Gclm (-/-) neurons lacking glutathione (21.97 pmol $\mathrm{DCF} / \mathrm{mg}$ of protein) than in Gclm (+/+) neurons $(10.23 \mathrm{pmol} \mathrm{DCF} / \mathrm{mg}$ of protein) after treatment with DomA (Giordano et al., 2006). In the same study, treatment of mouse CGNs with 1 and $10 \mu \mathrm{M}$ DomA elevate intracellular $\mathrm{Ca}^{2+}$ by approximately 5 or 8 fold higher compared to controls, respectively (Giordano et al., 2006), showing that the cytosolic $\mathrm{Ca}^{2+}$ increase (upstream KE) is higher than the down-stream KE (ROS production due to mitochondrial dysfunction).

- The same research group has measured intracellular $\mathrm{Ca}^{2+}$ concentrations at different time points after DomA treatment of cerebellar granule neuons (CGNs) from mice lacking the modifier subunit of glutamate-cysteine ligase (Gclm). Glutamate-cysteine ligase (Glc) catalyzes the first and rate-limiting step in glutathione (GSH) biosynthesis. CGNs from Gclm (-/-) mice have very low levels of GSH and are 10-fold more sensitive to DomAinduced toxicity than CGNs from Gclm (+/+) mice (Giordano et al., 2007). The low DomA dose $(0.1 \mu \mathrm{M})$ causes a small and delayed increase in intracellular $\mathrm{Ca}^{2+}$ concentration with a full recovery by $20 \mathrm{~min}$, whereas, the higher DomA concentration (10 $\mu \mathrm{M})$ causes a rapid and robust increase in intracellular $\mathrm{Ca}^{2+}$, which lasts even after $25 \mathrm{~min}$, revealing that upstream $\mathrm{KE}$ (cytosolic $\mathrm{Ca}^{2+}$ ) happens much earlier than the down-stream $\mathrm{KE}$ (ROS production). Interestingly, in the same study the mitochondrial $\mathrm{Ca}^{2+}$ concentration has been measured and showed that $0.1 \mu \mathrm{M}$ DomA causes an increase by about 3-fold, with a delay of about $15 \mathrm{~min}$, but no changes in mitochondrial $\mathrm{Ca}^{2+}$ concentration have been observed at $10 \mu \mathrm{M}$ of DomA (Giordano et al., 2007).

- Mice injected intraperitoneally (i.p.) at a dose of $2 \mathrm{mg} / \mathrm{kg}$ of DomA once a day for 3 weeks show markedly lowered (1.5-2 fold) respiratory control ratio, mitochondrial ATP 
production rate, electron transport chain activity and cellular ATP concentration (Lu et al., 2012; Wu et al., 2013). In Lu et al. 2013 the same treatment in mice causes a 3 or 1.8-fold decrease in electron transport chain activity and mitochondrial ATP content, respectively. Western blot analysis demonstrates that the level of complex I-V proteins (mt-Nd6, Sdha, Uqcrc1, mt-Co1, and Atp5a1) in the hippocampus of DomA-treated mice is significantly decreased compared to controls (Lu et al., 2012). In the same study, DomA treatment significantly elevate the expression of NOX subunits (p47phox and gp91phox), of ROS (3.2 fold increase) and protein carbonyl levels, as well as the production of superoxide anion radicals ( $\mathrm{Lu}$ et al., 2012). Under the same experimental conditions an increase of NOX activity ( 2 fold) has been reported in the hippocampus of DomA-treated mice (Lu et al., 2013). Furthermore, DomA exposure induces ER stress by increasing the levels of phosphorylated pancreatic endoplasmic reticulum-resident kinase (PERK), eukaryotic translation initiation factor $2 \alpha$ (eIF2 $\alpha$ ), glucose-regulated protein 78, C/EBP homologous protein $(\mathrm{CHOP}), \mathrm{X}$-box binding protein 1 (XBP1) and the phosphorylated inositolrequiring enzyme 1 (IRE1) (Lu et al., 2012).

- DomA (0.75 mg/kg body weight) administered intravenously in adult rats reveals no remarkable changes at the mRNA level of iNOS expression but demonstrates significant induction in the expression of iNOS protein level in the neurons and astrocytes of the hippocampus (Ananth et al., 2003). 


\begin{tabular}{|c|c|c|c|c|c|c|c|c|c|c|c|}
\hline Stressor & $\begin{array}{c}\text { Experimental } \\
\text { Model }\end{array}$ & $\begin{array}{c}\text { Tested } \\
\text { concentrations }\end{array}$ & Exposure route & $\begin{array}{l}\text { Exposure } \\
\text { duration }\end{array}$ & $\begin{array}{c}\text { Increased } \\
\text { intracelllular Ca }^{2+} \\
\text { levels (KE up) }\end{array}$ & $\begin{array}{c}\text { Mitochondrial } \\
\text { dysfunction (KE } \\
\text { down) }\end{array}$ & References & $\begin{array}{c}\text { Temporal } \\
\text { Relationship }\end{array}$ & \begin{tabular}{|c|} 
Dose- \\
response \\
relationship
\end{tabular} & Incidence & Comments \\
\hline DomA & $\begin{array}{l}\text { Mouse } \\
\text { cerebellar } \\
\text { granule } \\
\text { neurons } \\
\text { (CGNs) from } \\
\text { Gclm (+/+) and } \\
\text { Gclm (-/-) } \\
\text { mice }\end{array}$ & 0.01 to $10 \mu \mathrm{M}$ & & $\begin{array}{l}\text { Time } \\
\text { course }(15 \\
\text { to } 120 \\
\text { min) }\end{array}$ & $\begin{array}{l}5 \text { and } 8 \text { fold increase } \\
\text { of }\left[\mathrm{Ca}^{2+}\right] \mathrm{i} \text { compared } \\
\text { to controls. }\end{array}$ & $\begin{array}{l}\text { Increase in ROS } \\
\text { production }(2.5 \\
\text { fold) after } 1 \mathrm{~h} \text { of } \\
\text { exposure. }\end{array}$ & $\begin{array}{l}\text { Giordano et } \\
\text { al., } 2006\end{array}$ & & Same dose & $\begin{array}{l}\text { Incidence of } \\
\text { upstream KE } \\
\text { (Increased } \\
\text { intracelllular Ca } \\
{ }^{2+} \text { levels) is } \\
\text { higher than the } \\
\text { incidence of } \\
\text { downstream KE } \\
\text { (mitochondrial } \\
\text { dysfunction) }\end{array}$ & \\
\hline DomA & $\begin{array}{l}\text { CGNs from } \\
\operatorname{Gclm}(+/+) \text { and } \\
\operatorname{Gclm}(-/-) \\
\text { mice }\end{array}$ & 0.01 to $10 \mu \mathrm{M}$ & & $\begin{array}{l}\text { Time } \\
\text { course }(0 \\
\text { to } 25 \mathrm{~min})\end{array}$ & $\begin{array}{l}0.1 \mu \mathrm{M} \text { domoic acid } \\
\text { caused a small and } \\
\text { delayed increase ( } 4 \\
\text { fold) in }\left[\mathrm{Ca}^{2+}\right] \mathrm{i}, \text { with } \\
\text { a full recovery by } 20 \\
\text { min. In contrast, the } \\
\text { higher concentration } \\
\text { of domoic acid } \\
(10 \mu \mathrm{M}) \text { caused a } \\
\text { rapid and robust } \\
\text { increase ( } 8 \text { fold) in } \\
{\left[\mathrm{Ca}^{2+}\right] \mathrm{i} \text {, which was }} \\
\text { still elevated after } 25 \\
\text { min. } 0.1 \mu \mathrm{M} \text { DomA } \\
\left.\text { increases [Ca }{ }^{2+}\right] \mathrm{M} \text { by } \\
\text { about } 3 \text { fold, with a } \\
\text { delay of about } 15 \\
\text { min. In contrast, no } \\
\text { changes in }\left[\mathrm{Ca}{ }^{2+}\right] \mathrm{M} \\
\text { were observed } \\
\text { following } 10 \mu \mathrm{M} \text { of } \\
\text { DomA. }\end{array}$ & $\begin{array}{l}\text { DomA }(0.1 \mu \mathrm{M}) \\
\text { caused a } 3 \text { fold } \\
\text { increase in DHR } \\
\text { fluorescence, } \\
\text { which accumulates } \\
\text { in mitochondria } \\
\text { and fluoresces } \\
\text { when oxidized by } \\
\text { ROS or reactive } \\
\text { nitrogen species. } \\
\text { This occurred } \\
\text { between } 1 \text { and } 2 \mathrm{~h} \\
\text { and was higher in } \\
\text { CGNs from Gclm } \\
(-/-) \text { mice. }\end{array}$ & $\begin{array}{l}\text { Giordano et } \\
\text { al., } 2007\end{array}$ & Yes & Same dose & & \\
\hline
\end{tabular}




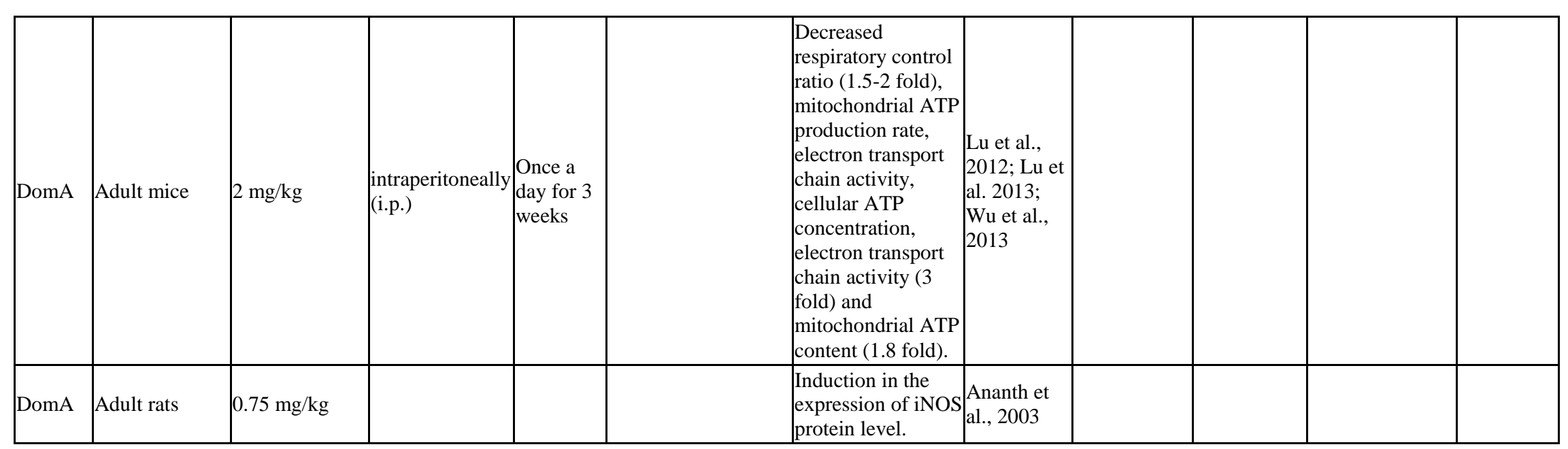


Gap of knowledge: there are no studies available showing that Glufosinate (GLF) increases intracellular calcium levels causing mitochondrial dysfunction. Such a mechanism of toxicity can be assumed taking into consideration that GLF neurotoxicity is induced by direct activation of NMDARs.

\section{Quantitative Understanding of the Linkage}

It was established that the dendritic calcium levels could underlie the differential vulnerability of C57BL/6 (resistant to kainite excitotoxicity) and C57BL/10 strains (vulnerable) mice to triggered neuronal degeneration induced by increased $\mathrm{Ca}^{2+}$ levels (Shuttleworth and Connor, 2001). A striking difference was found in dendrite calcium responses in hippocampus after kainate exposure of C57BL/6 (resistant to kainite excitotoxicity) and C57BL/10 strains (vulnerable). $\mathrm{Ca}^{2+}$ signals in distal dendrites were large in C57BL/10 neurons, and, if a threshold concentration of $1.5 \mathrm{uM}$ was reached, a region of sustained high $\mathrm{Ca}^{2+}$ was established in the distal dendritic tree. This region then served as an initiation site for a degenerative cascade, producing high $\mathrm{Ca}^{2+}$ levels that slowly spread to involve the entire neuron and led to neuronal cell death. Dendritic $\mathrm{Ca}^{2+}$ signals in C57BL/6 neurons were much smaller and did not trigger these propagating secondary responses. Neurons from both strains had similar membrane properties and responded to kainate with intense action potential firing. Degenerative $\mathrm{Ca}^{2+}$ responses were seen in both strains if soma calcium level was above $1.5 \mathrm{uM}$ serving as a threshold that if exceeded, it triggered excitotoxic neuronal cell death (Shuttleworth and Connor, 2001).

\section{Evidence Supporting Taxonomic Applicability}

DomA toxicosis in California sea lions (CSLs, Zalophus californianus) is accompanied by increased expression of markers of oxidative stress such as malondialdehyde (MDA) and 3nitrotyrosine (NT) in neurons (Madl et al., 2014).

In Atlantic salmon (Salmo salar), the cognition function has been investigated after exposure to sub-lethal doses of DomA (6 mg DA/kg bw). In addition, 14C-2-deoxyglucose has been injected i.m. to measure brain metabolic activity by autoradiography. The three brain regions investigated telencephalon, optic tectum and cerebellum have demonstrated a clear increase of metabolic activity in DomA exposed brains (Bakke and Horsberg, 2007).

\section{References}

Ananth, C., P. Gopalakrishnakone and C. Kaur (2003), Protective role of melatonin in domoic acidinduced neuronal damage in the hippocampus of adult rats, Hippocampus, Vol. 13, pp. 375-387.

Attwell, D. and S.B. Laughlin (2001), An energy budget for signaling in the grey matter of the brain. Journal of Cerebral Blood Flow \& Metabolism, Vol. 2, pp. 1133-1145.

Bakke, M.J. and T.E. Horsberg (2007), Effects of algal-produced neurotoxins on metabolic activity in telencephalon, optic tectum and cerebellum of Atlantic salmon (Salmo salar), Aquatic Toxicology, Vol. 85, pp. 96-103.

Choi, I.Y. et al. (2013), 4-hydroxy-2(E)-Nonenal facilitates NMDA-Induced Neurotoxicity via Triggering Mitochondrial Permeability Transition Pore Opening and Mitochondrial Calcium Overload, Experimental Neurobiology, Vol. 22, pp. 200-207. 
Giordano, G. et al. (2006), Neurotoxicity of domoic Acid in cerebellar granule neurons in a genetic model of glutathione deficiency, Molecular Pharmacology, Vol. 70, pp. 2116-2126.

Giordano, G. et al. (2007), Glutathione levels modulate domoic acid-induced apoptosis in mouse cerebellar granule cells, Toxicological Sciences, Vol. 100, pp. 433-444.

Gleichmann, M. and M.P. Mattson (2011), Neuronal calcium homeostasis and dysregulation, Antioxidants \& Redox Signaling, Vol. 14, pp. 1261-1273.

Lu, J. et al. (2012), Purple sweet potato color attenuates domoic acid-induced cognitive deficits by promoting estrogen receptor- $\alpha$-mediated mitochondrial biogenesis signaling in mice, Free Radical Biology and Medicine, Vol. 52, pp. 646-659.

Lu, J. et al. (2013), Troxerutin counteracts domoic acid-induced memory deficits in mice by inhibiting CCAAT/enhancer binding protein $\beta$-mediated inflammatory response and oxidative stress, Journal of Immunology, Vol. 190, pp. 3466-3479.

Madl, J.E. et al. (2014), Oxidative stress and redistribution of glutamine synthetase in California sea lions (Zalophus californianus) with domoic acid toxicosis, Journal of Comparative Pathology, Vol. 150, pp. 306-315.

Nicholls, D.G. (2009), Mitochondrial calcium function and dysfunction in the central nervous system, Biochimica et Biophysica Acta, Vol. 1787, pp. 1416-1424.

Peng, T.I. and M.J. Jou (2010), Oxidative stress caused by mitochondrial calcium overload Annals of the New York Academy of Sciences, Vol. 201, pp. 183-188.

Pivovarova, N.B. et al. (2004), Excitotoxic calcium overload in a subpopulation of mitochondria triggers delayed death in hippocampal neurons, Journal of Neuroscience, Vol. 24, pp. 5611-5622.

Rintoul, G.L. et al. (2003), Glutamate decreases mitochondrial size and movement in primary forebrain neurons, Journal of Neuroscience, Vol. 23, pp. 7881-7888.

Shalbuyeva, N. et al. (2006), Calcium-dependent spontaneously reversible remodeling of brain mitochondria, Journal of Biological Chemistry, Vol. 281, pp. 37547-37558.

Shuttleworth, C.W. and J.A. Connor (2001), Strain-dependent differences in calcium signaling predict excitotoxicity in murine hippocampal neurons, Journal of Neuroscience, Vol. 21, No. 12, pp- 42254236.

Wu, D.M. et al. (2013), Ursolic acid improves domoic acid-induced cognitive deficits in mice, Toxicology and Applied Pharmacology, Vol. 271, pp. 127-136.

\section{Mitochondrial dysfunction, N/A leads to Cell death, N/A}

How Does This Key Event Relationship Work

ROS generation is known to activate different pathways leading to apoptosis, whereas depletion of energy production induces necrotic cell death.

Weight of Evidence

Biological Plausibility

There is functional mechanistic understanding supporting this relationship between KE Mitochondrial dysfunction and KE Cell death.

ROS are known to stimulate a number of events and pathways that lead to apoptosis, triggered by ROS-induced ER stress signalling pathway (Lu et al., 2014), caspase-dependent and -independent 
apoptosis (Zhou et al., 2015) and mitogen-activated protein kinase (MAPK) signal transduction pathways (reviewed in Cuadrado and Nebreda, 2010; Harper and LoGrasso, 2001).

Depletion of cellular ATP is known to cause switching from apoptotic cell death triggered by a variety of stimuli to necrotic cell death (Leist et al., 1997) suggesting that the level of intracellular ATP determines whether the cell dies by apoptosis or necrosis (Nicotera et al., 1998). There is strong proof that apoptosis requires energy, as it is a highly regulated process involving a number of ATP-dependent steps such as caspase activation, enzymatic hydrolysis of macromolecules, chromatin condensation, bleb formation and apoptotic body formation (Richter et al., 1996).

Empirical support for linkage

\section{Domoic acid (DomA)}

In the case of DomA, in vitro studies have shown that oxidative stress and oxidative stressinduced activation of the stress-activated protein kinase/c-jun-N-terminal kinase (SAPK/JNK) pathway is implicated in DomA-mediated apoptosis (Giordano et al., 2007; 2008; 2009; Lu et al., 2010). In vivo findings also show that ROS-mediated cognitive deficits are associated with apoptosis induced by activation of the JNK pathway (Lu et al., 2010; 2011).

- Mice injected intraperitoneally (i.p.) with DomA at a dose of $2 \mathrm{mg} / \mathrm{kg}$ once a day for 4 weeks have shown increase ( 6 fold) of the TUNEL positive cells in the hippocampus. In the same study they have found that indicators of mitochondria function are markedly decreased (1.5-2 fold) and ROS levels are elevated (3.2 fold) (Lu et al., 2012). DomA treatment also significantly decreases the levels of bcl-2, procaspase- 3 and procaspase- 12 and increases the activation of caspase- 3 and caspase-12 in the mouse hippocampus (Lu et al., 2012). The same research group using similar dose but longer exposure (4 weeks), has shown increase of ROS ( 3 fold) and NOX ( 2 fold) and elevated ( 8 fold) mean value of TUNEL-positive cells in the hippocampal CA1 sections as well as increase in the activation of caspase- 8 and caspase- 3 (Wu et al., 2012). These two in vivo studies (Lu et al., 2012; Wu et al., 2012) suggest that both KEs are affected in response to the same dose of DomA and exposure paradigm and that the incidence of downstream KE (cell death) is higher than the incidence of upstream KE (mitochondrial dysfunction).

- The cell viability has been measured by the MTT reduction assay in mouse cerebellar granule neurons (CGNs) and showed that the IC50 values for DomA are $3.4 \mu \mathrm{M}$ in Gclm $(+/+)$ neurons and $0.39 \mu \mathrm{M}$ in Gclm (-/-) neurons (Giordano et al., 2006). This reduction in cell viability has been demonstrated to be concentration dependent after studying a range of concentrations of DomA $(0.01$ and $10 \mu \mathrm{M})$. Giordano et al. 2007 have shown that 100 $\mathrm{nM}$ DomA induce apoptotic cell death in mouse CGNs. In a follow-up study, the same research group has performed a dose response evaluation and showed that even $50 \mathrm{nM}$ DomA exposure for $1 \mathrm{~h}$ (after washout and additional $23 \mathrm{~h}$ incubation) can induce apoptosis in CGNs derived from Gclm $(+/+)$ mice, whereas neurons from Gclm $(-/-)$ mice that have very low levels of glutathione are more sensitive as $10 \mathrm{nM}$ DomA induces a significant increase in apoptotic cell number (Giordano et al., 2009). The maximal apoptosis ( 5 fold compared to controls) in CGNs from both genotypes has been caused by $100 \mathrm{nM}$ DomA. Interestingly, 1 and $10 \mu \mathrm{M}$ DomA still cause significant apoptosis in both cell types but to a lesser extent compared to $100 \mathrm{nM}$ DomA. ROS have been measured 
only at the dose of $100 \mathrm{nM}$ DomA, 30 min after treatment and showed 2.5 fold increase compared to controls in CGNs from Gclm (+/+) mice (Giordano et al., 2009). Caspase 3 activity has also been measured after $12 \mathrm{~h}$ with prior $1 \mathrm{~h}$ exposure to $100 \mathrm{nM}$ DomA and found to be increased ( 2.2 fold). In the same study, DomA (100 nM) caused a significant decrease $(25 \%)$ of Bcl-2 protein levels after $6 \mathrm{~h}$ exposure. Again these in vitro studies (Giordano et al., 2007; 2009) suggest that both KEs are affected by the same dose of DomA and that the incidence of KE down (cell death) is higher than the incidence of KE up (mitochondrial dysfunction). Furthermore, KE up (mitochondrial dysfunction) happens earlier (30 min) than KE down (cell death) that takes place 12-24 h later.

- Mixed cortical cultures have been treated with 3, 5, 10, or $50 \mu \mathrm{M}$ DomA for a variety of exposure durations (10 min, $30 \mathrm{~min}, 1 \mathrm{~h}$, or $2 \mathrm{~h}$ ), after which DomA is washed out and the culture medium is replaced with conditioned medium from unexposed sister cultures (Qiu et al., 2006). In all cases neuronal death has been measured $24 \mathrm{~h}$ following the beginning of exposure. The results show that DomA-induced neuronal death is determined by both concentration and duration of exposure. After a 10-min exposure, $50 \mu \mathrm{M}$ DomA produces marked neuronal death of $47.4 \%$, whereas by $1 \mathrm{~h}$ of treatment, the same concentration produces near maximal neuronal death but longer exposures do not increase neuronal death further (Qiu et al., 2006). Regarding time dependence, this study shows that low concentrations of DomA produces more neuronal death if this is measured $22 \mathrm{~h}$ after the washout than if measured immediately after DomA treatment, while higher concentrations of DomA $(20-100 \mu \mathrm{M})$ produces equivalent degrees of neuronal death when measured at these two time points (Qiu et al., 2006). Based on these findings, three EC50 exposure paradigms have been established, which represent weak/prolonged exposure $(3 \mu \mathrm{M} / 24 \mathrm{~h})$, moderate concentration and duration of exposure $(10 \mu \mathrm{M} / 2 \mathrm{~h})$, and strong/brief exposure (50 $\mu \mathrm{M} / 10 \mathrm{~min}$ ) (Qiu et al., 2006).

- The mean concentration of DomA in rat brain samples obtained at $30 \mathrm{~min}$ after intraperitoneal (i.p.) administration of $1 \mathrm{mg} / \mathrm{kg}$ DA is $7.2 \mathrm{ng} / \mathrm{g}$ (Tsunekawa et al., 2013). These animals have been examined and revealed after histopathological analysis neuronal shrinkage and cell death, including an increase in the percentage of TUNEL positive cells at 24 hours $(8.3 \%)$ and after 5 days $(19.0 \%)$ compared to the controls $(1.7 \%)$ (Tsunekawa et al., 2013). In the same study, indirectly it has been shown that ROS production is associated with these histopathological findings by using the radical scavenger edaravone (Tsunekawa et al., 2013).

- Brain slices from 8-day-old pups have been treated after 2 weeks with $10 \mu \mathrm{M}$ DomA and assessed with propidium iodine (PI) stain to determine cellular damage (Erin and Billingsley, 2004). A time course has been carried out and viable cultures have been visualized 12, 24, 48 and $92 \mathrm{~h}$ after DomA treatment. Changes in PI uptake has been detected after $24 \mathrm{~h}$ post-treatment and at $4 \mathrm{~h}$ the average fold-increase of PI uptake (DomA/control) was 14.5 and 34.5 in cortex and hippocampus, respectively (Erin and Billingsley, 2004). In the same study, incubation of brain slices with DomA induces degradation of $\alpha$-spectrin to the $120-\mathrm{kDa}$ product after $18 \mathrm{~h}$ of treatment but no change has been noted after $12 \mathrm{~h}$ incubation, whereas caspase 3 activity results have not been conclusive (Erin and Billingsley, 2004). 
- Using observations of neuronal viability and morphology, exposure of cultured murine cortical neurones to DomA for $24 \mathrm{~h}$ have shown to induce concentration-dependent neuronal cell death and the EC50 determined to be $75 \mu \mathrm{M}$ (Larm et al., 1997). 


\begin{tabular}{|c|c|c|c|c|c|c|c|c|c|c|c|}
\hline Stressor & $\underset{\text { Model }}{\text { Experimental }}$ & $\begin{array}{c}\text { Tested } \\
\text { concentrations }\end{array}$ & Exposure route & $\begin{array}{l}\text { Exposure } \\
\text { duration }\end{array}$ & $\begin{array}{c}\text { Mitochondrial } \\
\text { dysfunction (KE } \\
\text { up) }\end{array}$ & $\begin{array}{l}\text { Cell death (KE } \\
\text { down) }\end{array}$ & References & $\begin{array}{c}\text { Temporal } \\
\text { Relationship }\end{array}$ & $\begin{array}{c}\text { Dose- } \\
\text { response } \\
\text { relationship }\end{array}$ & Incidence & Comments \\
\hline DomA & $\left|\begin{array}{l}\text { 16-month-old } \\
\text { male ICR mice }\end{array}\right|$ & $2 \mathrm{mg} / \mathrm{kg}$ & $\begin{array}{l}\text { Intraperitoneally } \\
\text { (i.p.) }\end{array}$ & $\begin{array}{l}\text { Once a day } \\
\text { for } 4 \text { weeks }\end{array}$ & $\begin{array}{l}\text { Indicators of } \\
\text { mitochondrial } \\
\text { function were } \\
\text { markedly } \\
\text { decreased (1.5-2 } \\
\text { fold) and ROS } \\
\text { levels were } \\
\text { elevated ( } 3.2 \text { fold). }\end{array}$ & $\begin{array}{l}\text { The mean of } \\
\text { TUNEL positive } \\
\text { cells in the } \\
\text { hippocampus was } \\
\text { increased ( } 6 \text { fold). } \\
\text { The levels of bcl-2, } \\
\text { procaspase- } 3 \text { and } \\
\text { procaspase- } 12 \text { were } \\
\text { significantly } \\
\text { decreased and the } \\
\text { activation of } \\
\text { caspase- } 3 \text { and } \\
\text { caspase- } 12 \text { in the } \\
\text { mouse } \\
\text { hippocampus were } \\
\text { increased. }\end{array}$ & $\begin{array}{l}\text { Lu et al., } \\
2012\end{array}$ & & Same dose & \begin{tabular}{|l} 
Incidence of \\
downstream \\
KE (cell death) \\
is higher than \\
the incidence \\
of upstream \\
KE \\
(mitochondrial \\
dysfunction)
\end{tabular} & \\
\hline DomA & $\begin{array}{l}\text { 16-month-old } \\
\text { male ICR mice }\end{array}$ & $2 \mathrm{mg} / \mathrm{kg}$ & i.p. & $\begin{array}{l}\text { Once a day } \\
\text { for } 4 \text { weeks }\end{array}$ & $\begin{array}{l}\text { ROS levels were } \\
\text { increased ( } 3 \text { fold }) \\
\text { and NOX ( } 2 \text { fold }) .\end{array}$ & $\begin{array}{l}\text { The mean value of } \\
\text { TUNEL-positive } \\
\text { cells in the } \\
\text { hippocampal CA1 } \\
\text { sections was } \\
\text { elevated ( } 8 \text { fold) } \\
\text { and the activation } \\
\text { of caspase- } 8 \text { and } \\
\text { caspase- } 3 \text { was } \\
\text { increased. }\end{array}$ & $\begin{array}{l}\text { Wu et al., } \\
2012\end{array}$ & & Same dose & \begin{tabular}{|l} 
Incidence of \\
downstream \\
KE (cell death) \\
is higher than \\
the incidence \\
of upstream \\
KE \\
(mitochondrial \\
dysfunction)
\end{tabular} & \\
\hline DomA & \begin{tabular}{|l} 
Mouse \\
cerebellar \\
granule \\
neurons \\
(CGNs) from \\
Gclm $(+/+)$ \\
and Gclm \\
$(-/-)$ mice
\end{tabular} & 0.01 to $10 \mu \mathrm{M}$ & & $\begin{array}{l}\text { Time course } \\
\text { (15 to } 120 \\
\text { min) }\end{array}$ & $\begin{array}{l}\text { DomA caused a } \\
\text { significant time- } \\
\text { and concentration- } \\
\text { dependent increase } \\
\text { in ROS } \\
\text { production. The } \\
\text { higher ROS } \\
\text { production ( } 2.5 \\
\text { fold increase) was } \\
\text { recorded after } 1 \mathrm{~h} \\
\text { of exposure. }\end{array}$ & $\begin{array}{l}\text { IC50 values for } \\
\text { DomA were } 3.4 \\
\mu \mathrm{M} \text { in Gclm }(+/+) \\
\text { neurons and } 0.39 \\
\mu \mathrm{M} \text { in Gclm }(-/-) \\
\text { neurons based on } \\
\text { MTT assay after } 24 \\
\mathrm{~h} \text { of exposure. }\end{array}$ & $\begin{array}{l}\text { Giordano } \\
\text { et al., } 2006\end{array}$ & $\begin{array}{l}\text { KE up } \\
\text { (mitochondrial } \\
\text { dysfunction) } \\
\text { happens earlier } \\
\text { than KE down } \\
\text { (cell death) }\end{array}$ & Same doses & & \\
\hline
\end{tabular}




\begin{tabular}{|c|c|c|c|c|c|c|c|c|c|c|c|}
\hline Stressor & $\begin{array}{c}\text { Experimental } \\
\text { Model }\end{array}$ & $\begin{array}{c}\text { Tested } \\
\text { concentrations }\end{array}$ & Exposure route & $\begin{array}{l}\text { Exposure } \\
\text { duration }\end{array}$ & $\begin{array}{c}\text { Mitochondrial } \\
\text { dysfunction (KE } \\
\text { up) }\end{array}$ & $\begin{array}{c}\text { Cell death (KE } \\
\text { down) }\end{array}$ & References & \begin{tabular}{c|} 
Temporal \\
Relationship
\end{tabular} & $\begin{array}{c}\text { Dose- } \\
\text { response } \\
\text { relationship }\end{array}$ & Incidence & Comments \\
\hline DomA & $\begin{array}{l}\text { CGNs from } \\
\text { Gclm }(+/+) \\
\text { and Gclm } \\
(-/-) \text { mice }\end{array}$ & 0.01 to $10 \mu \mathrm{M}$ & & $\begin{array}{l}\text { Time course } \\
(0 \text { to } 180 \\
\text { min })\end{array}$ & $\begin{array}{l}\text { DomA }(0.1 \mu \mathrm{M}) \\
\text { caused a } 3 \text { fold } \\
\text { increase in DHR } \\
\text { fluorescence, } \\
\text { which accumulates } \\
\text { in mitochondria } \\
\text { and fluoresces } \\
\text { when oxidized by } \\
\text { ROS or reactive } \\
\text { nitrogen species. } \\
\text { This occurred } \\
\text { between } 1 \text { and } 2 \mathrm{~h} \\
\text { and was higher in } \\
\text { CGNs from Gclm } \\
(-/-) \text { mice. }\end{array}$ & $\begin{array}{l}0.1 \mu \mathrm{M} \text { DomA was } \\
\text { maximally } \\
\text { effective in } \\
\text { inducing apoptosis, } \\
\text { while a } \\
\text { concentration } \\
\text { causing high } \\
\text { toxicity }(10 \mu \mathrm{M}) \\
\text { induced very } \\
\text { limited apoptosis, } \\
24 \mathrm{~h} \text { after exposure. }\end{array}$ & $\begin{array}{l}\text { Giordano } \\
\text { et al., } 2007\end{array}$ & $\begin{array}{l}\text { KE up } \\
\text { (mitochondrial } \\
\text { dysfunction) } \\
\text { happens earlier } \\
(1-2 \text { h) than } \\
\text { KE down (cell } \\
\text { death) that } \\
\text { occurs after } 24 \\
\text { h }\end{array}$ & Same doses & & \\
\hline DomA & $\begin{array}{l}\text { CGNs from } \\
\text { Gclm }(+/+) \\
\text { and Gclm } \\
(-/-) \text { mice }\end{array}$ & 0.01 to $10 \mu \mathrm{M}$ & & $\begin{array}{l}\text { For ROS: } \\
\text { 30min, } \\
\text { Apoptosis: } \\
12-24 \text { h. }\end{array}$ & $\begin{array}{l}\text { ROS levels were } \\
\text { measured only at } \\
\text { the dose of } 100 \\
\text { nM DomA } 30 \text { min } \\
\text { after treatment in } \\
\text { CGNs from Gclm } \\
(+/+) \text { mice and } \\
\text { showed } 2.5 \text { fold } \\
\text { increase compared } \\
\text { to controls . }\end{array}$ & \begin{tabular}{|l|} 
A dose response \\
study that showed \\
that even $50 \mathrm{nM}$ \\
DomA exposure \\
for $1 \mathrm{~h}$ (after \\
washout and \\
additional $23 \mathrm{~h}$ \\
incubation) can \\
induce apoptosis in \\
CGNs from Gclm \\
(+/+) mice, \\
whereas neurons \\
from Gclm $(-/-)$ \\
mice that have very \\
low levels of \\
glutathione were \\
more sensitive as \\
10 nM DomA \\
induced a \\
significant increase \\
in apoptotic cells \\
number .The \\
maximal apoptosis \\
(5 fold compared to
\end{tabular} & \begin{tabular}{|l|} 
Giordano \\
et al., 2009
\end{tabular} & $\begin{array}{l}\text { KE up } \\
\text { (mitochondrial } \\
\text { dysfunction) } \\
\text { happens earlier } \\
\text { (30 min) than } \\
\text { KE down (cell } \\
\text { death) that take } \\
\text { place } 12-24 \mathrm{~h} \\
\text { later }\end{array}$ & Same dose & $\begin{array}{l}\text { Incidence of } \\
\text { downstream } \\
\text { KE (cell death) } \\
\text { is higher than } \\
\text { the incidence } \\
\text { of upstream } \\
\text { KE } \\
\text { (mitochondrial } \\
\text { dysfunction) }\end{array}$ & \\
\hline
\end{tabular}




\begin{tabular}{|c|c|c|c|c|c|c|c|c|c|c|c|}
\hline Stressor & $\begin{array}{c}\text { Experimental } \\
\text { Model }\end{array}$ & $\begin{array}{c}\text { Tested } \\
\text { concentrations }\end{array}$ & Exposure route & $\begin{array}{l}\text { Exposure } \\
\text { duration }\end{array}$ & \begin{tabular}{|c|} 
Mitochondrial \\
dysfunction (KE \\
up)
\end{tabular} & $\begin{array}{l}\text { Cell death (KE } \\
\text { down) }\end{array}$ & References & $\begin{array}{c}\text { Temporal } \\
\text { Relationship }\end{array}$ & $\begin{array}{c}\text { Dose- } \\
\text { response } \\
\text { relationship }\end{array}$ & Incidence & Comments \\
\hline & & & & & & $\begin{array}{l}\text { controls) in CGNs } \\
\text { from both } \\
\text { genotypes was } \\
\text { caused by } 100 \mathrm{nM} \\
\text { DomA. } 1 \text { and } 10 \\
\mu \mathrm{M} \text { DA caused } \\
\text { significant } \\
\text { apoptosis in both } \\
\text { cell types but to } \\
\text { less extend } \\
\text { compared to } 100 \\
\text { nM DomA. } \\
\text { Caspase } 3 \text { activity } \\
\text { after } 12 \mathrm{~h} \text { with } \\
\text { prior } 1 \text { h exposure } \\
\text { to } 100 \text { nM DomA } \\
\text { found to be } \\
\text { increased (2.2 } \\
\text { fold). DomA (100 } \\
\text { nM) caused a } \\
\text { significant decrease } \\
\text { (25\%) of Bcl-2 } \\
\text { protein levels after } \\
6 \mathrm{~h} \text { from exposure. }\end{array}$ & & & & & \\
\hline
\end{tabular}




\begin{tabular}{|c|c|c|c|c|c|c|c|c|c|c|c|}
\hline Stressor & $\begin{array}{c}\text { Experimental } \\
\text { Model }\end{array}$ & $\begin{array}{c}\text { Tested } \\
\text { concentrations }\end{array}$ & Exposure route & $\begin{array}{l}\text { Exposure } \\
\text { duration }\end{array}$ & $\begin{array}{c}\text { Mitochondrial } \\
\text { dysfunction (KE } \\
\text { up) }\end{array}$ & $\begin{array}{c}\text { Cell death (KE } \\
\text { down) }\end{array}$ & References & $\begin{array}{c}\text { Temporal } \\
\text { Relationship }\end{array}$ & $\begin{array}{c}\text { Dose- } \\
\text { response } \\
\text { relationship }\end{array}$ & Incidence & Comments \\
\hline DomA & $\begin{array}{l}\text { Mixed cortical } \\
\text { cultures } \\
\text { obtained from } \\
\text { pregnant } \\
\text { Holtzman rats } \\
\text { on embryonic } \\
\text { day (ED) 16- } \\
18\end{array}$ & $\begin{array}{l}3,5,10, \text { or } 50 \\
\mu \mathrm{M}\end{array}$ & & $\begin{array}{l}10 \text { min, } 30 \\
\text { min, } 1 \text { h or } 2 \\
\text { h, after } \\
\text { which } \\
\text { DomA was } \\
\text { washed out } \\
\text { and the } \\
\text { culture } \\
\text { medium } \\
\text { replaced } \\
\text { with } \\
\text { conditioned } \\
\text { medium } \\
\text { from } \\
\text { unexposed } \\
\text { sister } \\
\text { cultures. }\end{array}$ & & $\begin{array}{l}\text { EC50 exposure } \\
\text { paradigms have } \\
\text { been established, } \\
\text { which represent } \\
\text { weak/prolonged } \\
\text { exposure }(3 \mu \mathrm{M} / 24 \\
\text { h), moderate } \\
\text { concentration and } \\
\text { duration exposure } \\
(10 \mu \mathrm{M} / 2 \mathrm{~h}), \text { and } \\
\text { strong/brief } \\
\text { exposure }(50 \\
\mu \mathrm{M} / 10 \mathrm{~min}) \text {. }\end{array}$ & $\begin{array}{l}\text { Qiu et al., } \\
2006\end{array}$ & & & & \\
\hline
\end{tabular}




\begin{tabular}{|c|c|c|c|c|c|c|c|c|c|c|c|}
\hline Stressor & $\begin{array}{c}\text { Experimental } \\
\text { Model }\end{array}$ & $\begin{array}{c}\text { Tested } \\
\text { concentrations }\end{array}$ & Exposure route & $\begin{array}{c}\text { Exposure } \\
\text { duration }\end{array}$ & \begin{tabular}{|c|} 
Mitochondrial \\
dysfunction (KE \\
up)
\end{tabular} & $\begin{array}{l}\text { Cell death (KE } \\
\text { down) }\end{array}$ & References & $\begin{array}{c}\text { Temporal } \\
\text { Relationship }\end{array}$ & $\begin{array}{c}\text { Dose- } \\
\text { response } \\
\text { relationship }\end{array}$ & Incidence & Comments \\
\hline DomA & $\begin{array}{l}\text { Rat rain slices } \\
\text { from 8-day-old } \\
\text { pups }\end{array}$ & $10 \mu \mathrm{M}$ & & $\begin{array}{l}\text { Time course } \\
(12,24,48 \\
\text { and } 92 \mathrm{~h}) \\
\text { after DomA } \\
\text { treatment. }\end{array}$ & & \begin{tabular}{|l} 
PI uptake \\
(DomA/control) \\
was 14.5 and 34.5 \\
in cortex and \\
hippocampus, \\
respectively. \\
Degradation of $\alpha-$ \\
spectrin to the $120-$ \\
kDa product after \\
18 h of DomA \\
treatment was \\
noted but no \\
change was noted \\
after $12 \mathrm{~h}$ \\
incubation, \\
whereas caspase 3 \\
activity results \\
were not \\
conclusive.
\end{tabular} & \begin{tabular}{|l} 
Erin and \\
Billingsley, \\
2004
\end{tabular} & & & & \\
\hline DomA & $\begin{array}{l}\text { Cultured } \\
\text { murine cortical } \\
\text { neurones }\end{array}$ & & & & & $\begin{array}{l}\text { DomA induces } \\
\text { concentration- } \\
\text { dependent neuronal } \\
\text { cell death and the } \\
\text { EC50 determined } \\
\text { to be } 75 \mu \mathrm{M} \text {. } \\
\end{array}$ & $\begin{array}{l}\text { Larm et al., } \\
1997\end{array}$ & & & & \\
\hline
\end{tabular}


Gap of knowledge: there are no studies showing that GLF induces neuronal cell death through mitochondrial dysfunction.

Uncertainties or Inconsistencies

Rats have been administered with DA at the dose of $1.0 \mathrm{mg} / \mathrm{kg}$ for 15 days. The histochemical analysis of hippocampus from these animals has revealed no presence of apoptotic bodies and no Fluoro-Jade B positive cells (Schwarz et al., 2014).

\section{Quantitative Understanding of the Linkage}

The experiments describing semi-quantitative effects for this KER is described in the table above.

\section{Evidence Supporting Taxonomic Applicability}

Neuronal necrosis has been noted in sea lions accidentally exposed to DomA (Silvagni et al., 2005) that correlated well with the histopathological findings previously reported in experimental studies (Tryphonas et al., 1990).

\section{References}

Cuadrado, A. and A.R. Nebreda (2010), Mechanisms and functions of p38 MAPK signalling, Biochemical Journal, Vol. 429, No. 3, pp. 403-417.

Erin, N. and M.L. Billingsley (2004), Domoic acid enhances Bcl-2-calcineurin-inositol-1,4,5-trisphosphate receptor interactions and delayed neuronal death in rat brain slices, Brain Research, Vol. 1014, pp. 45-52.

Giordano, G. et al. (2006), Neurotoxicity of domoic Acid in cerebellar granule neurons in a genetic model of glutathione deficiency, Molecular Pharmacology, Vol. 70, pp. 2116-2126.

Giordano, G. et al. (2007), Glutathione levels modulate domoic acid-induced apoptosis in mouse cerebellar granule cells, Toxicological Sciences, Vol. 100, pp. 433-444.

Giordano, G. et al (2008), Apoptosis induced by domoic acid in mouse cerebellar granule neurons involves activation of p38 and JNK MAP kinases, Neurochemistry International, Vol. 52, pp. 1100-1105.

Giordano, G. et al. (2009), Muscarinic receptors prevent oxidative stress-mediated apoptosis induced by domoic acid in mouse cerebellar granule cells, Journal of Neurochemistry, Vol. 109, pp. 525-538.

Harper, S.J. and P. LoGrasso (2001), Signalling for survival and death in neurones: the role of stressactivated kinases, JNK and p38, Cellular Signalling, Vol. 13, No. 5, pp. 299-310.

Larm, J.A., P.M. Beart and N.S. Cheung (1997), Neurotoxin domoic acid produces cytotoxicity via kainate- and AMPA-sensitive receptors in cultured cortical neurones, Neurochemistry International, Vol. 31, pp. 677-682.

Leist, M. et al. (1997), Intracellular adenosine triphosphate (ATP) concentration: a switch in the decision between apoptosis and necrosis, Journal of Experimental Medicine, Vol. 185, pp. 1481-1486.

Lu, J. et al. (2010), Purple sweet potato color alleviates D-galactose-induced brain aging in old mice by promoting survival of neurons via PI3K pathway and inhibiting cytochrome C-mediated apoptosis, Brain Pathology, Vol. 20, pp. 598-612.

Lu, J. et al. (2011), Troxerutin protects against high cholesterol-induced cognitive deficits in mice, Brain, Vol. 134, pp. 783-797. 
Lu, J. et al. (2012), Purple sweet potato color attenuates domoic acid-induced cognitive deficits by promoting estrogen receptor- $\alpha$-mediated mitochondrial biogenesis signaling in mice, Free Radical Biology and Medicine, Vol. 52, No. 3, pp. 646-659.

Lu, T.H. et al. (2014), Chloroacetic acid triggers apoptosis in neuronal cells via a reactive oxygen speciesinduced endoplasmic reticulum stress signaling pathway, Chemico-Biological Interactions, Vol. 225, pp. 1-12.

Nicotera, P., M. Leist and E. Ferrando-May (1998), Intracellular ATP, a switch in the decision between apoptosis and necrosis, Toxicology Letters, 1998, Vol. 102-103, pp. 139-142.

Qiu, S., C.W. Pak and M.C. Currás-Collazo (2006), Sequential involvement of distinct glutamate receptors in domoic acid-induced neurotoxicity in rat mixed cortical cultures: effect of multiple dose/duration paradigms, chronological age, and repeated exposure, Toxicological Sciences, Vol. 89, pp. 243-256.

Richter, C. et al. (1996), Control of apoptosis by the cellular ATP level, FEBS Letters, Vol. 378, pp. 107110.

Schwarz, M. et al. (2014), Low dose domoic acid influences spontaneous behavior in adult rats, Physiological research, Vol. 63, pp. 369-376.

Silvagni, P.A. et al. (2005), Pathology of Domoic Acid Toxicity in California Sea Lions (Zalophus californianus), Veterinary Pathology, Vol. 42, pp. 184-191.

Tryphonas, L. et al. (1990), Neuropathology of experimental domoic acid poisoning in non-human primates and rats, Canada diseases weekly report, Vol. Suppl 1E, pp. 75-81.

Tsunekawa, K. et al. (2013), Enhanced expression of WD repeat-containing protein 35 (WDR35) stimulated by domoic acid in rat hippocampus: involvement of reactive oxygen species generation and p38 mitogen-activated protein kinase activation, BMC Neuroscience, Vol. 14, pp. 4-16.

Wu, D.M. et al. (2012), Small interfering RNA-mediated knockdown of protein kinase C zeta attenuates domoic acid-induced cognitive deficits in mice, Toxicological Sciences, Vol. 128, pp. 209-222.

Zhou, Q. et al. (2015), Rotenone induction of hydrogen peroxide inhibits mTOR-mediated S6K1 and 4EBP1/eIF4E pathways, leading to neuronal apoptosis, Toxicological Sciences, Vol. 143, pp. 81-96.

\section{Cell death, N/A leads to Neurodegeneration, N/A}

How Does This Key Event Relationship Work

Weight of Evidence

Biological Plausibility

There is well established mechanistic understanding supporting the relationship between these two KEs.

Neurodegeneration in the strict sense of the word is referring to any pathological condition primarily affecting brain cell populations (Przedborski et al., 2003). At histopathological level, neurodegenerative conditions are described by neuronal death and reactive gliosis (Przedborski et al., 2003).

Empirical support for linkage

\section{Domoic acid (DomA)}


- Acute brain damage induced by DomA is characterised by neurodegenerative changes consisting of neuronal shrinkage, vacuolization of the cytoplasm, cell drop out, edema, microvacuolation of the neuropil and hydropic cytoplasmic swelling of resident astrocytes (reviewed in Pulido, 2008). These histopathological changes can be identified within structures of the limbic system, in hippocampus, in the CA3, CA4 or hilus of the dentate gyrus (DG) (reviewed in Pulido, 2008). Other brain areas known to be affected by DomA include: the olfactory bulb, the piriform and entorhinal cortices, the lateral septum, the subiculum, the arcuate nucleus and several amygdaloid nuclei. The area postrema is another target for DomA toxicity as it has been identified in both rodents and non-human primates, providing a possible explanation of emetic symptoms (nausea, retching, and/or vomiting) induced by DomA. There has been an effort to map and create a 3-D reconstruction of DomA-induced neurodegeneration in the mouse brain demonstrating that the affected areas include the olfactory bulb, septal areas and the limbic system (Colman et al., 2005; Barlow et al., 2004).

- Female Sprague-Dawley rats dosed once intraperitoneally (i.p.) with 0, 1, 2, 4, or 7.5 DomA mg $/ \mathrm{kg}$ of body weight have been euthanized after $24 \mathrm{~h}$ and their nervous system has been examined for microscopic alterations revealing neuronal degeneration and vacuolation of the neurophil in the limbic and the olfactory systems (Tryphonas et al., 1990).

- The mean of TUNEL positive cells in the hippocampus is increased ( 6 fold) in mice injected intraperitoneally (i.p.) at a dose of 2 DomA mg/kg once a day for 3 weeks (Lu et al., 2012). However, the same treatment protocol does not cause any neurodegeneration (Lu et al., 2012). In contrast, when the same treatment has been prolonged for one more week (total 4 weeks), the mean values of NeuN-positive cells in the hippocampal CA1 sections of DomA-treated cells decreases by 3 fold compared to controls ( $\mathrm{Lu}$ et al., 2012). This study shows that the incidence of upstream KE (cell death) is higher than the incidence of downstream KE (neurodegeneration) and that upstream KE (cell death) precedes downstream KE (neurodegeneration).

- The bcl-2 and bax mRNA levels in the hippocampus are significantly increased at $16 \mathrm{~h}$ and gradually decreased at $24 \mathrm{~h}$ following the administration of DomA $(0.75 \mathrm{mg} / \mathrm{kg}$ body weight) in adult rats. In situ hybridization analysis reveals complete loss of bcl-2, bax, and caspase-3 mRNA at $24 \mathrm{~h}$ after DA administration in the region of the hippocampus, whereas neurodegeneration by Nissl staining is detected at the same time point but has been reported to be more pronounced after 5 days (Ananth et al., 2001). This study demonstrates that both KEs occur after exposure to the same dose of DomA and that the upstream KE (cell death) occurs earlier than the downstream KE (neurodegeneration).

- Adult rats received i.p. injections with DomA $1.0 \mathrm{mg} / \mathrm{kg} / \mathrm{h}$ until animals exhibited first motor seizures. After a week of recovery, aggressive behaviors and motor seizures of the animals have been monitored for $3 \mathrm{~h}$ twice a week. After 12 weeks, animals were euthanised and brains have been examined for indications of cell loss by using thionine (Nissl) staining, which highlights the cell bodies of all living neurons. In piriform cortex a reduced cell density has been noted in the medial layer 3 (1.3-1.8 fold decrease compared to controls), an area that shows also prominent amino cupric staining (stain that assesses 
neuronal damage) (Tiedeken and Ramsdell, 2013a). The same research group has reported that by following the above experimental procedure but sacrificing the rats 7 days after DomA-induced seizures intense and widespread silver reaction product in the olfactory bulb occurs, whereas minor or no evident damage is found in the hippocampus (Tiedeken et al., 2013b).

- Injection of DomA $0.5 \mathrm{mg} / \mathrm{kg}$, i.p. to adult C57BL/6 male mice results in loss of $32 \%$ and $30 \%$ of Nissl-stained neurons in hilus and CA1 pyramidal layer of the hippocampus, respectively, compared to control mice when they are sacrificed $7 \mathrm{~d}$ after the administration (Antequera et al., 2012).

- The severity and extent of hippocampal neuronal degeneration varies significantly depending on the dose of DomA $(1 \mu \mathrm{M}$ to $1 \mathrm{mM})$ that is tested after microinjection to adult male Sprague Dawley rats (Qiu and Currás-Collazo, 2006). In rats dosed with $1 \mathrm{mM}$ DomA and sacrificed after $24 \mathrm{~h}$, histopathological analysis using toluidine blue staining has revealed extensive neuronal damage throughout the ipsilateral hippocampal structure. Shrunken, disorganized and densely stained neurons of irregular shape have been identified throughout CA1, CA2, CA3 pyramidal layer as well as the dentate gyrus hilus and granule cells layer. For the $100 \mu \mathrm{M}$ group animals, CA1 neuronal changes have been less prominent, whereas $10 \mu \mathrm{M}$ and $1 \mu \mathrm{M}$ DomA have not produced any resolvable histopathological changes (Qiu and Currás-Collazo, 2006).

- Adult male rats treated with $2 \mathrm{mg} / \mathrm{kg}$ DomA i.p. have been sacrificed after $3 \mathrm{~d}$ and showed that the silver stain that is used to assess neurodegeneration clearly distinguishes treated from control animals, whereas a number of other markers has failed to do so (Scallet et al., 2005). The same results have been found after even longer exposure times ( $7 \mathrm{~d}$ ) to DomA (Appel et al., 1997).

- Male Wistar rats have been given a single i.v. injection of DA $(0.75 \mathrm{mg} / \mathrm{kg})$ in the right external jugular vein and brain sections have been stained with Nissl stain at $5 \mathrm{~d}$ after DomA administration. Histopathological analysis has revealed a large number of darkly stained shrunken neurons in the hippocampus (Ananth et al., 2003). However, complete absence of hippocampal neurons has been observed in CA1 and CA3 regions in DomA treated animals at 3 months after DomA administration (Ananth et al., 2003).

- In 2-3 week old hippocampal slice cultures, derived from 7 day old rat pups, DomA (0.1$100 \mu \mathrm{M})$ has been added to the culture medium and neurodegeneration in the fascia dentata (FD), CA3 and CA1 hippocampal subfields has been measured. The CA1 region appears to be most sensitive to DomA, with an EC50 value of $6 \mu \mathrm{M}$ DomA after estimating the PI-uptake at $72 \mathrm{~h}$ (Jakobsen et al., 2002).

- Cynomolgus monkeys have been given i.v. a range of DomA doses from 0.25 to 4.0 $\mathrm{mg} / \mathrm{kg}$. Silver staining of brain sections have revealed that doses in the range of 0.5-1.0 $\mathrm{mg} / \mathrm{kg}$ produces a small area of silver grains restricted to axons of the hippocampal CA2 stratum lucidum, whereas higher concentrations produce degenerating axons and cell bodies (Slikker et al., 1998). The same research group treated (i.v.) adult monkeys with DomA at one of a range of doses from 0.25 to $4 \mathrm{mg} / \mathrm{kg}$. After a week, silver staining has 
demonstrated degenerating axons and cell bodies that are restricted to CA2 stratum lucidum at a lower doses (0.5 to 1.0 DomA mg/kg). Doses of more than $1.0 \mathrm{mg} / \mathrm{kg}$ cause widespread damage to pyramidal neurons and axon terminals of CA4, CA3, CA2, CA1, and subiculum subfields of the hippocampus. However, when DomA is orally administered to cynomolgus monkeys at doses of $0.5 \mathrm{mg} / \mathrm{kg}$ for 15 days and then at 0.75 $\mathrm{mg} / \mathrm{kg}$ for another 15 days no histopathoogical changes in the brain are detected (Truelove et al., 1997).

- In humans, autopsy of individuals intoxicated by DomA reveal brain damage characterised by neuronal necrosis and in the hippocampus and the amygdaloid nucleus (Pulido, 2008). The thalamus and subfrontal cortex are damaged only in some patients suffering from Amnesic Shellfish Poisoning (ASP). The detailed examination of one patient intoxicated by DomA has revealed complete neuronal loss in the CA1, CA3 and CA4 regions, whereas moderate loss is seen in the CA2 region (Cendes et al., 1995). Non-severe neuronal loss has been detected in amygdale, overlying cortex, the dorsal and ventral septal nuclei, the secondary olfactory areas, and the nucleus accumbens (Cendes et al., 1995). 


\begin{tabular}{|c|c|c|c|c|c|c|c|c|c|c|c|}
\hline Stressor & $\begin{array}{c}\text { Experimental } \\
\text { Model }\end{array}$ & $\begin{array}{c}\text { Tested } \\
\text { concentrations }\end{array}$ & $\begin{array}{c}\text { Exposure } \\
\text { route }\end{array}$ & $\begin{array}{l}\text { Exposure } \\
\text { duration }\end{array}$ & $\begin{array}{l}\text { Cell death } \\
\text { (KE up) }\end{array}$ & $\begin{array}{c}\text { Neurodegeneratio } \\
\text { n (KE down) }\end{array}$ & $\begin{array}{c}\text { Reference } \\
\mathrm{s}\end{array}$ & $\begin{array}{c}\text { Temporal } \\
\text { Relationship }\end{array}$ & $\begin{array}{c}\text { Dose- } \\
\text { response } \\
\text { relationship }\end{array}$ & Incidence & Comments \\
\hline DomA & $\begin{array}{l}\text { Female } \\
\text { Sprague- } \\
\text { Dawley rats }\end{array}$ & $\begin{array}{l}0,1,2,4, \text { or } 7.5 \\
\text { DomA mg } / \mathrm{kg}\end{array}$ & $\begin{array}{l}\text { Intraperit } \\
\text { oneally } \\
\text { (i.p.) }\end{array}$ & $\begin{array}{l}\text { Euthanised } \\
\text { after } 24 \mathrm{~h}\end{array}$ & & \begin{tabular}{|l|} 
Neuronal \\
degeneration and \\
vacuolation of the \\
neuropil in the \\
limbic and the \\
olfactory systems
\end{tabular} & $\begin{array}{l}\text { Tryphonas } \\
\text { et al., } 1990\end{array}$ & & & & \\
\hline DomA & $\left|\begin{array}{l}\text { 16-month-old } \\
\text { male ICR mice }\end{array}\right|$ & $2 \mathrm{mg} / \mathrm{kg}$ & i.p. & $\begin{array}{l}\text { Once a day } \\
\text { for } 3 \text { or } 4 \\
\text { weeks }\end{array}$ & \begin{tabular}{|l|} 
The mean of \\
TUNEL \\
positive cells \\
in the \\
hippocampus \\
was increased \\
(6 fold). The \\
levels of bcl-2, \\
procaspase-3 \\
and \\
procaspase-12 \\
were \\
significantly \\
decreased and \\
the activation \\
of caspase-3 \\
and caspase-12 \\
in the mouse \\
hippocampus \\
were \\
increased.
\end{tabular} & $\begin{array}{l}\text { The mean OD of } \\
\text { NeuN } \\
\text { immunoreactivity } \\
\text { in the } \\
\text { hippocampus of } \\
\text { mice decreased (3 } \\
\text { fold) indicating } \\
\text { significant neuron } \\
\text { loss by apoptosis, } \\
\text { which is one of the } \\
\text { pathological } \\
\text { hallmarks of } \\
\text { neurodegeneration }\end{array}$ & $\begin{array}{l}\text { Lu et al., } \\
2012\end{array}$ & $\begin{array}{l}\text { Upstream KE } \\
\text { (cell death) } \\
\text { precedes } \\
\text { downstream } \\
\text { KE } \\
\text { (neurodegenera } \\
\text { tion) }\end{array}$ & Same dose & $\begin{array}{l}\text { Incidence of } \\
\text { upstream KE } \\
\text { (cell death) is } \\
\text { higher than the } \\
\text { incidence of } \\
\text { downsteam KE } \\
\text { (neurodegenerat } \\
\text { ion) }\end{array}$ & $\begin{array}{l}\text { Mice treated with } \\
\text { DomA once a day } \\
\text { for } 3 \text { weeks } \\
\text { showed that } \\
\text { apoptosis was } \\
\text { increased. } \\
\text { However, the } \\
\text { same treatment } \\
\text { protocol did not } \\
\text { cause any } \\
\text { neurodegeneratio } \\
\text { n. In contrast, } \\
\text { when the same } \\
\text { treatment has } \\
\text { been prolonged } \\
\text { for one more } \\
\text { week (total } 4 \\
\text { weeks) induced } \\
\text { marked neuron } \\
\text { loss. }\end{array}$ \\
\hline
\end{tabular}




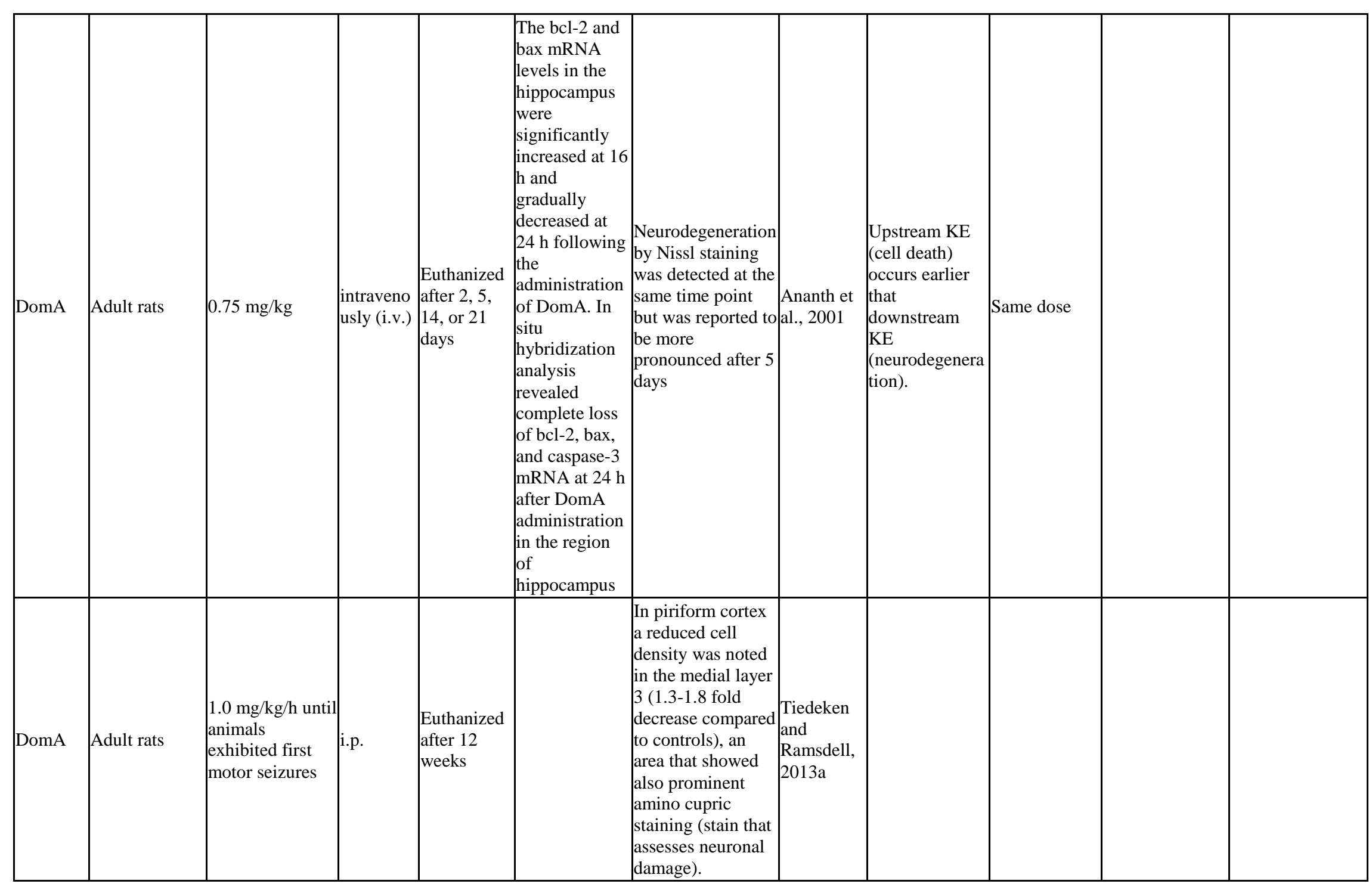




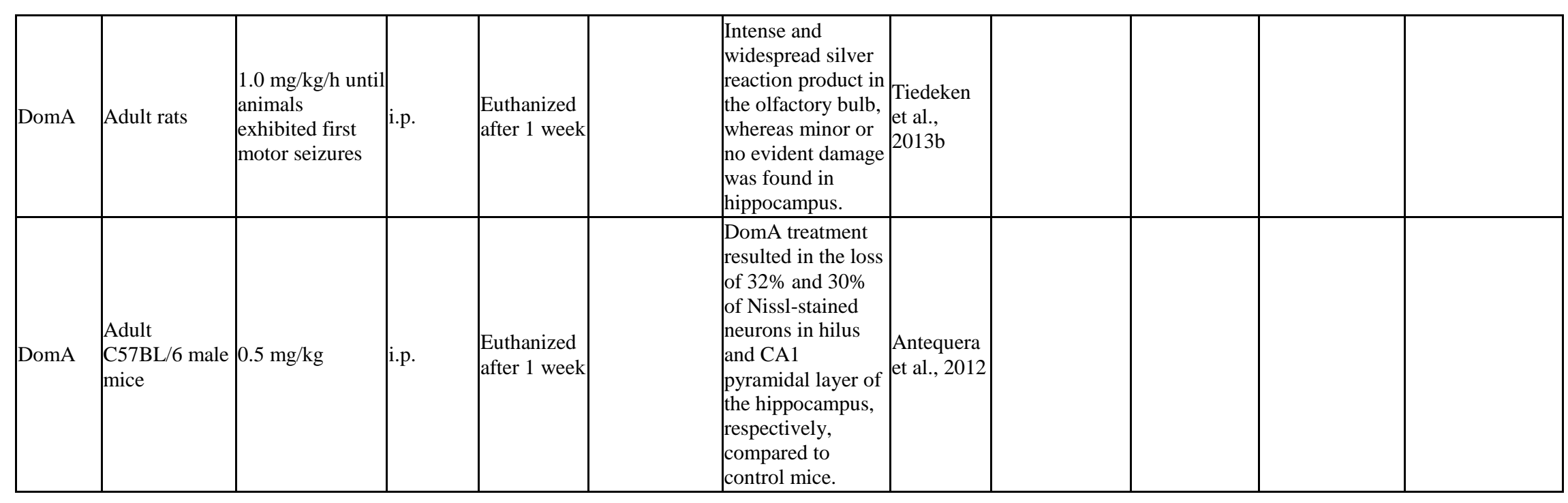




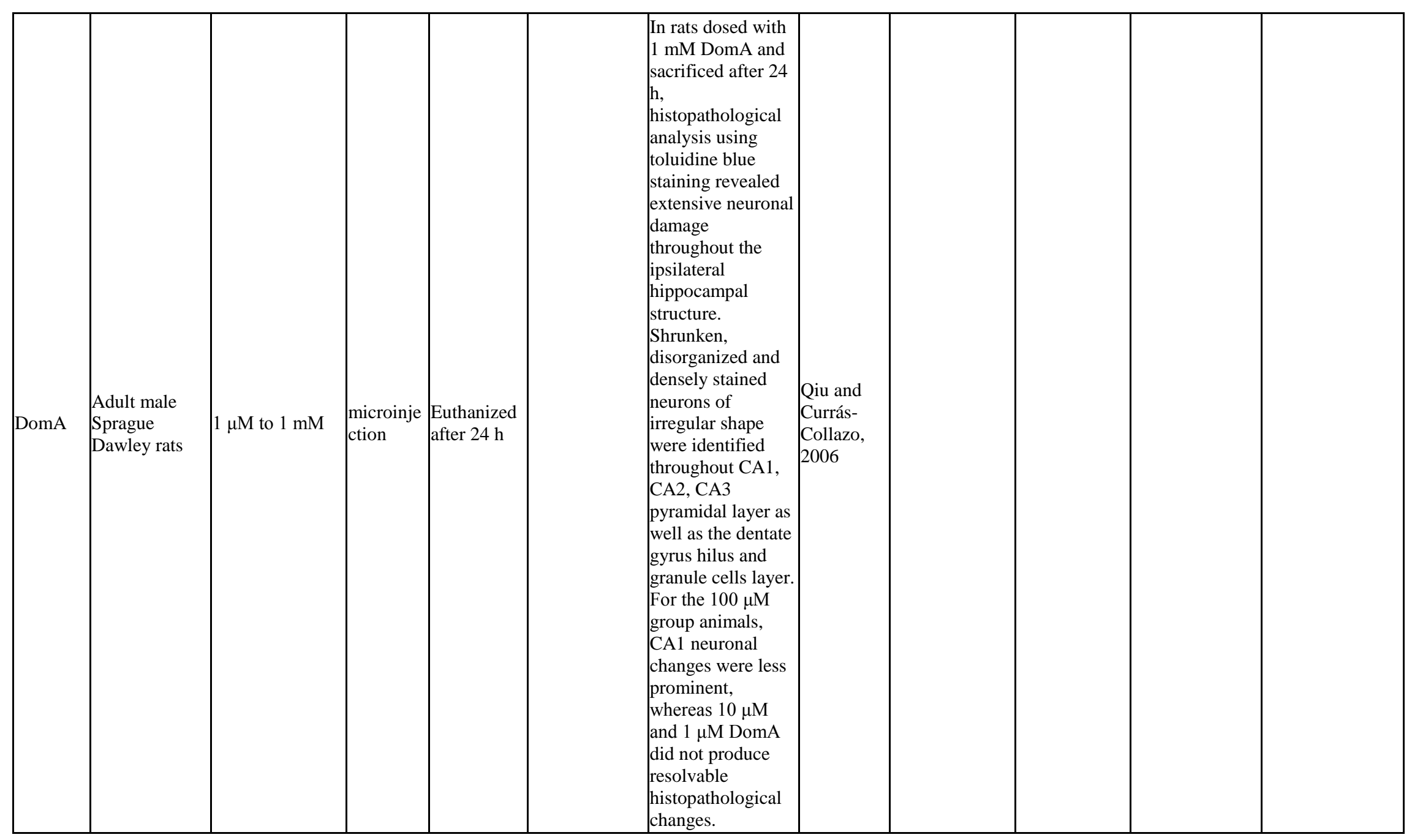




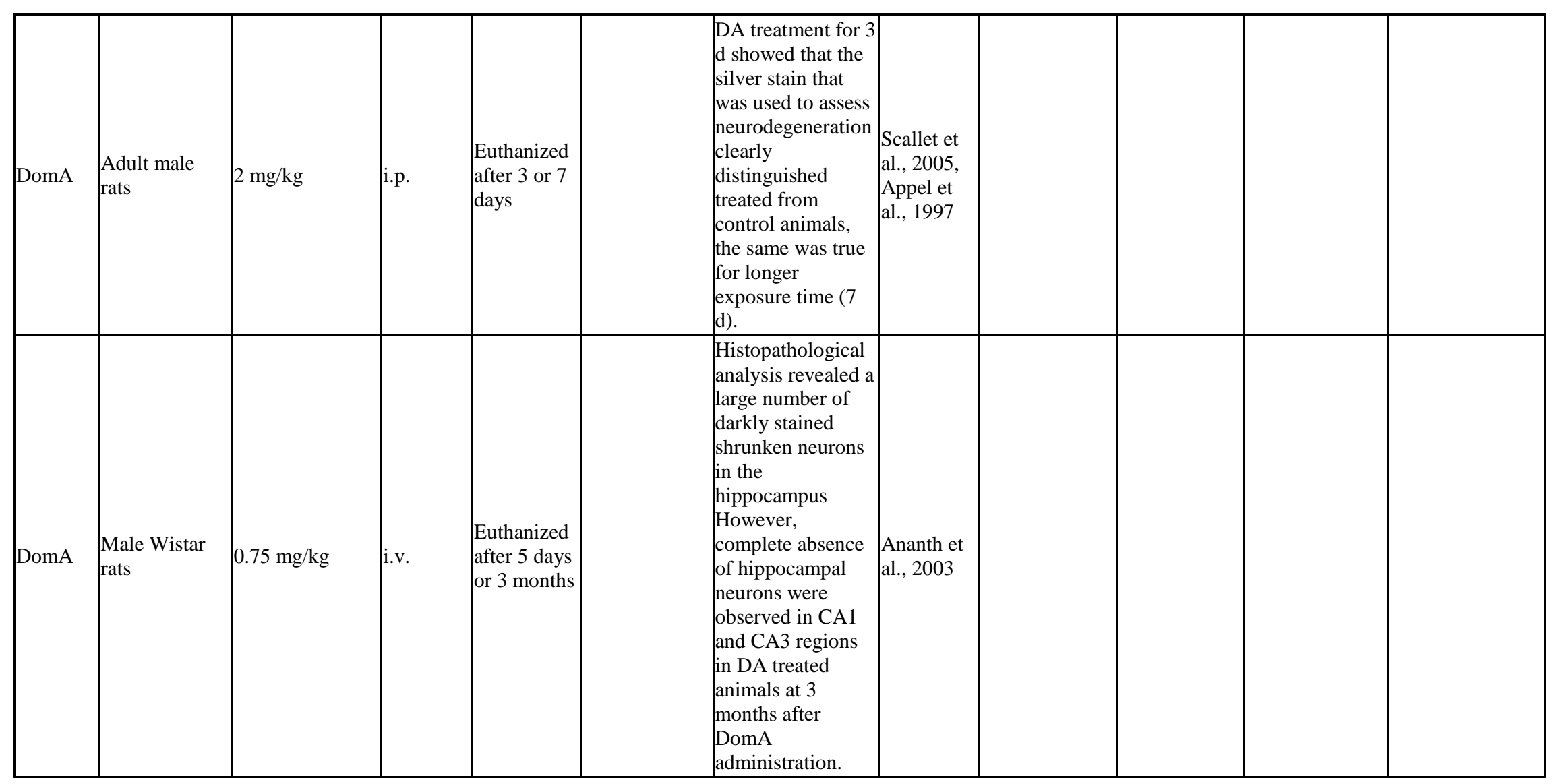




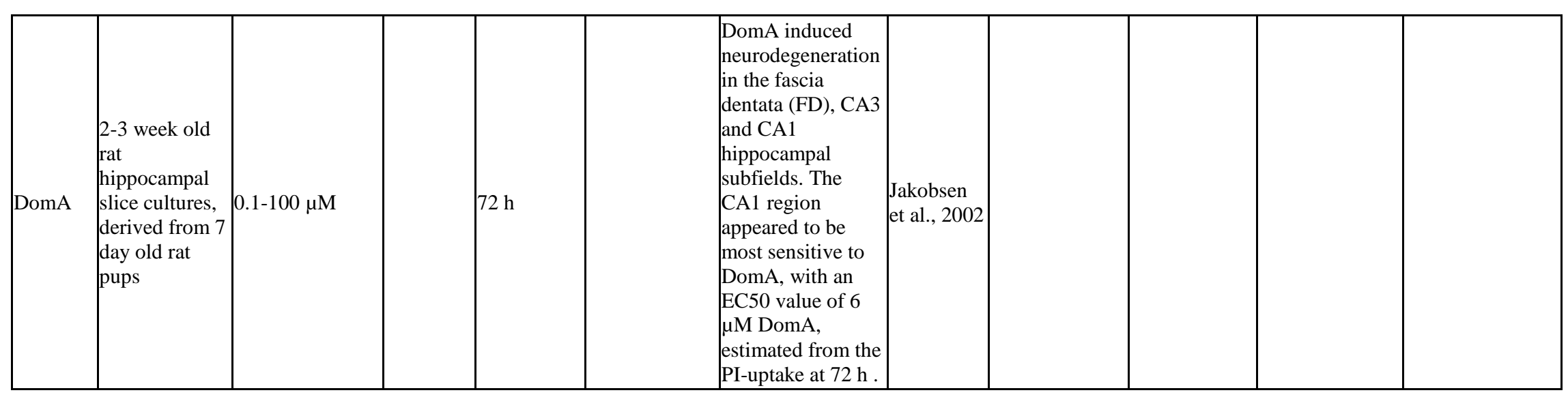




$$
\text { (n) }
$$


Gap of knowledge: there are no studies showing that GLF-induced cell death leads to neurodegeneration.

Uncertainties or Inconsistencies

Zebrafish has been exposed for 36-weeks to DomA and has shown no excitotoxic neuronal death and no histopathological lesions in glutamate-rich brain areas (Hiolski et al., 2014).

Administration of DomA (9.0 mg DomA kg(-1) bw, i.p.) to Sparus aurata (seabream) leads to measurement of $0.61,0.96$, and $0.36 \mathrm{mg}$ DomA $\mathrm{kg}(-1)$ of brain tissue at 1,2 and 4 hours. At this dose but also at lower concentrations (0.45 and $0.9 \mathrm{mg} \operatorname{DomA} \operatorname{kg}(-1)$ bw) no major permanent brain damage has been detected (Nogueira et al., 2010). Leopard sharks possess the molecular target for DomA but it has been shown to be resistant to doses of DomA that can cause neurotoxicity to other vertebrates, suggesting the presence of some protective mechanism (Schaffer et al., 2006).

All these reports support the view that there is possible a species specific susceptibility to DomA toxicity.

\section{Quantitative Understanding of the Linkage}

The experiments describing semi quantitative effects for this KER are provided in the table above.

\section{Evidence Supporting Taxonomic Applicability}

There is an overall agreement regarding the histopathology of the brain lesions related to acute DomA neurotoxicity across certain species. Data derived from humans, rodents, non-human primates and sea lions suggest that common neudegeneration features in selected brain areas are found despite the fact that study design, estimated exposure, processing of samples and history of event may differ (Pulido, 2008).

Furthermore, the distribution of brain damage by DomA has also been established by magnetic resonance imaging microscopy (MRM) for both human and rat, demonstrating similar distribution as that described by histopathological studies (Pulido, 2008).

It is important to notice that human sensitivity to DomA exposure is well documented in the published literature and seems to be much higher than in other species (Lefebvre and Robertson 210; Barlow et al., 2004). In 1987 in Canada, more than 200 people became acutely ill after ingesting of mussels contaminated with DomA. The outbreak resulted in 20 hospitalisations and four deaths. Clinical effects observed included gastrointestinal symptoms and neurotoxic effects such as hallucinations, memory loss and coma. For this reason, the condition was termed amnesic shellfish poisoning (Barlow et al., 2004). The neurotoxic properties of domoic acid result in neuronal degeneration and necrosis in specific regions of the hippocampus (Teitelbaum et al., 1990).

\section{References}

Ananth, C. et al. (2001), Domoic acid-induced neuronal damage in the rat hippocampus: changes in apoptosis related genes (bcl-2, bax, caspase-3) and microglial response, Journal of Neuroscience Research, Vol. 66, pp. 177-190. 
Ananth, C., P. Gopalakrishnakone and C. Kaur (2003), Induction of inducible nitric oxide synthase expression in activated microglia following domoic acid (DA)-induced neurotoxicity in the rat hippocampus, Neuroscience Letters, Vol. 338, pp. 49-52.

Antequera, D. et al. (2012), Effects of a tacrine-8-hydroxyquinoline hybrid (IQM-622) on A $\beta$ accumulation and cell death: involvement in hippocampal neuronal loss in Alzheimer's disease, Neurobiology of Disease, Vol. 46, pp. 682-691.

Appel, N.M., S.I. Rapoport and J.P. O'Callaghan (1997), Sequelae of parenteral domoic acid administration in rats: comparison of effects on different anatomical markers in brain, Synapse, Vol. 25 , pp. 350-358.

Barlow, J.B. et al. (2004), Amnesic shellfish poison, Food and Chemical Toxicology, Vol. 42, No. 4, pp. 545-557.

Cendes, F. et al. (1995), Temporal lobe epilepsy caused by domoic acid intoxication: evidence for glutamate receptor-mediated excitotoxicity in humans, Annals of Neurology, Vol. 37, pp. 123-126.

Colman, J.R. et al. (2005), Mapping and reconstruction of domoic acid-induced neurodegeneration in the mouse brain, Neurotoxicology and Teratology, Vol. 27, pp. 753-767.

Hiolski, E.M. et al. (2014), Chronic low-level domoic acid exposure alters gene transcription and impairs mitochondrial function in the CNS, Aquatic Toxicology, Vol. 155, pp. 151-159.

Jakobsen, B., A. Tasker and J. Zimmer (2002), Domoic acid neurotoxicity in hippocampal slice cultures, Amino Acids, Vol. 23, pp. 37-44.

Lefebvre, K.A. and A. Robertson (2010), Domoic acid and human exposure risks: A review, Toxicon, Vol. 56, pp. 218-230.

Lu, J. et al. (2012), Purple sweet potato color attenuates domoic acid-induced cognitive deficits by promoting estrogen receptor- $\alpha$-mediated mitochondrial biogenesis signaling in mice, Free Radical Biology and Medicine, Vol. 52, No. 3, pp. 646-659.

Nogueira, I. et al. (2010), Toxic effects of domoic acid in the seabream Sparus aurata, Marine Drugs, Vol. 8, pp. 2721-2732.

Przedborski, S., M. Vila and V. Jackson-Lewis (2003), Neurodegeneration: What is it and where are we?, Journal of Clinical Investigation, Vol. 111, pp. 3-10.

Pulido, O.M. (2008), Domoic acid toxicologic pathology: a review, Marine Drugs, Vol. 6, pp. 180-219.

Qiu, S. and M.C. Currás-Collazo (2006), Histopathological and molecular changes produced by hippocampal microinjection of domoic acid. Neurotoxicology and Teratology, Vol. 28, pp. 354-362.

Scallet, A.C., L.C. Schmued and J.N. Johannessen (2005), Neurohistochemical biomarkers of the marine neurotoxicant, domoic acid, Neurotoxicology and Teratology, Vol. 27, pp. 745-752.

Schaffer, P. et al. (2006), Absence of neurotoxic effects in leopard sharks, Triakis semifasciata, following domoic acid exposure, Toxicon, Vol. 47, pp. 747-752.

Slikker, W.Jr., A.C. Scallet and D.W. Gaylor (1998), Biologically-based dose-response model for neurotoxicity risk assessment, Toxicology Letters, Vol. 102-103, pp. 429-433.

Teitelbaum, J.S. et al. (1990), Neurologic sequelae of domoic acid intoxication due to the ingestion of contaminated mussels, New England Journal of Medicine, Vol. 322, pp. 1781-1787.

Tiedeken, J.A., N. Muha and J.S. Ramsdell (2013a), A cupric silver histochemical analysis of domoic acid damage to olfactory pathways following status epilepticus in a rat model for chronic recurrent spontaneous seizures and aggressive behaviour, Toxicologic Pathology, Vol. 41, pp. 454-469.

Tiedeken, J.A. and J.S. Ramsdell (2013b), Persistent neurological damage associated with spontaneous recurrent seizures and atypical aggressive behavior of domoic acid epileptic disease, Toxicological Sciences, Vol. 133, pp. 133-143. 
Truelove, J. et al. (1997), 30-day oral toxicity study of domoic acid in cynomolgus monkeys: lack of overt toxicity at doses approaching the acute toxic dose, Natural Toxins, Vol. 5, pp. 111-114.

Tryphonas, L. et al. (1990), Acute neurotoxicity of domoic acid in the rat, Toxicologic Pathology, Vol. 18, pp. 1-9.

\section{Cell death, N/A leads to Neuroinflammation, N/A}

\section{How Does This Key Event Relationship Work}

The pioneering work of Kreutzberg and coworkers $(1995,1996)$ has shown that neuronal injury leads to neuroinflammation, with microglia and astrocyte reactivities. Several chemokines and chemokines receptors (fraktalkine, CD200) control neuron-microglia interactions and a loss of this control can trigger microglial reactivity (Blank and Prinz, 2013; Chapman et al., 2000; Streit et al., 2001). Upon injury causing neuronal death (mainly necrotic), signals termed DamageAssociated Molecular Patterns (DAMPs) are released by damaged neurons and promote microglial reactivity (Marin-Teva et al., 2011; Katsumoto et al., 2014; Ransohoff and Brown, 2014). Toll-like receptors (TLRs) are pattern-recognition receptors that recognise specific pathogen- and danger-associated molecular signatures (PAMPs and DAMPs) and subsequently initiate inflammatory and immune responses. Microglial cells express Toll-like receptors (TLRs), mainly TLR-2, which can detect neuronal cell death (for review, see Hayward and Lee, 2014). TLR-2 functions as a master sentry receptor to detect neuronal death and tissue damage in many different neurological conditions including nerve trans-section injury, traumatic brain injury and hippocampal excitotoxicity (Hayward and Lee, 2014). Astrocytes, the other cellular actor of neuroinflammation (Ranshoff and Brown, 2012) are also able to sense tissue injury via TLR-3 (Farina et al., 2007; Rossi, 2015).

Weight of Evidence

Biological Plausibility

It is widely accepted that cell/neuronal injury and death leads to neuroinflammation (microglial and astrocyte reactivities) is widely accepted.

Empirical support for linkage

\section{Domoic acid (DomA)}

- Astrogliosis is one of the histopathological findings revealed by the assessment of brains derived from patients diagnosed with Amnesic Shellfish Poisoning (ASP) (reviewed in Pulido, 2008). In a reference study, where the brain of a patient after acute DomA intoxication has been examined in great detail gliosis has been detected in the overlying cortex, dorsal and ventral septal nuclei, the secondary olfactory areas and the nucleus accumbens (Cendes et al., 1995). Reactive astrogliosis has also been confirmed in the sixth cortical layer and subjacent white matter in the orbital and lateral basal areas, the first and second temporal gyri, the fusiform gyrus, the parietal parasagittal cortex, and the insula (Cendes et al., 1995). 
- Adult rats have been assessed seven days after the administration of DomA $(2.25 \mathrm{mg} / \mathrm{kg}$ i.p.) and revealed astrocytosis identified by glial fibrillary acidic protein (GFAP)immunostaining and activation of microglia by GSI-B4 histochemistry (Appel et al., 1997). More investigators have suggested that DomA can activate microglia (Ananth et al., 2001; Chandrasekaran et al., 2004).

- DomA treatment (2 mg/kg once a day for 3 weeks) in mice significantly stimulates the expression of inflammatory mediators, including IL- $1 \beta$ (1.7 fold increase), TNF- $\alpha$ ( 2 fold increase), GFAP (1.4 fold increase), Cox-2 (3 fold increase), and iNOS (1.6 fold increase) compared to controls ( $\mathrm{Lu}$ et al, 2013).

- Adult female and male mice have been injected i.p. with $4 \mathrm{mg} / \mathrm{kg}$ (LD50) of DomA and Real-time PCR has been performed in the brain derived at 30, 60 and 240 min postinjection. The inflammatory response element cyclooxygenase $2(\mathrm{COX}-2)$ has been found to be 8 fold increased at the 30 and 60 min time points and then showed a descent back toward basal expression levels by 240 min (Ryan et al., 2005).

- Adult male rats treated with $2 \mathrm{mg} / \mathrm{kg}$ DomA i.p. have been sacrificed after 3 or $7 \mathrm{~d}$ and shown that GFAP and lectin staining could identify regions of reactive gliosis within areas of neurodegeneration but at higher magnifications compared to the ones used for neurodegeneration (Appel et al., 1997; Scallet et al., 2005).

- At 5 days and 3 months following DomA administration of male Wistar rats, a large number of OX-42 positive microglial cells exhibiting intense immunoreactivity in CA1 and CA3 regions of the hippocampus have been detected. With an antibody against GFAP, immunoreactive astrocytes have been found to be sparsely distributed in the hippocampus derived from DomA treated rats after 3 months' time interval (Ananth et al., 2003). At 5 days after the administration of DomA, GFAP positive astrocytes have been found increased in the hippocampus (Ananth et al., 2003).

$\mathbf{P b}^{2+}$

Neural stem cells (NSCs) derived from newborn were more sensitive to $\mathrm{Pb}$ treatment $(0-200$ microM for $48 \mathrm{~h}$ ) than NSCs derived from adult brain. $\mathrm{Pb}$ treatment induced a decrease in cell viability and an increase in the astrocytic marker GFAP, consistent with astrogliosis (Chan et al., 2013). Similar observations were made in 3D cultures prepared from fetal rat brain cells exposed to $\mathrm{Pb}$ (10-6 - 10-4 M for 10 days). Pb-induced neuronal death was evidenced by a decrease of cholinergic and GABAergic markers associated to a decrease in protein content, accompanied by microglial and astrocyte reactivities (Zurich et al., 2002). These effects were more pronounced in immature than in differentiated cultures (Zurich et al., 2002). In young mice (Sobin et al., 2013) as well as adult rats, exposure to $100 \mathrm{ppm}$ of $\mathrm{Pb}$ during 8 weeks caused neuronal death, evidenced by an increase in apoptosis (TUNEL) that was associated to microglial reactivity and an increase in IL-1 $\beta$, TNF- $\alpha$ and i-NOS expression (Liu et al., 2012). Acute exposure to $\mathrm{Pb}(25 \mathrm{mg} / \mathrm{kg}$, ip, for 3 days) increased GFAP and glutamate synthetase expression with impaiment of glutamate uptake and probable neuronal injury (Struzunska, 2000; Struzunska et al., 2001). 
Uncertainties or Inconsistencies

\section{Domoic acid (DomA)}

Adult male and female Sprague Dawley rats have received a single intraperitoneal (i.p.) injection of DomA $(0,1.0,1.8 \mathrm{mg} / \mathrm{kg})$ and have been sacrificed $3 \mathrm{~h}$ after the treatment. Histopathological analysis of these animals has shown no alterations for GFAP immunostaining in the dorsal hippocampus and olfactory bulb, indicating absence of reactive gliosis (Baron et al., 2013).

The exposed zebrafish from the 36-week treatment with DomA showed no neuroinflammation in brain (Hiolski et al., 2014). At the same time, microarray analysis revealed no significant changes in gfap gene expression, a marker of neuroinflammation and astrocyte activation (Hiolski et al., 2014).

\section{$\mathbf{P b}^{2+}$}

Sobin and coworkers (2013) described a $\mathrm{Pb}$-induced decrease in dentate gyrus volume associated with microglial reactivity at low dose of $\mathrm{Pb}(30 \mathrm{ppm})$, but not at high doses $(330 \mathrm{ppm})$. A possible way to explain this inconsistency is the death of microglial cells at the high dose of $\mathrm{Pb} . \mathrm{Pb}$ decreased IL-6 secretion by isolated astrocytes (Quian et al., 2007). Such a decrease was observed in isolated astrocytes treated with methylmercury, and was reverted in microglia astrocyte cocultures, suggesting that cell-cell interactions can modify the response to a toxicant (Eskes et al., 2002). It is interesting to note that glial cells and in particular astrocytes are able to accumulate lead, suggesting that these cells may be also a primary target of lead neurotoxic effects (Zurich et al., 1998; Lindhal et al., 1999).

\section{Quantitative Understanding of the Linkage}

Quantitative evalutation of this KER does not exist (gap of knowledge).

\section{Evidence Supporting Taxonomic Applicability}

California sea lions that have been exposed to the marine biotoxin DomA developed an acute or chronic toxicosis marked by seizures, whereas histopathological analysis revealed neuroinflammation characterised by gliosis (Kirkley et al., 2014).

\section{References}

Ananth, C. et al. (2001), Domoic acid-induced neuronal damage in the rat hippocampus: changes in apoptosis related genes (bcl-2, bax, caspase-3) and microglial response, Journal of Neuroscience Research, Vol. 66, pp.177-190.

Ananth, C., P. Gopalakrishnakone and C. Kaur (2003), Induction of inducible nitric oxide synthase expression in activated microglia following domoic acid (DA)-induced neurotoxicity in the rat hippocampus, Neuroscience Letters, Vol. 338, pp. 49-52.

Appel, N.M. et al. (1997), Sequelae of parenteral domoic acid administration in rats: comparison of effects on different metabolic markers in brain, Brain Research, Vol. 754, pp. 55-64.

Baron, A.W. et al. (2013), Sex differences in effects of low level domoic acid exposure, Neurotoxicology, Vol. 34, pp. 1-8. 
Blank, T. and M. Prinz (2013), Microglia as modulators of cognition and neuropsychiatric disorders, Glia, Vol. 61, pp. 62-70.

Chan, Y.H., M. Gao and W. Wu (2013), Are newborn rat-derived neural stem cells more sensitive to lead neurotoxicity?, Neural regeneration research, Vol. 8, No. 7, pp. 581-592.

Chandrasekaran, A., G. Ponnambalam and C. Kaur (2004), Domoic acid-induced neurotoxicity in the hippocampus of adult rats, Neurotoxicity Research, Vol. 6, pp. 105-117.

Chapman, G.A. et al. (2000), Fractalkine Cleavage from Neuronal Membrans Represents an Acute Event in Inflammatory Response to Excitotoxic Brain Damage, Journal of Neuroscience, Vol. 20, No. 5, pp. RC87.

Cendes, F. et al. (1995), Temporal lobe epilepsy caused by domoic acid intoxication: evidence for glutamate receptor-mediated excitotoxicity in humans, Annals of Neurology, Vol. 37, pp. 123-126.

Eskes, C. et al. (2002), Microglial reaction induced by noncytotoxic methylmercury treatment leads to neuroprotection via interactions with astrocytes and IL-6 release, Glia, Vol. 37, No. 1, pp. 43-52.

Farina, C., F. Aloisi and E. Meinl (2007), Astrocytes are active players in cerebral innate immunity, Trends in Immunology, Vol. 28, No. 3, pp. 138-145.

Hayward, J.H. and S.J. Lee (2014), A Decade of Research on TLR2 Discovering Its Pivotal Role in Glial Activation and Neuroinflammation in Neurodegenerative Diseases, Experimental Neurobiology, Vol. 23, No. 2, pp. 138-147.

Hiolski, E.M. et al. (2014), Chronic low-level domoic acid exposure alters gene transcription and impairs mitochondrial function in the CNS, Aquatic Toxicology, Vol. 155, pp. 151-159.

Katsumoto, A. et al. (2014), Ontogeny and functions of central nervous system macrophages, Journal of Immunology, Vol. 193, No. 6, pp. 2615-2621.

Kirkley, K.S. et al. (2014), Domoic acid-induced seizures in California sea lions (Zalophus californianus) are associated with neuroinflammatory brain injury, Aquatic Toxicology, Vol. 156C, pp. 259-268.

Kreutzberg, G.W. (1995), Microglia, the first line of defence in brain pathologies, Arzneimittelforschung, Vol. 45, pp. 357-360.

Kreutzberg, G.W. (1996), Microglia: a sensor for pathological events in the CNS, Trends in Neurosciences, Vol. 19, pp. 312-318.

Lindhal, L.S. et al. (1999), Differential ability of astroglia and neuronal cells to accumulate lead: Dependence on cell type and on degree of differentiation, Toxicological Sciences, Vol. 50, pp. 236243.

Liu, M.C. et al. (2012), Involvement of microglia activation in the lead induced long-term potentiation impairment, PLoS One, Vol. 7, No. 8, pp. e43924.

Lu, J. et al. (2013), Troxerutin counteracts domoic acid-induced memory deficits in mice by inhibiting CCAAT/enhancer binding protein $\beta$-mediated inflammatory response and oxidative stress, Journal of Immunology, Vol. 190, pp. 3466-3479.

Marin-Teva, J.L. et al. (2011), Microglia and neuronal cell death, Neuron glia biology, Vol. 7, No. 1, pp. $25-40$.

Pulido, O.M. (2008), Domoic acid toxicologic pathology: a review, Marine Drugs, Vol. 6, pp. 180-219.

Qian, Y. et al. (2007), A 78-kDa glucose-regulated protein is involved in the decrease of interleukin-6 secretion by lead treatment from astrocytes, American journal of physiology Cell physiology, Vol. 293, No. 3, pp. C897-C905.

Ransohoff, R.M. and M.A. Brown (2012), Innate immunity in the central nervous system, Journal of Clinical Investigation, Vol. 122, No. 4, pp. 1164-1171.

Rossi, D. (2015), Astrocyte physiopathology: At the crossroads of intercellular networking, inflammation and cell death, Progress in Neurobiology, Vol. 130, pp. 86-120. 
Ryan, J.C. et al. (2005), Acute phase gene expression in mice exposed to the marine neurotoxin domoic acid, Neuroscience, Vol. 136, pp. 1121-1132.

Scallet, A.C., L.C. Schmued and J.N. Johannessen (2005), Neurohistochemical biomarkers of the marine neurotoxicant, domoic acid, Neurotoxicology and Teratology, Vol. 27, pp. 745-752.

Sobin, C. et al. (2013), Microglial disruption in young mice with early chronic lead exposure, Toxicology Letters, Vol. 220, No. 1, pp. 44-52.

Streit, W.J., J. Conde and J.K. Harrison (2001), Chemokines and Alzheimer's disease, Neurobiology of Aging, Vol. 22, pp. 909-913.

Struzynska, L. (2000), The protective role of astroglia in the early period of experimental lead toxicity in the rat, Acta Neurobiologiae Experimentalis, Vol. 60, No. 2, pp. 167-173.

Struzynska, L. et al. (2001), Astroglial reaction during the early phase of acute lead toxicity in the adult rat brain, Toxicology, Vol. 165, pp. 121-131.

Zurich, M.G. et al. (1998), Lead acetate toxicity in vitro: Dependence on the cell composition of the cultures, Toxicology in Vitro, Vol. 12, No. 2, pp. 191-196.

Zurich, M.G. et al. (2002), Maturation-dependent neurotoxicity of lead aceate in vitro: Implication of glial reactions, Journal of Neuroscience Research, Vol. 70, pp. 108-116.

\section{Neurodegeneration, N/A leads to Neuroinflammation, N/A}

\section{How Does This Key Event Relationship Work}

According to its definition, neurodegeneration includes the death of neurons. Therefore, the KER describing the link between cell death and neuroinflammation is applicable to this KER. The fact that neuronal death can trigger neuroinflammation and that neuroinflammation can, in turn, cause neuronal degeneration, is known as a vicious circle, which is involved in the pathogeny of neurodegenerative diseases (Griffin et al., 1998; McGeer and Mc Geer, 1998; Blasko et al., 2004; Cacquevel et al., 2004; Barbeito et al., 2010; Rubio-Perez and Morillas-Ruiz, 2012; Thundyil and Lim, 2015; Hayward and Lee, 2014). Proteinopathies associated with neurodegenerative disorders such as Alzheimer's disease (AD) and Parkinson's disease (PD) may be sensed as damage associated molecular patterns (DAMPs) and thus activate microglia within the CNS. In animal neurodegeneration models and post-mortem brain samples from patients suffering from neurodegenerative disorders often revealed the presence of activated microglia and the accumulation of inflammatory mediators at the lesion sites, which suggests a continuous crosstalk between the brain immune system and the injured neurons during neurodegeneration. Microglial are typically activated acutely in response to an initial triggering insult, but their continued presence in large numbers around the lesion areas may actually promote neuronal death despite the absence of the initial triggering insult. Inflammatory factors being released by dying neurons and/or actively secreted from the activated microglia aid in maintaining the vicious cycle between activated microglia and damaged neurons (Thundyil and Lim 2015).

\section{Weight of Evidence}

\section{Biological Plausibility}

In Alzheimer's disease, Griffin and coworkers (1997) described the presence of reactive microglial cells inside the amyloid plaques and of reactive astrocytes around the plaques. Intra- 
cerebroventricular injections of beta-amyloid resulted in age-related increase in cholinergic loss and microglial activation (Nell et al., 2015). Increased neuronal expression of presequence protease (PreP) decreased the accumulation of beta-amyloid in synaptic mitochondria and the neuroinflammatory response (Fang et al., 2015), showing a link between the accumulation of insoluble proteins and neuroinflammation. In addition, having the apolipoprotein E4 (APOE) allele, the strongest genetic risk factor for the development of Alzheimer's disease, increases microglial reactivity in the amyloid plaques of a mouse model of beta-amyloid deposition, suggesting a role for APOE in modulation beta-amyloid-induced neuroinflammation in Alzheimer's disease progression (Rodriguez et al., 2014).

Empirical support for linkage

\section{Domoic acid (DomA)}

DomA $(0.75 \mathrm{mg} / \mathrm{kg}$ body weight $)$ when administered intravenously in adult rats reveals neuronal degeneration followed by glial activation (Ananth et al., 2001; 2003). More specifically, 5 days after DomA administration, Nissl staining of brain sections derived from DomA-treated animals have shown extensive neuronal damage in the pyramidal neurons of CA1, CA3 subfields and hilus of the dentate gyrus in the hippocampus. In the same brain areas, neuroinflammation has also been evident characterised by increased GFAP and OX-42 immunoreactivity at 5 days after DomA administration but not earlier (24 h) (Ananth et al., 2003). Previously, the same research team has shown increased number of stained degenerated neurons in the hippocampus by Nissl staining as early as $24 \mathrm{~h}$ following the administration of DomA, however, the degeneration has been found to be more severe after 5 days (Ananth et al., 2001).

Gap of knowledge: there are no studies showing that GLF-induced neurodegeneration leads to neuroinflammation.

Uncertainties or Inconsistencies

Quantitative Understanding of the Linkage

Quantitative evaluation of these KERs, when KEup and KEdown are measured in the same experiment in a dose and time dependent manner following exposure to DomA or GLF is not available.

\section{References}

Ananth, C. et al. (2001), Domoic acid-induced neuronal damage in the rat hippocampus: changes in apoptosis related genes (bcl-2, bax, caspase-3) and microglial response, Journal of Neuroscience Research, Vol. 66, pp. 177-190.

Ananth, C., P. Gopalakrishnakone and C. Kaur (2003), Protective role of melatonin in domoic acidinduced neuronal damage in the hippocampus of adult rats, Hippocampus, Vol. 13, pp. 375-387.

Barbeito, A.G., P. Mesci and S. Boillee (2010), Motor neuron-immune interactions: the vicious circle of ALS, Journal of Neural Transmission, Vol. 117, No. 8, pp. 981-1000.

Blasko, I. et al. (2004), How chronic inflammation can affect the brain and support the development of Alzheimer's disease in old age: the role of microglia and astrocytes, Aging cell, Vol. 3, No. 4, pp. 169-176. 
Cacquevel, M. et al. (2004), Cytokines in neuroinflammation and Alzheimer's disease, Curr Drug Targets, Vol. 5, No. 6, pp. 529-534.

Fang, D. et al. (2015), Increased neuronal PreP activity reduces Abeta accumulation, attenuates neuroinflammation and improves mitochondrial and synaptic function in Alzheimer disease's mouse model, Human molecular genetics, Vol. 24, No. 18, pp. 5198-5210.

Griffin, W.S.T., J. Sheng and R.E. Mrak (1997), Inflammatory Pathways. Implications in Alzheimer's disease, Humana Press, pp. 169-176.

Griffin, W.S. et al. (1998), Glial-neuronal interactions in Alzheimer's disease: the potential role of a 'cytokine cycle' in disease progression, Brain Pathology, Vol. 8, No. 1, pp. 65-72.

Hayward, J.H. and S.J. Lee (2014), A Decade of Research on TLR2 Discovering Its Pivotal Role in Glial Activation and Neuroinflammation in Neurodegenerative Diseases, Experimental neurobiology, Vol. 23, No. 2, pp. 138-147.

McGeer, P.L. and E.G. McGeer (1998), Glial cell reactions in neurodegenerative diseases: Pathophysiology and Therapeutic Interventions, Alzheimer Disease \& Associated Disorders, Vol. 12, Suppl. 2, pp. S1-S6.

Nell, H.J., S.N. Whitehead and D.F. Cechetto (2015), Age-Dependent Effect of beta-Amyloid Toxicity on Basal Forebrain Cholinergic Neurons and Inflammation in the Rat Brain, Brain Pathology, Vol. 25, No. 5, pp. 531-542.

Rodriguez, G.A. et al. (2014), Human APOE4 increases microglia reactivity at Abeta plaques in a mouse model of Abeta deposition, Journal of Neuroinflammation, Vol. 11, pp. 111.

Rubio-Perez, J.M. and J.M. Morillas-Ruiz (2012), A review: inflammatory process in Alzheimer's disease, role of cytokines, Scientific World Journal, Vol. 2012, pp. 756357.

Thundyil, J. and K.L. Lim (2015), DAMPs and Neurodegeneration, Ageing research reviews, Vol. 24, Pt. A, pp. 17-28.

\section{Neuroinflammation, N/A leads to Neurodegeneration, N/A}

\section{How Does This Key Event Relationship Work}

It is well accepted that chronic neuroinflammation is involved in the pathogenesis of neurodegenerative diseases (McNaull et al., 2010; Tansey and Goldberg, 2010; Thundyil and Lim, 2015). Chronic neuroinflammation can cause secondary damage (Kraft and Harry, 2011). The mechanisms by which neuroinflammation (i.e. activated microglia and astrocytes) can kill neurons and induce/exacerbate the neurodegenerative process has been suggested to include the release of nitric oxide that causes inhibition of neuronal respiration, ROS and RNS production, and rapid glutamate release resulting in excitotoxic death of neurons (Brown and Bal-Price, 2003; Kraft and Harry, 2011; Taetzsch \& Block, 2013). Glial reactivity is also associated with an excessive production and release of pro-inflammatory cytokines that not only affect neurons, but also cause detrimental feedback effects on microglia (Heneka et al., 2014). For example, sustained exposure to bacterial lipopolysaccharide (LPS) or to other pro-inflammatory mediators was shown to restrict microglial phagocytosis of misfolded and aggregated proteins (Sheng et al., 2003). Systemic immune challenge during pregnancy leading to microglial activation caused increased deposition of amyloid plaques and tau hyperphosphorylation in aged mice (Krstic et al., 2012), suggesting that neuroinflammation is involved in the amyloid plaques and neurofibrillary tangles formation. There is further evidence that the formation of neurofibrillary tangles is caused by 
microglial cell-driven neuroinflammation, since LPS-induced systemic inflammation increased tau pathology (Kitazawa et al., 2005).

Weight of Evidence

Biological Plausibility

Neuroinflammation is a component of neurodegenerative diseases such as Alzheimer's and Parkinson's disease (Neumann, 2001; Mutter et al., 2004), playing a secondary or an active primary role in the disease process (Hirsch and Hunot, 2009). Mc Naull and coworkers (Mc Naull et al., 2010) suggested that early developmental onset of brain inflammation could be linked with late onset of Alzheimer's disease. A recent paper by Krstic and coworkers (2012) showed that a systemic immune challenge during late gestation predispose mice to develop Alzheimer's like pathology when aging, suggesting a causal link between systemic inflammation, neuroinflammation, and the onset of Alzheimer's disease. Regarding toxicant-induced neuroinflammation, microglial/astrocyte activation and chronic neuron damage may continue for years after initial exposure (Taetsch and Block, 2013), suggesting that chronical neuroinflammation and neurodegeneration have a slow and long term temporal evolution. Ongoing neuroinflammation can be visualized in patients using the positron emission tomography (PET) ligand [11C] (R)-PK11195 (Cagnin et al., 2001). Recent genome-wide association study (GWAS) analyses of sporadic Alzheimer's disease revealed a set of genes that point to a pathogenic role of neuroinflammation in Alzheimer's disease (for review, see Heneka et al., 2014). High levels of pro-inflammatory cytokines produced by activated microglia and astrocytes are detected in the brain of Alzheimer's subjects and animal models (Mc Geer and Mc Geer, 1998; Janelsins et al., 2005).

Empirical support for linkage

\section{Domoic acid (DomA)}

DomA promotes the expression of inflammatory genes in the brain, such as cyclooxygenase 2 (COX2) and the development of neurodegeneration (Ryan et al., 2005). By using COX2 inhibitors that causes decrease the appearance of DomA-induced neurodegeneration, they have concluded that neuroinflammation contributes towards the development of neurodegeneration (Ryan et al., 2011).

$\mathbf{P b}^{2+}$

Rats treated during pregnancy from gestational day 5 throughout life till postnatal day 180 with a mixture of $\mathrm{Pb} / \mathrm{Cd} / \mathrm{As}$ showed in early adulthood increased levels of IL-1 $\beta$, IL- 6 and TNF- $\alpha$ in hippocampus and frontal cortex associated with increased $A \beta$ levels (Ashok et al., 2015). Similarly, monkeys exposed during infancy to $\mathrm{Pb}(1 \mathrm{mg} / \mathrm{kg} /$ day from birth to 400 days $)$ showed in aging (23 y old) an overexpression of APP and Abeta (Bihaqi et al., 2011), and of Tau mRNA and protein (Bihaqi and Zawa, 2013). Similar observations were made in old rats (18-20 months) after early life exposure to $\mathrm{Pb}(0.2 \%$ in drinking water from postnatal day 1 to 20 ) (Basha et al., 2005; Zawia and Basha, 2005; Bihaqi et al., 2014). This was associated with cognitive impairment that was observed only if animals were exposed when young (Bihaqi et al., 2014). Adult exposure may also increase the risk of neurodegeneration, as suggested by the two following studies: - human Tg-SwD1 APP transgenic mice treated with $\mathrm{Pb}(27 \mathrm{mg} / \mathrm{kg} /$ day by gavage $)$ for 6 weeks beginning at 8 weeks of age showed increased accumulation of Abeta and amyloid plaques (Gu et al., 2012). 
- former organolead workers had increased tibia $\mathrm{Pb}$ level associated with peristent brain damage measured by MRI (Stewart et al., 2006). Some in vitro experiments also show that neuroinflammation can lead to degeneration: the conditionned medium of $\mathrm{Pb}$-treated microglial cells (10 microM for 12h) caused the death of neuroblastoma cells (Kumawak et al., 2014). And $3 \mathrm{D}$ cultures treated with $\mathrm{Pb}$ for 10 days exhibited neuroinflammation accompanied by neuronal death (Zurich et al., 2002).

\section{Uncertainties or Inconsistencies}

Long-term treatments with NSAIDs (non-steroidal anti-inflammatory drugs) have a preventive effect on Alzheimer's disease development (Piertrzick and Behl, 2005), but such treatment has no effect or is even detrimental if applied once the disease is in an advanced stage (Lichtenstein et al., 2010), These ambivalent effects may be due to the dual role of neuroinflammation and to its complexity.

Serum $\mathrm{Pb}$ level negatively correlates with verbal memory score, but not with abnormal cognition in Alzheimer's disease (Park et al., 2014). Estimates of exposure are uncertain in epidemiological studies, because of the the long latency period between putative exposures during early life and late onset of Alzheimer's disease, even though bone $\mathrm{Pb}$ content is an accurate measure of historical $\mathrm{Pb}$ exposure in adults (Bakulski et al., 2012).

In addition to neuroinflammation or associated to neuroinflammation, other mechanisms may be involved in neurodegeneration with Abeta and tau accumulation: Pb-induced epigenetic modifications of genes involved in the amyloid cascade or tau expression may participate to the accumulation of Abeta and tau accumulation following developmental exposure to $\mathrm{Pb}$ (Zawia and Basha, 2005; Basha and Reddy, 2010). Also oxidative damage to DNA was shown to be involved in delayed effects observed in old rats (PD 600), if exposed early postanatally (PD 1 to 20) (Bolin et al., 2006).

Gap of knowledge: there are no studies showing that GLF-induced neuroinflammation leads to neurodegeneration.

\section{Quantitative Understanding of the Linkage}

There are no model and no dose-response experiments allowing to link neuroinflammation and neurodegeneration. The development of neurodegeneration may not depend on the quantity/intensity of neuroinflammation, but rather on the properties of the neuroinflammatory process (e.g. chronicity, expression of the neurodegenerative M1 phenotype by microglial cells,...)

\section{Evidence Supporting Taxonomic Applicability}

The hypotheisis of developmental origin of $\mathrm{Pb}$-induced neurodegeneration was tested and observed in Zebra fish by Lee and Freeman (2014). 


\section{References}

Ashok, A. et al. (2015), Exposure to As-, Cd-, and Pb-mixture induces Abeta, amyloidogenic APP processing and cognitive impairments via oxidative stress-dependent neuroinflammation in young rats, Toxicological Sciences, Vol. 143, No. 1, pp. 64-80.

Bakulski, K.M. et al. (2014), Lead exposure, B vitamins, and plasma homocysteine in men 55 years of age and older: the VA normative aging study, Environmental Health Perspectives, Vol. 122, No. 10, pp. 1066-1074.

Basha, M.R. et al. (2005), Lead ( $\mathrm{Pb})$ exposure and its effect on APP proteolysis and Abeta aggregation, FASEB Journal, Vol. 19, No. 14, pp. 2083-2084.

Basha, R. and G.R. Reddy (2010), Developmental exposure to lead and late life abnormalities of nervous system, Indian journal of experimental biology, Vol. 48, No. 7, pp. 636-641.

Bihaqi, S.W. et al. (2011), Infant exposure to lead $(\mathrm{Pb})$ and epigenetic modifications in the aging primate brain: implications for Alzheimer's disease, Journal of Alzheimer's Disease, Vol. 27, No. 4, pp. 819833.

Bihaqi, S.W. and N.H. Zawia (2013), Enhanced taupathy and AD-like pathology in aged primate brains decades after infantile exposure to lead $(\mathrm{Pb})$, Neurotoxicology, Vol. 39, pp. 95-101.

Bihaqi, S.W. et al. (2014), Infantile exposure to lead and late-age cognitive decline: relevance to AD, Alzheimer's \& dementia, Vol. 10, No. 2, pp. 187-195.

Bolin, C.M. et al. (2006), Exposure to lead and the developmental origin of oxidative DNA damage in the aging brain, FASEB Journal, Vol. 20, No. 6, pp. 788-790.

Brown, G.C. and A. Bal-Price (2003), Inflammatory neurodegeneration mediated by nitric oxide, glutamate, and mitochondria, Molecular Neurobiology, Vol. 27, No. 3, pp. 325-355.

Cagnin, A. et al. (2001), In-vivo measurement of activated microglia in dementia, Lancet, Vol. 358, No. 9280, pp. 461-467.

$\mathrm{Gu}, \mathrm{H}$. et al. (2012), Increased beta-amyloid deposition in Tg-SWDI transgenic mouse brain following in vivo lead exposure, Toxicology Letters, Vol. 213, No. 2, pp. 211-219.

Heneka, M.T., M.P. Kummer and E. Latz (2014), Innate immune activation in neurodegenerative disease, Nature Reviews Immunology, Vol. 14, No. 7, pp. 463-477.

Hirsch, E.C. and S. Hunot (2009), Neuroinflammation in Parkinson's disease: a target for neuroprotection?, Lancet Neurology, Vol. 8, pp. 382-397.

Janelsins, M.C. et al. (2005), Early correlation of microglial activation with enhanced tumor necrosis factor-alpha and monocyte chemoattractant protein-1 expression specifically within the entorhinal cortex of triple transgenic Alzheimer's disease mice, Journal of Neuroinflammation, Vol. 2, pp. 23.

Kraft, A.D. and G.J. Harry (2011), Features of microglia and neuroinflammation relevant to environmental exposure and neurotoxicity, International Journal of Environmental research and Public Health, Vol. 8, No. 7, pp. 2980-3018.

Kitazawa, M. et al. (2005), Lipopolysaccharide-induced inflammation exacerbates tau pathology by a cyclin-dependent kinase 5-mediated pathway in a transgenic model of Alzheimer's disease, Journal of Neuroscience, Vol. 25, No. 39, pp. 8843-8853.

Krstic, D. et al. (2012), Systemic immune challenges trigger and drive Alzheimer-like neuropathology in mice, Journal of Neuroinflammation, Vol. 9, pp. 151.

Kumawat, K.L. et al. (2014), Acute exposure to lead acetate activates microglia and induces subsequent bystander neuronal death via caspase-3 activation, Neurotoxicology, Vol. 41, pp. 143-153.

Lee, J. and J.L. Freeman (2014), Zebrafish as a model for investigating developmental lead (Pb) neurotoxicity as a risk factor in adult neurodegenerative disease: a mini-review, Neurotoxicology, Vol. 43, pp. 57-64. 
Lichtenstein, M.P. et al. (2010), Staging anti-inflammatory therapy in Alzheimer's disease, Frontiers in Aging Neuroscience, Vol. 2, pp. 142.

McGeer, P.L. and E.G. McGeer (1998), Glial cell reactions in neurodegenerative diseases: Pathophysiology and therapeutic interventions, Alzheimer Disease and Associated Disorders, Vol. 12, Suppl. 2, pp. S1-S6.

McNaull, B.B. et al. (2010), Inflammation and Anti-Inflammatory Strategies for Alzheimer's Disease - A Mini-Review, Gerontology, Vol. 56, pp. 3-14.

Mutter, J. et al. (2004), Alzheimer disease: mercury as pathogenetic factor and apolipoprotein E as a moderator, Neuroendocrinology Letters, Vol. 25, pp. 331-339

Neumann, H. (2001), Control of Glial Immune Function by Neurons, Glia, Vol. 36, pp. 191-199.

Park, J.H. et al. (2014), Serum trace metal levels in Alzheimer's disease and normal control groups, American journal of Alzheimer's disease and other dementias, Vol. 29, No. 1, pp. 76-83.

Pietrzik, C. and C. Behl (2005), Concepts for the treatment of Alzheimer's disease: molecular mechanisms and clinical application, International Journal of Experimental Pathology, Vol. 86, No. 3, pp. 173185.

Ryan, J.C., et al. (2005), Acute phase gene expression in mice exposed to the marine neurotoxin domoic acid, Neuroscience, Vol. 136, pp. 1121-1132.

Ryan, J.C., C.A. Cross and F.M. Van Dolah (2011), Effects of COX inhibitors on neurodegeneration and survival in mice exposed to the marine neurotoxin domoic acid, Neuroscience Letters, Vol. 487, pp. 83-87.

Sheng, J.G. et al. (2003), Lipopolysaccharide-induced-neuroinflammation increases intracellular accumulation of amyloid precursor protein and amyloid beta peptide in APPswe transgenic mice, Neurobiology of Disease, Vol. 14, No. 1, pp. 133-145.

Sherer, T.B., R. Betarbet and J.T. Greenamyre (2002), Environment, mitochondria, and Parkinson's disease, Neuroscientist, Vol. 8, pp. 192-197.

Stewart, W.F. et al. (2006), Past adult lead exposure is linked to neurodegeneration measured by brain MRI, Neurology, Vol. 66, No. 10, pp. 1476-1484.

Taetzsch, T. and M.L. Block (2013), Pesticides, microglial NOX2, and Parkinson's disease, Journal of Biochemical and Molecular Toxicology, Vol. 27, No. 2, pp. 137-149.

Tansey, M.G. and M.S. Goldberg (2010), Neuroinflammation in Parkinson's disease: Its role in neuronal death and implications for therapeutic intervention, Neurobiology of Disease, Vol. 37, No. 3, pp. $510-518$

Thundyil, J. and K.L. Lim (2015), DAMPs and neurodegeneration, Ageing research reviews, Vol. 24(Pt A), pp. 17-28.

Zawia, N.H. and M.R. Basha (2005), Environmental risk factors and the developmental basis for Alzheimer's disease, Reviews in the Neurosciences, Vol. 16, No. 4, pp. 325-337.

Zurich, M.G. et al. (2002), Maturation-dependent neurotoxicity of lead aceate in vitro: Implication of glial reactions, Journal of Neuroscience Research, Vol. 70, pp. 108-116. 


\title{
9. Neurodegeneration, N/A leads to Neuronal network function in adult brain, Decreased
}

\author{
How Does This Key Event Relationship Work
}

Neurodegeneration (retraction of dendrites or axons) or neuronal cell death decreases the number of synaptic connections affecting the neuronal network function (Seeley et al., 2009). Based on neuropathology (Braak and Braak, 1991), neuroimaging (Buckner et al., 2005; Greicius et al., 2004), and evidence from transgenic animal models (Palop et al., 2007a), it is suggested that neurodegeneration leads to neural network dysfunction (Buckner et al., 2005 and Palop et al., 2006). In human spongiform encephalopathies, which cause rapidly progressive dementia, direct evidence supports disease propagation along affected trans-synaptic connections (Scott et al., 1992). For all other neurodegenerative diseases, there are limited human experimental data supporting the "network degeneration hypothesis." It is demonstrated as a class-wide phenomenon, with major mechanistic significance, predicting that the spatial patterning of disease relates to some structural, metabolic, or physiological aspect of neural network biology dysfunction. Confirming the network degeneration hypothesis has clinical impact, stimulating development of new network-based diagnostic and disease-monitoring assays.

\section{Weight of Evidence}

\section{Biological Plausibility}

Based on neuropathological findings and neuroimaging from patients suffering from neurodegeneration as well as from evidence derived by transgenic animal models of neurodegeneration, it has been suggested that neurodegeneration is related to neural network dysfunction (Palop et al., 2007b; Seeley et al., 2009). Neurodegeneration leads to impairment of retrograde axonal transport that prohibits the growth factor supply to long-range projection neurons, causing synapse loss, and post-synaptic dendrite retraction that leads to decreases of the neuronal network (Seeley et al., 2009).

Empirical support for linkage

\section{Domoic acid (DomA)}

The effective concentration of DomA causing a decrease to $50 \%$ of control mean firing rate (MFR) values (EC50) in rat primary cultures (13-30 DIV) is $0.28 \mu \mathrm{M}$ (Mack et al., 2014). Decrease of MFR has also been reported before by Hogberg et al. 2011, where mature cultures (28-35 DIV) have been exposed acutely to a wide range of concentrations of DomA. The concentration of $0.5 \mu \mathrm{M}$ DomA significantly reduces MFR (77\%), the MBR $(78 \%)$ and the number of spikes per burst $(71 \%)$. Higher concentrations of DomA (1 and $2 \mu \mathrm{M})$ also significantly decrease the MFR, whereas concentrations up to $0.1 \mu \mathrm{M}$ of DomA do not cause any effect on MFR (Hogberg et al., 2011). In primary rat cortical neurons (12-22 DIV), DomA (50 $\mu \mathrm{M}$ ) has been reported to reduce MFR by more than $90 \%$ (McConnell et al., 2012).

Ten-minute exposure of rat hippocampal CA1 region slices to $400 \mathrm{nM}$ DA causes depression of fEPSP (Qiu et al., 2009). After $1 \mathrm{~h}$ washout, fEPSP gradually has been gradually recovered. DomA-potentiated slices have shown also less tetanus-induced LTP compared with control slices when tested with either original stimulus or reset stimulus (Qiu et al., 2009). In addition, 
prolonged application of $400 \mathrm{nM}$ DA reversibly depresses CA1 fEPSP and impairs the subsequent development of tetanus LTP (Qiu et al., 2009).

Gap of knowledge: there are no experiments to support such a KE relationship after exposure to GLF.

Uncertainties or Inconsistencies

Administration of high dose DomA (4.4 mg/kg) to adult male Sprague-Dawley rats causes elevation of electrocorticogram $(\mathrm{ECoG})$ beginning $30 \mathrm{~min}$ post injection, whereas at a lower dose $(2.2 \mathrm{mg} / \mathrm{kg}$ ) ECoG becomes elevated after $110 \mathrm{~min}$ (Binienda et al., 2011).

Quantitative Understanding of the Linkage

Not enough information exists to understand this linkage quantitativly.

Evidence Supporting Taxonomic Applicability

It has been shown at the neuromascular junction of D. melanogaster that quisqualate-type glutamate receptors are blocked by DomA (1 mM) (Lee et al., 2009). However, in crayfish (Procambarus clarkia) the same concentration of DomA has no effect in spike activity (Bierbower and Cooper, 2013).

\section{References}

Bierbower, S.M. and R.L. Cooper (2013), The mechanistic action of carbon dioxide on a neural circuit and NMJ communication. Journal of Experimental Zoology Part A: Ecological Genetics and Physiology, Vol. 319, pp. 340-54.

Binienda, Z.K. et al. (2011), Beaudoin MA, Thorn BT, Ali SF. Analysis of electrical brain waves in neurotoxicology: $\gamma$-hydroxybutyrate. Current Neuropharmacology, Vol. 9, pp. 236-9.

Braak H. and E. Braak (1991), Neuropathological staging of Alzheimer-related changes, Acta Neuropathologica, Vol. 82, pp. 239-259.

Buckner, R.L. et al. (2005), Molecular, structural, and functional characterization of Alzheimer's disease: evidence for a relationship between default activity, amyloid, and memory. Journal of Neuroscience, Vol. 25, pp. 7709-7717.

Greicius, M.D. et al. (2004), Default-mode network activity distinguishes Alzheimer's disease from healthy aging: evidence from functional MRI. Proc. Natl. Acad. Sci. USA, Vol. 101, pp. 4637-4642.

Hogberg, H.T. et al. (2011), Application of micro-electrode arrays (MEAs) as an emerging technology for developmental neurotoxicity: evaluation of domoic acid-induced effects in primary cultures of rat cortical neurons. Neurotoxicology, Vol. 32, pp.158-168.

Lee, J.Y. et al. (2009), Furthering pharmacological and physiological assessment of the glutamatergic receptors at the Drosophila neuromuscular junction. Comparative Biochemistry and Physiolology. Part C: Toxicolology and Pharmacology, Vol. 150, No. 4, pp. 546-57.

Mack, C.M. (2014), Burst and principal components analyses of MEA data for 16 chemicals describe at least three effects classes. Neurotoxicology, Vol. 40, pp. 75-85.

McConnell, E.R. et al., (2012), Evaluation of multi-well microelectrode arrays for neurotoxicity screening using a chemical training set. Neurotoxicology, Vol. 33, pp. 1048-1057. 
Palop, J.J., L. Chin and A. Mucke (2006), A network dysfunction perspective on neurodegenerative diseases. Nature, Vol. 443, pp. 768-773.

Palop, J.J.J., Chin J, Roberson ED, Wang J, Thwin MT, Bien-Ly N, Yoo J, Ho KO, Yu GQ, Kreitzer A, et al. Aberrant excitatory neuronal activity and compensatory remodeling of inhibitory hippocampal circuits in mouse models of Alzheimer's disease. Neuron, 2007a, 55: 697-711.

Palop, J.J.J. et al. (2007b), Aberrant excitatory neuronal activity and compensatory remodeling of inhibitory hippocampal circuits in mouse models of Alzheimer's disease. Neuron, Vol. 55, pp. 697711.

Qiu, S. et al. (2009), Jebelli AK, Ashe JH, Currás-Collazo MC. Domoic acid induces a long-lasting enhancement of CA1 field responses and impairs tetanus-induced long-term potentiation in rat hippocampal slices. Toxicological Sciences, Vol. 111, pp. 140-150.

Scott, R.S., D. Davies and H. Fraser (1992), Scrapie in the central nervous system: neuroanatomical spread of infection and Sinc control of pathogenesis. Journal of General Virology, Vol. 73, pp. 1637-1644.

Seeley, W.W. et al. (2009), Crawford RK, Zhou J, Miller BL, Greicius MD. Neurodegenerative diseases target large-scale human brain networks. Neuron, Vo.62, pp. 42-52.

\section{Neuronal network function in adult brain, Decreased leads to Learning and memory, Impairment}

\section{How Does This Key Event Relationship Work}

It is well established in the existing literature that NMDA receptor-dependent synaptic potentiation (LTP) and depression (LTD) are two forms of activity directly linked to long-term changes in synaptic efficacy and plasticity, the fundamental processes underlying learning and memory. The best characterised form of LTP occurs in the CA3-CA1 region of the hippocampus, in which LTP is initiated by transient activation of NMDARs that leads to a persistent increase in synaptic transmission through AMPA receptors (Benke et al., 1998) that can be achieved either through increasing the number of AMPA receptors at the post-synaptic surface or by increasing the single channel conductance of the receptors expressed. It has been shown that LTP in the CA1 region of the hippocampus could be accounted for by these two mechanisms (Benke et al 1998). The degree of activity of NMDARs is determined in part by extracellular $\mathrm{Mg}(2+)$ and by the coagonists for this receptor, glycine and D-serine. During strong stimulation, a relief of the voltagedependent block of NMDARs by $\mathrm{Mg}(2+)$ provides a positive feedback for NMDAR $\mathrm{Ca}(2+)$ influx into postsynaptic CA1 spines. The induction of LTP at CA3-CA1 synapses requires further signal amplification of NMDAR activity. Src family kinases (SFKs) play a "core" role in the induction of LTP by enhancing the function and expression of NMDARs. At CA3-CA1 synapses, NMDARs are largely composed of NR1 (NMDA receptor subunit 1)-NR2A or NR1-NR2B containing subunits. Recent, but controversial, evidence has correlated NR1-NR2A receptors with the induction of LTP and NR1-NR2B receptors with LTD. However, LTP can be induced by activation of either subtype of NMDAR and the ratio of NR2A:NR2B receptors has been proposed as an alternative determinant of the direction of synaptic plasticity. Many transmitters and signal pathways can modify NMDAR function and expression and, for a given stimulus strength, they can potentially lead to a change in the balance between LTP and LTD (MacDonald et al., 2006). 
Mammalian learning and memory is one of the outcomes of the functional expression of neurons connected into neural networks. Neuronal damage or cell death induced by chemical compounds disrupts integration and transmission of information through neural networks thereby setting the stage for subsequent impairment of learning and memory. Exposure to chemicals that will increase the risk of functional neuronal network damage lead to learning and memory impairment.

Weight of Evidence

Biological Plausibility

Long-term potentiation (LTP) is a long-lasting increase in synaptic efficacy after high-frequency stimulation of afferent fibers, and its discovery potentiated the idea that individual synapses possess the properties expected for learning and memory (reviewed in Lynch et al., 2014). Moreover, LTP is intimately related to the theta rhythm, an oscillation long-associated with learning. Learning-induced enhancement in neuronal excitability, a measurement of neural network function, has also been shown in hippocampal neurons following classical conditioning in several experimental approaches (reviewed in Saar and Barkai, 2003). On the other hand, memory requires the increase in magnitude of EPSCs to be developed quickly and to be persistent for a at least a few weeks without disturbing already potentiated contacts. Once again, a substantial body of evidence has demonstrated that tight connection between LTP and diverse instances of memory exist (reviewed in Lynch et al., 2014).

The recent studies suggest that NMDA receptor-dependent long-term depression of both LTD and LTP is usually accompanied by morphological changes in spines. LTD is characterised by long lasting dendritic spine shrinkage and reduced F-actin polymerization, in addition to reduced numbers of synaptic AMPA receptors. Moreover, the actin binding protein cofilin has been implicated in mediating such synaptic structural plasticity (Chen et al., 2007). If sustained, such LTD-changes in hippocampus or cortex, triggered by NMDARs overactivation could lead to synaptic dysfunction, contributing to learning and memory damage (Calabrese et al., 2014).

\section{Empirical support for linkage}

A series of important findings support that the biochemical changes that happen after induction of LTP also occur during memory acquisition, showing temporality between the two KEs (reviewed in Lynch et al., 2014). Furthermore, a review of Morris water maze (MWM) data as a tool to investigate spatial learning and memory in laboratory rats also pointed to the disconnection between neuronal networks rather than brain damage of certain regions is responsible for the impairment of MWM performance(D'Hooge and De Deyn, 2001). Functional integrated neural networks that involve the coordination action of different brain regions are consequently important for spatial learning and MWM performance. Morris et al. 1986 found that blocking the NMDA receptor with AP5 inhibits spatial learning in rats. More importantly, in the same study they measured brain electrical activity and recorded that this agent also inhibits LTP, however, they did not prove that spatial learning and LTP inhibition are causally related (Morris et al., 1986). Since then a number of NMDA receptor antagonists have been studied for their ability to induce impairment of learning and memory. It is worth mentioning that similar findings have been found in human subjects, where by combining behavioural and electrophysiological data from patients with temporal lobe epilepsy exposed to ketamine, the involvement of NMDA receptors in human memory processes was demonstrated (Grunwald et al., 1999). 


\section{Domoic Acid (DomA)}

Mice exposed to DomA $(2.0 \mathrm{mg} / \mathrm{kg})$ showed impairment of the acquisition of the place task in the Morris water maze (Petrie et al., 1992). These animals also failed to select the appropriate problem-solving strategies in their attempt to search for the underwater platform (longer escape latencies than controls) (Petrie et al., 1992). This impairment of acquisition and retention of this spatial navigation task by DomA, was associated with neuronal damage not only in the hippocampus, but also in limbic brain regions (Petrie et al., 1992). Similar results were obtained in a different study that also utilised the Morris water maze but in rats (Kuhlmann and Guilarte, 1997). These animals received DomA (1.5 or $3.0 \mathrm{mg} / \mathrm{kg}$ i.p.) and exhibited significant learning deficits while animals treated with a lower dose $(0.75 \mathrm{mg} / \mathrm{kg})$ showed no deficits. By incorporating in the test a visual cue trial (a black flag was positioned over the goal platform to eliminate the learning and memory components), it was possible to rule out sensory and motor deficits in the treated animals unable to solve the task (Kuhlmann and Guilarte, 1997).

Rats were examined using a neurobehavioral test battery (passive avoidance, auditory startle and conditioned avoidance) after DomA treatment with $0,0.22,0.65$, or $1.32 \mathrm{mg} / \mathrm{kg}$ i.p. that caused hardly any measurable brain injury (Sobotka et al., 1996). Approximately $25 \%$ of the animals that received the higher dose $(1.32 \mathrm{mg} / \mathrm{kg})$ DomA died or were euthanized. Surviving animals were assessed three days after exposure and showed changes on the auditory startle test (Sobotka et al., 1996). This effect was limited to exaggerated startle responses as measured by mean-response amplitude changes and did not include changes in habituation, suggesting the presence of behavioural hyper-reactivity rather than memory impairment. No change on the other two measures of avoidance learning was detected for all DomA treated groups compared to controls (Sobotka et al., 1996).

In an experimental approach aiming to evaluate single versus repeated doses of DomA on learning and memory, adult mice were treated with single or four i.p. injections of 1.0 or $2.0 \mathrm{mg} / \mathrm{kg}$ over a seven day period. All animals were tested on a spatial delayed matching-to-sample test in Morris water maze (Clayton et al., 1999). Animals given a single dose of $2.0 \mathrm{mg} / \mathrm{kg}$ DomA performed more poorly than controls on "nonalternation" test days; sessions in which the correct response was the same as the preceding day (Clayton et al., 1999). This finding implies that DomA-treated animals had difficulty recalling information after a $24 \mathrm{~h}$ delay period and were exhibiting behavioural signs similar to human antegrade amnesia. Animals exposed to multiple doses displayed initially greater general symptomatology but after recovery, did not show greater cognitive impairment than subjects treated with a single injection (Clayton et al., 1999).

In the only study where DomA i.v. administration was tested in relation to impairment of learning and memory, rats were dosed with $0.04 \mu \mathrm{g}$ DomA $/ \mathrm{kg}$ (and diazepam, ip). Radial arm maze tests revealed severe learning impairment, suggesting deficits in working memory. In subjects that were able to ultimately solve the maze, performance deficits were documented on re-learning the same task. The memory-based deficits observed in these animals are similar to human antegrade amnesia that has been reported after DomA exposure (Nakajima and Potvin, 1992). In humans, the hallmark of DomA-induced neurotoxicity is the rather dramatic disruption of memory processing. Clinical evaluation of 14 adult human subjects poisoned by DomA (after the outbreak in Canada) revealed that the majority of them (12/14) had severe antegrade memory deficits with relative preservation of higher cortical functions, since the patients were unable to remember 
events that occurred after DomA intoxication and had difficulty recalling new information (reviewed in Pulido, 2008; Grant et al., 2010).

In a separate clinical report of one case, a patient that received treatment at the hospital for DomA poisoning showed memory impairment which was resolved after three weeks (reviewed in Pulido, 2008; Grant et al., 2010). Other symptoms of the syndrome include nausea, vomiting, abdominal cramps, diarrhoea, headache, unstable blood pressure, cardiac arrhythmias and neurological dysfunction, including coma and seizures (reviewed in Pulido, 2008; Grant et al., 2010).

Treatment of female Sprague-Dawley rats with $0,1,2$, 4, or $7.5 \mathrm{mg}$ domoic acid $/ \mathrm{kg}$ of body weight for $24 \mathrm{~h}$ caused neurobehavioural changes at doses above $4 \mathrm{mg} / \mathrm{kg}$ of body weight characterised by unequivocal behavioural and neurological signs leading to partial seizures and status epilepticus (Tryphonas et al., 1990). Similar effects were observed in other in vivio studies (Fuquay et al., 2012; Muha and Ramsdell, 2011).

The exposed zebrafish from the 36-week treatment with DomA showed no visible signs of neurobehavioral excitotoxicity (i.e.circle- or spiral-swimming) when observed over a 30-45 min period following each injection (Hiolski et al., 2014). The latencies measured during training sessions did not differ among treated and not treated animals but the step-through latency in the $24 \mathrm{~h}$ retention trial was significantly lowered in DomA-exposed mice $(2 \mathrm{mg} / \mathrm{kg}$ once a day for 3 weeks) (Lu et al., 2012). DomA-treated mice had longer escape latencies compared to controls in Morris water maze. The same group reported that DomA-treated mice $(2 \mathrm{mg} / \mathrm{kg}$ once a day for 3 weeks) compared to controls showed a decrease ( 4.5 fold) in the step-through latency in the $24 \mathrm{~h}$ retention trial, a decrease ( 4 fold) in the number of crossings over the exact former location of the platform and a reduction ( 3 fold) in the time spent in the target quadrant (where the platform was located during hidden platform training) during the MWM task probe test (Wu et al., 2013, Wu et al, 2012). In this study FoxO1 knockdown reversed the cognitive deficits induced by DA in mice (Wu et al., 2013).

Adult male and female Sprague Dawley rats received a single intraperitoneal injection of DomA $(0,1.0,1.8 \mathrm{mg} / \mathrm{kg})$. These low levels of DomA showed that males may be more susceptible to severe neurotoxicity, whereas females are affected more quickly as it increased locomotor and grooming activity after monitoring behaviour for $3 \mathrm{~h}$ (Baron et al., 2013).

\section{Glufosinate (GLF)}

1. GLF impairs neuronal network function. The networks of cortical rat neurons were exposed to glufosinate (GLF) and its primary metabolite N-acetylglufosinate (NAcGLF) and electrical activity was measured using microelectrode array (MEA). The MEA recordings showed the concentration-responses for GLF and NAcGLF on network mean firing rates (MFR) that were biphasic, increasing at lower concentrations, decreasing below control levels at higher concentrations (similarly to NMDA). Increases in MFR occurred between 100-300 uM for NAcGLF (190\% control, maximum) and 10-1000 uM for GLF (340\% control, maximum) indicating that GLF is affecting neuronal network function (Lantz et al., 2014). Toxicokinetic data from reports of intentional human poisonings indicate that GLF concentrations in the CNS could reach levels high enough to lead to effects mediated via NMDARs (Watanabe and Sano, 1998).

Direct activation of NMDARs by GLF is also suggested by in vivo studies where three NMDA receptor antagonists, dizocilpine, LY235959, and Compound 40, and AMPA/KA antagonist, 
NBQX, were co-administrated with glufosinate ammonium ( $80 \mathrm{mg} / \mathrm{kg}$, intraperitoneally) in mice. Statistical analyses showed that the NMDA receptor antagonists markedly inhibited the GLFinduced convulsions, while the AMPA/KA receptor antagonist had no effect. These results suggest that the convulsion caused by glufosinate ammonium were mediated through NMDA receptors (Matsumura et al., 2001).

2. GLF exposure triggers convulsions and memory impairment. GLF expsoure produces moderate to severe convulsions and memory loss (Koyama et al., 1994; Watanabe and Sano, 1998; Ohtake et al., 2001; Park et al., 2006, 2013; Mao et al., 2011a and b, 2012), as well as causes structural changes to several brain regions, including the cortex and hippocampus (Calas et al., 2008; Meme et al., 2009; Park et al., 2006 ), two brain structures rich in NMDARs that play an important role in learning and memory processes.

- A 64 year old patient who ingested GLF suffered mental disturbances and later developed generalized convulsions, impaired respiration and circulatory failure. During recovery he exhibited loss of short-term memory (retrograde and anterograde amnesia) (Watanabe and Sano, 1998).

- Similarly, a 34-yr-old man who ingested glufosinate ammonium developed mental deterioration (Park et al., 2013).

- Retrograde amnesia has been reported following acute GLF toxicity in humans (Park et al., 2006).

- Chronic GLA (glufosinate-ammonium) treatments with 5 and $10 \mathrm{mg} / \mathrm{kg}$ induce mild memory impairments and a modification of hippocampal texture in mice. It is suggested that these modifications may be causally linked one to another. Hippocampal MRI texture and spatial memory alterations might be the consequences of hippocampal glutamate homeostasis modification (Calas et al., 2008).

- Spatial memory impairment was observed in mice after chronic exposure to as low as $2.5 \mathrm{mg} / \mathrm{kg}$ of GLF (Calas et al., 2008; Meme et al., 2009).

\section{Uncertainties or Inconsistencies}

One of the most difficult issues for neuroscientists is to link neuronal network function to cognition, including learning and memory. It is still unclear exactly what modifications in neuronal circuits need to happen in order to alter motor behaviour as it is recorded in a learning and memory test (Mayford et al., 2012), meaning that there is no clear understanding about how these two KEs are connected.

It is unclear whether GLF affects only glutamatergic systems since other potential mechanisms underlying GLF neurotoxicity have not been widely investigated. Based on the existing data it is understood that exposure to GLF or NAcGLF could disrupt the neuronal network function through disruption of glutamatergic neurotransmission but further work is required to clarify molecular mechanisms that cause impairment of memory.

Quantitative Understanding of the Linkage

Quantitative evaluation of this KER does not exist. 
Evidence Supporting Taxonomic Applicability

\begin{tabular}{l|l|l|l|}
\hline Name & \multicolumn{1}{|c|}{ Scientific Name } & Evidence & Links \\
\hline human & Homo sapiens & Strong & NCBI \\
\hline mouse & Mus sp. & Strong & NCBI \\
\hline rat & Rattus sp. ABTC 42503 & Strong & NCBI \\
\hline
\end{tabular}

Administration of DomA (9.0 mg DomA kg(-1) bw, i.p.) to Sparus aurata (seabream) caused neurological disturbances such as swimming in a circle, in a spiral, or upside down, that were reversed 24 hours after exposure (Nogueira et al., 2010). In rainbow trout (Oncorhynchus mykiss), DomA (0.75 mg/kg bw) administration caused increased aggressive behaviour $30 \mathrm{~min}$ after exposure compared to controls (Bakke et al., 2010).

\section{References}

Bakke, M.J., H.K. Hustoft and T.E. Horsberg (2010), Subclinical effects of saxitoxin and domoic acid on aggressive behaviour and monoaminergic turnover in rainbow trout (Oncorhynchus mykiss). Aquatic Toxicol, Vol. 99, pp. 1-9.

Baron, A.W. et al. (2013), Rushton SP, Rens N, Morris CM, Blain PG, Judge SJ., Sex differences in effects of low level domoic acid exposure. Neurotoxicology, Vol. 34, pp. 1-8.

Benke, T.A. et al. (1998), Modulation of AMPA receptor unitary conductance by synaptic activity. Nature, Vol. 25, pp. 793-7.

Calabrese, B. J. M. Saffin and S. Halpain (2014), Activity-dependent dendritic spine shrinkage and growth involve downregulation of cofilin via distinct mechanisms. PLoS One, Vol. 16, No. 9(4):e94787.

Calas, A.G. et al. (2008), Chronic exposure to glufosinate-ammonium induces spatial memory impairments, hippocampal MRI modifications and glutamine synthetase activation in mice. Neurotoxicology, Vol. 29, No. 4, pp. 740-7

Chen, L.Y. et al., (2007), Rex CS, Casale MS, Gall CM, Lynch G., Changes in synaptic morphology accompany actin signaling during LTP. Journal of Neuroscience, Vol. 27, pp. 5363-5372.

Clayton, E.C. et al., (1999), Peng YG, Means LW, Ramsdell JS. Working memory deficits induced by single but not repeated exposures to domoic acid. Toxicon, Vol. 37, pp. 1025-1039.

D'Hooge, R. and P.P. De Deyn (2001), Applications of the Morris water maze in the study of learning and memory. Brain Research Reviews, Vol. 36, pp. 60-90.

Fuquay, J.M. et al., (2012), Muha N, Pennington PL, Ramsdell JS., Domoic acid induced status epilepticus promotes aggressive behavior in rats. Physiology \& Behavior, Vol. 105, pp. 315-320.

Grant, K.S. et al. (2010), Burbacher TM, Faustman EM, Gratttan L., Domoic acid: neurobehavioral consequences of exposure to a prevalent marine biotoxin. Neurotoxicology and Teratology, Vol. 32, pp. 132-141.

Grunwald, T. et al., (1999), Evidence relating human verbal memory to hippocampal N-methyl-D-aspartate receptors. Proceedings of the National Academy of Sciences of the United States USA, Vol. 96, pp. 12085-12089.

Hiolski, E.M. et al., (2014), Chronic low-level domoic acid exposure alters gene transcription and impairs mitochondrial function in the CNS. Aquatic Toxicology, Vol. 155, pp. 151-9. 
Koyama, K. et al., (1994), Delayed and severe toxicities of a herbicide containing glufosinate and a surfactant. Veterinary and Human Toxicology, Vol. 36, pp. 17-8.

Kuhlmann, A.C. and T.R. Guilarte (1997), The peripheral benzodiazepine receptor is a sensitive indicator of domoic acid neurotoxicity. Brain Research, Vol. 751, pp. 281-288.

Lantz, S.R. et al. (2014), Mack CM, Wallace K, Key EF, Shafer TJ, Casida JE., Glufosinate binds to Nmethyl-D-aspartate receptors and increases neuronal network activity in vitro. Neurotoxicology, Vol. 45 , pp. 38-47.

Lu, J. et al (2012), Wu DM, Zheng YL, Hu B, Cheng W, Zhang ZF., Purple sweet potato color attenuates domoic acid-induced cognitive deficits by promoting estrogen receptor- $\alpha$-mediated mitochondrial biogenesis signaling in mice. Free Radical Biology and Medicine, Vol. 52, pp. 646-59.

Lynch, G., C.D. Cox and C.M. Gall (2014), Pharmacological enhancement of memory or cognition in normal subjects. Frontiers in Systems Neuroscience, Vol. 8, pp. 90-103.

MacDonald, J.F., M.F. Jackson and M.A. Beazely (2006), Hippocampal long-term synaptic plasticity and signal amplification of NMDA receptors. Crit Rev Neurobiol, Vol. 18, pp. 71-84.

Mao, Y.C. et al (2012), Hung D-Z, Wu M-L, Tsai W-J, Wang L-M, Ger J, et al. Acute human glufosinatecontaining herbicide poisoning. Clinical Toxicology, Vol. 5, pp. 1-7.

Mao, Y.C. et al. (2011a), Hyperammonemia following glufosinate-containing herbicide poisoning: a potential marker of severe neurotoxicity. Clinical Toxicology (Phila), Vol 49, pp. 48-52.

Mao, Y.C. and C.C. Yang (2011), Response to "Hyperammonemia following glufosinate-containing herbicide poisoning: A potential marker of severe neurotoxicity" by Yan-Chido Mao et al., Clinical Toxicology (Phila) 2011b; 49: 48-52. Clinical Toxicology 2011;49(July (6)): 513-514.

Mayford, M., S.A. Siegelbaum and E.R. Kandel (2012), Synapses and memory storage. Cold Spring Harb Perspect Biol., 4(6). pii: a005751.

Meme, S. et al. (2009), MRI characteri- zation of structural mouse brain changes in response to chronic exposure to the glufosinate ammonium herbicide. Toxicological Sciences, Vol. 111, pp. 321-30.

Matsumura, N. et al. (2001), Takeuchi C, Hishikawa K, Fujii T, Nakaki T., Glufosinate ammonium induces convulsion through N-methyl-D-aspartate receptors in mice. Neurosci Letters, Vol. 304, No. 1-2, pp. 123-5.

Morris, R.G. (1986), Selective impairment of learning and blockade of long-term potentiation by an Nmethyl-Daspartate receptor antagonist, AP5. Nature, Vol. 319, pp. 774-776.

Muha, N. and J.S. Ramsdell (2011), Domoic acid induced seizures progress to a chronic state of epilepsy in rats. Toxicon, Vol. 57, pp. 168-171.

Nakajima, S. and J.L. Potvin (1992), Neural and behavioural effects of domoic acid, an amnesic shellfish toxin, in the rat. Canadian Journa lof Psychology, Vol. 46, pp. 569-581.

Nogueira, I. (2010), Toxic effects of domoic acid in the seabream Sparus aurata. Marine Drugs, Vol. 8, pp. 2721-232.

Ohtake, T. et al. (2001), Decreased plasma and cerebrospinal fluid glutamine concentrations in a patient with bialaphos poisoning. Human Experimantal Toxicology, Vol. 20, pp. 429-34.

Park, J.S. et al. (2013), Glufosinate herbicide intoxication causing unconsciousness, convulsion, and 6th cranial nerve palsy. Journal of Korean Medical Science, Vol. 28, pp. 1687-9.

Park, H.Y. et al. (2006), Lee PH, Shin DH, Kim GW., Anterograde amnesia with hippocampal lesions following glufosinate intoxication. Neurology, Vol. 67, pp. 914-5.

Petrie, B.F. et al. (1992), Pinsky C, Standish NM, Bose R, Glavin GB., Parenteral domoic acid impairs spatial learning in mice. Pharmacoogyl Biochemistry and Behavior, Vol. 41, pp. 211-214.

Pulido, O.M. (2008), Domoic acid toxicologic pathway: a review. Marine Drugs, Vol. 6, pp. 180-219. 
Saar, D., and E. Barkai (2003), Long-term modifications in intrinsic neuronal properties and rule learning in rats. European Journal of Neuroscience, Vol. 17, pp. 2727-2734.

Sobotka, T.J. et al. (1996), Domoic acid: neurobehavioral and neurohistological effects of low-dose exposure in adult rats. Neurotoxicology and Teratology, Vol. 18, pp. 659-670.

Tryphonas, L. Et al. (1990), Truelove J, Nera E, Iverson F., Acute neurotoxicity of domoic acid in the rat. Toxicologic Pathology, Vol.18, pp. 1-9.

Watanabe, T. and T. Sano (1998), Neurological effects of glufosinate poisoning with a brief review. Human Experimantal Toxicology, Vol. 17, No. 1, pp. 35-9.

Wu, D.M. et al. (2012), Small interfering RNA-mediated knockdown of protein kinase C zeta attenuates domoic acid-induced cognitive deficits in mice. Toxicological Sciences, Vol. 128, pp. 209-222.

Wu, D.M. et al., (2013), Ursolic acid improves domoic acid-induced cognitive deficits in mice. Toxicology and Applied Pharmacology, Vol. 271, pp. 27-36.

\section{Overall Assessment of the AOP}

The aim of the present AOP is to construct a linear pathway that captures the KEs and KERs that occur after binding of agonist to NMDA receptor in hippocampal and cortical neurons of adults. The majority of the KEs of the AOP are characterised by MODERATE essentiality for the AO (loss or reduction of cognitive function) or other KEs that follow. The biological plausibility in the majority of KERs is rated STRONG as there is extensive mechanistic understanding. However, the empirical support for the majority of presented KERs cannot be rated high as in most occasions the KEup and KEdown of a KER has not been investigated simultaneously, under the same experimental protocol or not in the suggested brain regions (cortex and hippocampus).

\section{Domain of Applicability}

Life Stage Applicability: This AOP is applicable for adults. However, studies exploring the neurotoxic effects of DomA on the developing nervous system demonstrate that DomA can cause neurobehavioral, biochemical and morphological effects similar to the ones observed in adult animals (reviewed in Costa et al., 2010). The DomA doses required to cause these effects in developing organisms are one to two orders of magnitude lower than those needed for loss or reduction of cognitive function in adults. This difference has been attributed to toxicokinetic and/or toxicodynamic particularities that exist between adults and children.

Taxonomic Applicability: The data used to support the KERs in this AOP derives from experimental studies conducted in primates, rats and mice or cell cultures of similar origin as well as from human epidemiological studies or clinical cases of DomA poisoning. The majority of the KEs in this AOP seem to be highly conserved across species. It remains to be proved if these KERs of the present AOP are also applicable for other species rather than human, primates, rats or mice. Increasing evidence from sea lions exposed to DomA further supports some of the KERs of the present AOP.

Sex Applicability: The majority of the studies addressing the KEs and KERs of this AOP have been carried out mainly in male laboratory animals. Few studies are available in females and some 
of them compare the effects between females and males. It appears that this AOP is applicable for both females and males.

Essentiality of the Key Events

\begin{tabular}{|c|c|}
\hline Molecular Initiating Event & Support for Essentiality \\
\hline Inotropic glutamate receptors, Binding of agonist & Strong \\
\hline Key Event & Support for Essentiality \\
\hline NMDARs, Overactivation & Moderate \\
\hline Calcium influx, Increased & Moderate \\
\hline Mitochondrial dysfunction, N/A & Strong \\
\hline Cell death, N/A & Strong \\
\hline Neurodegeneration, N/A & Strong \\
\hline Neuroinflammation, N/A & Weak \\
\hline Neuronal network function in adult brain, Decrease & ed Moderate \\
\hline
\end{tabular}

1) Essentiality of KE "NMDARs, Overactivation" for the KE "Cell death" is MODERATE. NMDARs play a central role in excitotoxic neuronal injury. Over-activation of these receptors causes disruption of $\mathrm{Ca}^{2+}$ homeostasis that through mitochondrial dysfunction triggers signals leading to apoptotic or necrotic death. However, the ways that cells respond to mitochondrial injury vary and often are considered unclear and controversial (Pivovarova and Andrews, 2010). However, NMDAR antagonists failed to reverse these $\mathrm{Ca}^{2+}$ induced cell deaths, leading to suggestions that NMDAR-independent pathways that involve $\alpha$-amino-3-hydroxy-5-methyl-4isoxazolepropionic acid receptors (AMPARs), acid-sensing channels and transient receptor potential channels might be also responsible for excitotoxic neuronal injury (Pivovarova and Andrews, 2010). Several agonists have higher affinity than NMDA itself but are not relevant for behavioural studies as NMDA activation leads to epilepsy and cell death, a common approach to induce neurotoxic lesions.

2) Essentiality of KE "Calcium influx, Increased" for the KE "Cell death" is MODERATE. $\mathrm{Ca}^{2+}$ plays important role in excitotoxicity but the mechanisms involved in excitotoxic cell death are still debated (Berliocchi et al., 2005). Depending on the extent and the duration of the $\mathrm{Ca}^{2+}$ influx, neurons survive, die through apoptotic mechanisms in case of sustained slow $\mathrm{Ca}^{2+}$ influx, or undergo necrosis when rapid high $\mathrm{Ca}^{2+}$ influx occurs. Over-expression of the endogenous calpain inhibitor, calpastatin, or the calpain-resistant isoform the $\mathrm{Na}+/ \mathrm{Ca}^{2+}$ exchanger 2 ( $\mathrm{NCX} 2$ ) prevents $\mathrm{Ca}^{2+}$ overload and protects neurons from excitotoxicity (Bano et al., 2005).

3) Essentiality of KE "Mitochondria dysfunction" for the AO "Impairment of learning and memory" is STRONG. ROS is known to have a negative effect on synaptic plasticity and 
learning and memory (reviewed in Lynch, 2004). $\mathrm{H}_{2} \mathrm{O}_{2}$ inhibits LTP both in vitro and in vivo, which is associated with increased ROS. A negative correlation has been found between ROS concentration in hippocampus and ability of rats to sustain LTP. Administration of antioxidants, vitamins $\mathrm{E}$ and $\mathrm{C}$, reverses the inhibitory effects of stress on LTP and prevents the increase of ROS in hippocampus. In transgenic mice that overexpress superoxide dismutase (SOD), the enzyme which catalyzes the conversion of superoxide to $\mathrm{H}_{2} \mathrm{O}_{2}$, the LTP in CA1 is inhibited. Intracerebroventricular injection of $\mathrm{H}_{2} \mathrm{O}_{2}$, at a concentration which increases ROS levels in hippocampus, impairs LTP that is prevented after pretreatment with the antioxidant phenylarsine oxide. Knocking down Forkhead box protein O1 (FoxO1) in mice, which is an important regulator of mitochondrial function, reverses mitochondrial abnormalities and cognitive impairment induced by DA in mice (Wu et al., 2013).

4) Essentiality of KE "Mitochondria dysfunction" for the KE "Cell death" is MODERATE. There is a considerable number of mitochondrial associated processes that lead to necrotic or apoptotic cell death such as uncoupling of oxidative phosphorylation, activation of the mitochondrial permeability transition pore (MPTP), release of pro-apoptotic proteins, activation of poly(ADP-ribose) polymerase-1 and proteases such as calpain, increased levels of and delayed $\mathrm{Ca}^{2+}$ de-regulation (Pivovarova and Andrews, 2010). Although the understanding of these mechanisms is clearly established, the cascade of events and the significance of them are less clear (Pivovarova and Andrews, 2010). A significant body of evidence, both clinical and experimental, supports a role for the mitochondrial permeability transition pore in excitotoxicity (reviewed in Pivovarova and Andrews, 2010). However, the effects of cyclosporin A, the classical MPTP inhibitor, on neuronal mitochondria are inconsistent raising doubts about its role in neural cell death. However, ADP/ATP translocator deficiency, which is not essential for MPTP but does regulate pore opening, protects neurons against excitotoxicity. Furthermore, MPTP opening renders neurons vulnerable to excitotoxicity.

Weight of Evidence Summary

\begin{tabular}{|l|l|l|l|}
\hline \multicolumn{1}{|c|}{ Event } & Description & \multicolumn{1}{|c|}{ Triggers } & \multicolumn{1}{c|}{$\begin{array}{c}\text { Weight of } \\
\text { Evidence }\end{array}$} \\
\hline Calcium influx, Increased & $\begin{array}{l}\text { Indirectly } \\
\text { Leads to }\end{array}$ & Mitochondrial dysfunction, N/A & Strong \\
\hline NMDARs, Overactivation & $\begin{array}{l}\text { Directly Leads } \\
\text { to }\end{array}$ & Calcium influx, Increased & Moderate \\
\hline Mitochondrial dysfunction, N/A & $\begin{array}{l}\text { Indirectly } \\
\text { Leads to }\end{array}$ & Cell death, N/A & Moderate \\
\hline Cell death, N/A & $\begin{array}{l}\text { Directly Leads } \\
\text { to }\end{array}$ & Neurodegeneration, N/A & Moderate \\
\hline Cell death, N/A & $\begin{array}{l}\text { Indirectly } \\
\text { Leads to }\end{array}$ & Neuroinflammation, N/A & Weak \\
\hline Neuroinflammation, N/A & $\begin{array}{l}\text { Directly Leads } \\
\text { to }\end{array}$ & Neurodegeneration, N/A & Moderate \\
\hline
\end{tabular}




\begin{tabular}{|c|c|c|c|}
\hline Event & Description & Triggers & $\begin{array}{l}\text { Weight of } \\
\text { Evidence }\end{array}$ \\
\hline Neurodegeneration, N/A & $\begin{array}{l}\text { Directly Leads } \\
\text { to }\end{array}$ & Neuroinflammation, N/A & Moderate \\
\hline $\begin{array}{l}\text { Neuronal network function in } \\
\text { adult brain, Decreased }\end{array}$ & $\begin{array}{l}\text { Indirectly } \\
\text { Leads to }\end{array}$ & Learning and memory, Impairment & Moderate \\
\hline Neurodegeneration, N/A & $\begin{array}{l}\text { Indirectly } \\
\text { Leads to }\end{array}$ & $\begin{array}{l}\text { Neuronal network function in } \\
\text { adult brain, Decreased }\end{array}$ & Weak \\
\hline $\begin{array}{l}\text { Inotropic glutamate receptors, } \\
\text { Binding of agonist }\end{array}$ & $\begin{array}{l}\text { Directly Leads } \\
\text { to }\end{array}$ & NMDARs, Overactivation & Strong \\
\hline
\end{tabular}

The table provides a summary of the biological plausibility and the empirical support for each KER described in this AOP based on "Annex 1: Guidance for assessing relative level of confidence in the overall AOP based on rank ordered elements" found in the User's Handbook.

More information about the evidence that support these KERs and the relevant literature can be found in each KER description.

The main base for the overall scoring is that the empirical support coming from the experiments with one stressor (domoic acid, DomA). However this AOP is not specific for DomA, it is applicable to any chemicals that act as NMDARs agonists.

\begin{tabular}{|c|c|c|c|c|c|}
\hline KERs WoE & $\begin{array}{l}\text { Biological } \\
\text { plausibility }\end{array}$ & $\begin{array}{c}\text { Does KEup } \\
\text { occurs at } \\
\text { lower doses } \\
\text { than } \\
\text { KEdown? }\end{array}$ & $\begin{array}{l}\text { Does KEup } \\
\text { occurs at } \\
\text { earlier } \\
\text { time points } \\
\text { than KE } \\
\text { down? }\end{array}$ & $\begin{array}{l}\text { Is there } \\
\text { higher } \\
\text { incidence } \\
\text { of KEup } \\
\text { than of } \\
\text { KEdown? }\end{array}$ & Inconsistencies/Uncertainties \\
\hline $\begin{array}{l}\text { Binding of agonist } \\
\text { to NMDARs } \\
\text { directly leads to } \\
\text { NMDARs } \\
\text { overactivation }\end{array}$ & $\begin{array}{l}\text { Extensive } \\
\text { understanding }\end{array}$ & N/A & Yes & N/A & Limited conficting data \\
\hline $\begin{array}{l}\text { NMDARs } \\
\text { overactivation } \\
\text { directly leads to } \\
\text { increased calcium } \\
\text { influx }\end{array}$ & $\begin{array}{l}\text { Extensive } \\
\text { understanding }\end{array}$ & Same dose & Yes & $\begin{array}{l}\text { Not } \\
\text { investigated }\end{array}$ & Limited conficting data \\
\hline $\begin{array}{l}\text { Increased calcium } \\
\text { influx indirectly } \\
\text { leads } \\
\text { mitochondrial } \\
\text { dysfunction }\end{array}$ & $\begin{array}{l}\text { Extensive } \\
\text { understanding }\end{array}$ & Same dose & Yes & Yes & No conflicting data \\
\hline $\begin{array}{l}\text { Mitochondrial } \\
\text { dysfunction directly } \\
\text { leads to cell death }\end{array}$ & $\begin{array}{l}\text { Extensive } \\
\text { understanding }\end{array}$ & Same dose & Yes & Yes & Limited conficting data \\
\hline
\end{tabular}




\begin{tabular}{|c|c|c|c|c|c|}
\hline $\begin{array}{l}\text { Cell death leads to } \\
\text { Neurodegeneration }\end{array}$ & $\begin{array}{l}\text { Extensive } \\
\text { understanding }\end{array}$ & Same dose & Yes & Yes & Limited conficting data \\
\hline $\begin{array}{l}\text { Cell death leads to } \\
\text { Neuroinflammation }\end{array}$ & $\begin{array}{l}\text { Extensive } \\
\text { understanding }\end{array}$ & $\begin{array}{l}\text { Not } \\
\text { investigated }\end{array}$ & $\begin{array}{l}\text { Not } \\
\text { investigated }\end{array}$ & $\begin{array}{l}\text { Not } \\
\text { investigated }\end{array}$ & N/A \\
\hline $\begin{array}{l}\text { Neurodegeneration } \\
\text { directly leads to } \\
\text { Decreased neuronal } \\
\text { network function }\end{array}$ & $\begin{array}{l}\text { Extensive } \\
\text { understanding }\end{array}$ & $\begin{array}{l}\text { Not } \\
\text { investigated }\end{array}$ & $\begin{array}{l}\text { Not } \\
\text { investigated }\end{array}$ & $\begin{array}{l}\text { Not } \\
\text { investigated }\end{array}$ & N/A \\
\hline $\begin{array}{l}\text { Decreased neuronal } \\
\text { network function } \\
\text { indirectly leads to } \\
\text { loss or reduction of } \\
\text { cognitive function }\end{array}$ & $\begin{array}{l}\text { Scientific } \\
\text { understanding } \\
\text { is not } \\
\text { completely } \\
\text { established }\end{array}$ & $\begin{array}{l}\text { Not } \\
\text { investigated }\end{array}$ & $\begin{array}{l}\text { Not } \\
\text { investigated }\end{array}$ & $\begin{array}{l}\text { Not } \\
\text { investigated }\end{array}$ & N/A \\
\hline
\end{tabular}


Quantitative Considerations

\begin{tabular}{|c|c|c|c|}
\hline Event & Description & Triggers & $\begin{array}{l}\text { Quantitative } \\
\text { Understanding }\end{array}$ \\
\hline Calcium influx, Increased & $\begin{array}{l}\text { Indirectly } \\
\text { Leads to }\end{array}$ & $\begin{array}{l}\text { Mitochondrial dysfunction, } \\
\text { N/A }\end{array}$ & \\
\hline NMDARs, Overactivation & $\begin{array}{l}\text { Directly } \\
\text { Leads to }\end{array}$ & Calcium influx, Increased & \\
\hline $\begin{array}{l}\text { Mitochondrial dysfunction, } \\
\text { N/A }\end{array}$ & $\begin{array}{l}\text { Indirectly } \\
\text { Leads to }\end{array}$ & Cell death, N/A & \\
\hline Cell death, N/A & $\begin{array}{l}\text { Directly } \\
\text { Leads to }\end{array}$ & Neurodegeneration, N/A & \\
\hline Cell death, N/A & $\begin{array}{l}\text { Indirectly } \\
\text { Leads to }\end{array}$ & Neuroinflammation, N/A & \\
\hline Neuroinflammation, N/A & $\begin{array}{l}\text { Directly } \\
\text { Leads to }\end{array}$ & Neurodegeneration, N/A & \\
\hline Neurodegeneration, N/A & $\begin{array}{l}\text { Directly } \\
\text { Leads to }\end{array}$ & Neuroinflammation, N/A & \\
\hline $\begin{array}{l}\text { Neuronal network function in } \\
\text { adult brain, Decreased }\end{array}$ & $\begin{array}{l}\text { Indirectly } \\
\text { Leads to }\end{array}$ & $\begin{array}{l}\text { Learning and memory, } \\
\text { Impairment }\end{array}$ & Weak \\
\hline Neurodegeneration, N/A & $\begin{array}{l}\text { Indirectly } \\
\text { Leads to }\end{array}$ & $\begin{array}{l}\text { Neuronal network function in } \\
\text { adult brain, Decreased }\end{array}$ & \\
\hline $\begin{array}{l}\text { Inotropic glutamate receptors, } \\
\text { Binding of agonist }\end{array}$ & $\begin{array}{l}\text { Directly } \\
\text { Leads to }\end{array}$ & NMDARs, Overactivation & \\
\hline
\end{tabular}

\section{Considerations for Potential Applications of the AOP}

Exposure to xenobiotics can potentially affect the nervous system resulting in neurobehavioral alterations and/or neurological clinical symptoms. To assess the neurotoxic properties of compounds, current testing largely relies on neurobehavioural tests in laboratory animals, histopathological analysis, neurochemical and occasionally electrophysiological observations. Throughout the years, a significant number of methods have been developed to assess neurobehaviour in laboratory animals and a comprehensive summary of them can be found in OECD Series on testing and assessment, number 20, Guidance Document for Neurotoxicity Testing (2004). This document is considered an essential supplement to a substantial number of already existing OECD Test Guidelines that are applied to gain information on the neurotoxicity properties of chemical compounds. Namely, these are: general Test Guidelines such as single dose toxicity (e.g. OECD 402, 403, 420, 423 and 425), repeated dose toxicity (e.g. OECD 407 and 
408), chronic exposure (e.g. OECD 452) as well as Test Guidelines specifically developed for the study of neurotoxicity in adult laboratory animals, such as OECD Test Guideline for Neurotoxicity (424).

Learning and memory is an important endpoint and a wide variety of tests to assess chemical effects on cognitive functions is available and used for the study of neurotoxicity. Some of these tests that allow the appreciation of cognitive function in laboratory animals are: habituation, ethologically based anxiety tests (elevated plus maze test, black and white box test, social interaction test), conditioned taste aversion (CTA), active avoidance, passive avoidance, spatial mazes (Morris water maze, Biel water maze, T-maze), conditional discrimination (simple discrimination, matching to sample), delayed discrimination (delayed matching-to-sample, delayed alternation) and eye-blink conditioning.

The present AOP can potentially provide the basis for development of a mechanistically informed IATA for neurotoxicity. The construction of IATA for predicting neurotoxic effects in adults is expected to make use of more than one AOP within an interconnected network in order to take into consideration all critical biological processes that may contribute to impairment of learning and memory in adults. Through this network, identification of KEs and KERs common across multiple AOPs can emerge that should be considered during IATA construction and that may inform also in vitro assay development. The development of alternative assays would allow screening of chemicals for potential NMDAR activators and reducing the use of in vivo studies.

Results from assays based on the KEs of this AOP can serve to interpret and accept results that derive from non-standard test methods. Omics data from toxicogenomic, transcriptomic, proteomic, and metabolomic studies can be interpreted in a structured way using this AOP that is relevant to adult neurotoxicity. Currently learning and memory testing is not required by the OECD TG 424. This AOP could serve as a base for chemical evaluation with potential to cause impairment of learning and memory. The assay development would refer to the identified in this AOP KEs that could form a testing strategy for identifying chemicals with potential to cause cognitive deficit. Finally, this AOP could provide the opportunity to group chemicals using not only chemical properties but also mechanistic information that can later inform data gap filling by read-across and predict neurotoxic properties of a target substance.

\section{References}

Bano, D. et al. (2005), Cleavage of the plasma membrane Na+/Ca2+ exchanger in excitotoxicity. Cell, Vol. 120, pp. 275-285.

Berliocchi, L., D. Bano, P. Nicotera (2005), $\mathrm{Ca}^{2+}$ signals and death programmes in neurons. Philosophical Transactions of the Royal Socciety of Lonon B Biological Sciences, Vol. 360, pp. 2255-2258.

Costa, L.G., G. Giordano and E.M. Faustman (2010), Domoic acid as a developmental neurotoxin. Neurotoxicology, Vol. 31, No. 5, pp. 409-23.

Health Effects Test Guidelines OPPTS 870.6300 Developmental Neurotoxicity Study, US EPA, Prevention, Pesticides and Toxic Substances (7101), EPA 712-C-96, 239, 1996, 1-14.

Lynch, M.A. (2004), Long-term potentiation and memory. Physiological Reviews, Vol. 84, No. 1, pp. 87136.

OECD (1981). Test Guideline 403. OECD Guideline for Testing of Chemicals. Acute Inhalation Toxicity. 
OECD (1987). Test Guideline 402. OECD Guideline for Testing of Chemicals. Acute Dermal Toxicity.

OECD (1997). Test Guideline 424. OECD Guideline for Testing of Chemicals. Neurotoxicity Study in Rodents.

OECD (1998). Test Guideline 408. OECD Guideline for Testing of Chemicals. Repeated Dose 90-day Oral Toxicity Study in Rodents.

OECD (2002). Test Guideline 420. OECD Guideline for Testing of Chemicals. Acute Oral Toxicity Fixed Dose Procedure.

OECD (2002). Test Guideline 423. OECD Guideline for Testing of Chemicals. Acute Oral Toxicity Acute Toxic Class Method.

OECD (2004) Series on testing and assessment number 20, Guidance document for neurotoxicity testing.

OECD (2007). Test Guideline 426. OECD Guideline for Testing of Chemicals. Developmental Neurotoxicity Study. http://www.oecd.org/document/55/0,3343,en_2649_34377_2349687_1_1_ $1 \_1,00 . h t m l$

OECD (2008) Nr 43 GUIDANCE DOCUMENT ON MAMMALIAN REPRODUCTIVE TOXICITY TESTING AND ASSESSMENT. ENV/JM/MONO(2008)16

OECD (2008). Test Guideline 425. OECD Guideline for Testing of Chemicals. Acute Oral Toxicity - Upand-Down Procedure.

OECD (2008). Test Guideline 407. OECD Guideline for Testing of Chemicals. Repeated Dose 28-day Oral Toxicity Study in Rodents.

OECD (2009). Test Guideline 452. OECD Guideline for Testing of Chemicals. Chronic Toxicity Studies.

Pivovarova, N.B, and S.B. Andrews (2010), Calcium-dependent mitochondrial function and dysfunction in neurons. FEBS J, Vol. 2277, pp. 3622-3636.

$\mathrm{Wu}$, et al. (2013), Ursolic acid improves domoic acid-induced cognitive deficits in mice. Experimental Zoology Part A: Ecological Genetics and Physiology, Vol. 271, pp. 127-36.

\section{Acknowledgments}

We would like to thank Florianne Tschudi-Monnet from University of Lausanne who developed the KEs on Neurodegeneration and Neuroinflammation. The data on lead $\left(\mathrm{Pb}^{2+}\right)$ in the Empirical Support for Linkage sections derive from the AOP named "Chronic binding of antagonist to Nmethyl-D-aspartate receptors (NMDARs) during brain development leads to neurodegeneration with impairment in learning and memory in aging" that shares KERs with the present AOP. We would also like to show our gratitude to Brigitte Landesmann from Chemicals Safety and Alternative Methods Unit, JRC for developing the KE on Cell death. We are also immensely grateful to reviewers for their comments on earlier versions of the AOP. 